DR\#0633.5 SOLAR/0802-84/01 (DE85001190)

\title{
ACTUAL VERSUS DESIGN PERFORMANCE OF SOLAR SYSTEMS IN THE NATIONAL SOLAR DATA NETWORK
}

September 1984
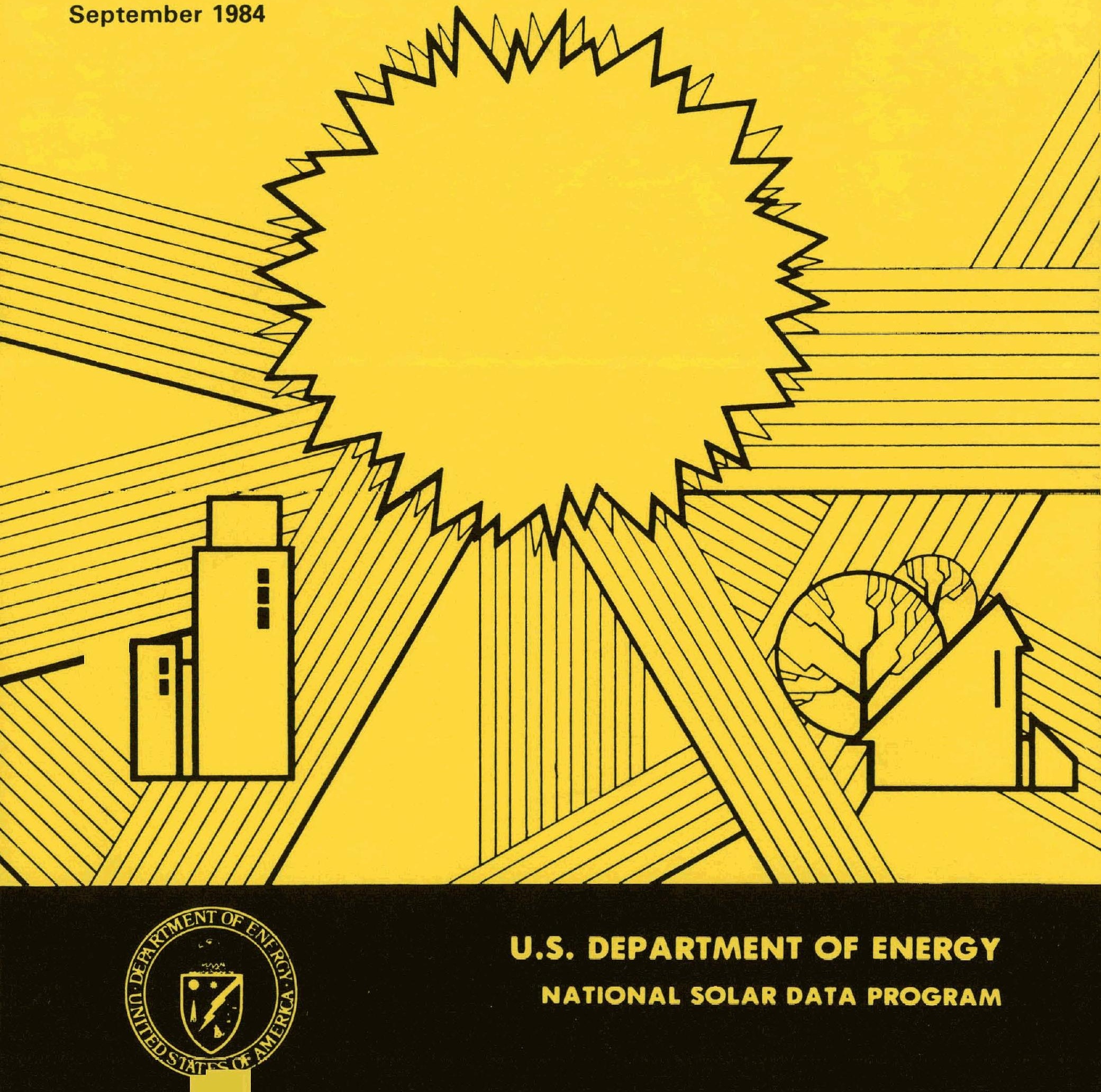

U.S. DEPARTMENT OF ENERGY NATIONAL SOLAR DATA PROGRAM 


\section{DISCLAIMER}

This report was prepared as an account of work sponsored by an agency of the United States Government. Neither the United States Government nor any agency Thereof, nor any of their employees, makes any warranty, express or implied, or assumes any legal liability or responsibility for the accuracy, completeness, or usefulness of any information, apparatus, product, or process disclosed, or represents that its use would not infringe privately owned rights. Reference herein to any specific commercial product, process, or service by trade name, trademark, manufacturer, or otherwise does not necessarily constitute or imply its endorsement, recommendation, or favoring by the United States Government or any agency thereof. The views and opinions of authors expressed herein do not necessarily state or reflect those of the United States Government or any agency thereof. 


\section{DISCLAIMER}

Portions of this document may be illegible in electronic image products. Images are produced from the best available original document. 


\section{DISCLAIMER}

This report was prepared as an account of work sponsored by an agency of the United States Government. Neither the United States Government nor any agency thereof, nor any of their employees, makes any warranty, express or implied, or assumes any legal liability or responsibility for the accuracy, completeness, or usefulness of any information, apparatus, product, or process disclosed, or represents that its use would not infringe privately owned rights. Reference herein to any specific commercial product, process, or service by trade name, trademark, manufacturer, or otherwise does not necessarily constitute or imply its endorsement, recommendation, or favoring by the United States Government or any agency thereof. The views and opinions of authors expressed herein do not necessarily state or reflect those of the United States Government or sily agency thereof.

This report has been reproduced directly from the best available copy.

Available from the National Technical Information Service, U. S. Department of Commerce, Springfield, Virginia 22161.

Price: Printed Copy A07

Microfiche A01

Codes are used for pricing all publications. The code is determined by the number of pages in the publication. Information pertaining to the pricing codes can be found in the current issues of the following publications, which are generally available in most libraries: Energy Research Abstracts (ERA); Government Reports Announcements and Index (GRA and 1); Scientific and Technical Abstract Reports (STAR); and publication NTIS-PR-360 available from NTIS at the above address.

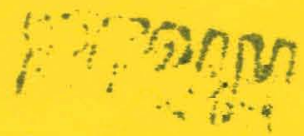




\section{ACTUAL VERSUS DESIGN PERFORMANCE OF SOLAR SYSTEMS IN THE NATIONAL SOLAR DATA NETWORK}

Prepared by:

T.L. Logee P.W. Kendall

Approved by:

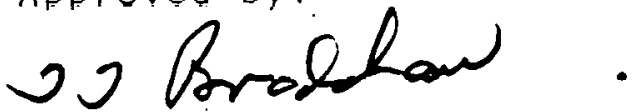

T.T. Bradshaw

Program Manager

Vitro Corporation 14000 Georgia Avenue Silver Spring, Maryland 20910

The National Solar Data Network Department of Energy Contract Number DE-ACO1-79CS30027 


\section{FOREWORD}

In 1974, the U.S. Department of Energy (DOE) was authorized by Congress to create the National Solar Data Network (NSDN) as part of the National Solar Demonstration Act. Under the NSDN, some 170 solar systems have been instrumented, monitored, and analyzed for periods of up to three years.

The present report was commissioned by DOE to consolidate some of the accumulated knowledge on solar systems specifically relating to design predicted performance versus actual field performance. This report is, therefore, a compendium of the performance of both large and small, public and private solar systems compared to the designer predicted performance. This study is intended to answer the questions:

- How good were the design predictions?

- When solar systems did not perform as predicted, what caused the poorer performance?

- Was performance affected by integration of solar system components?

It should be noted that the data in this report is based on analysis of components and systems designed in the late $1970 \mathrm{~s}$ and early 1980s; data from later designs was not available for inclusion in this study. 


\section{THIS PAGE \\ WAS INTENTIONALLY \\ LEFT BLANK}




\section{TABLE OF CONTENTS}

Section

Page

FOREWORD

TABLE OF CONTENTS

LIST OF ILLUSTRATIONS

LIST OF TABLES

INTRODUCTION

I SITE SELECTION AND DESCRIPTION

3

II COMPARISON OF DESIGN AND PREDICTED PERFORMANCE VERSUS ACTUAL PERFORMANCE

5

A. DESIGN GOALS MET OR EXCEEDED 10

B. DESIGN GOALS REALISTIC, PERFORMANCE LESS

THAN EXPECTED

C. DESIGN GOALS OPTIMISTIC

III SUMMARY AND CONCLUSIONS

IV REFERENCES

Appendix

A System Descriptions

$A-1$

B The f-Chart Version 5.1

$B-1$ 


\section{LIST OF ILLUSTRATIONS}

Figure

Number

1 Bar Chart of Actual Solar Fraction Minus

Design Expected Solar Fraction

Bar Chart of Actual Solar Fraction Minus

f-Chart Predicted Solar Fraction

3 Bar Chart of Actual System Efficiency Minus

Dcsign Expected System Efficiency

$A-3$

A-1 ARATEX Scrvices Solar Energy System Schematic

$A-4$

$A-2$

Energy Flow Diagram for ARATEX Services

$A-3$

Bell Telephone of Pennsylvania Solar Energy System Schematic

$A-7$

A-4 Energy Flow Diagram for Bell Telephone of Pennsylvania

$A-8$

A-

Cathedral Square Solar Energy System Schematic

Energy Flow Diagram for Cathedral Square

Facilities Development Solar Energy System

Schematic

$A=8$

Enelgy Flow Diagram for Facilities Development:

First Manufactured Homes Lot 9 Solar Energy

System Schematic

$A=18$

A-10 Energy Flow Diagram for First Manufactured

Homes Lot 9

$A-19$

A-11 First Manufactured Homes Lot 10 Solar Energy

System Schematic

$A-22$

A-1? Encrgy Flow Diagram for First Manufartured Homes Lot 10

$A-23$

A-13 Forest City Dillon Solar Energy System Schematic

$A-25$

A-14 Encrgy Flow Diagram for Forest City Dillon

A -26

A-15 General Electric-Dallas Solar Energy System

Schematic

$A-29$

A-16 Energy Flow Diagram for General Electric-Dallas

7

9

$A-12$

$A-14$

$A=15$ 


\section{LIST OF I LLUSTRATIONS \\ (Continued)}

Figure

Number

$A-17$

$A-18$

$A-19$

$A-20$

$A-21$

$A-22$

$A-23$

$A-24$

$A-25$

$A-26$

$A-27$

$A-28$

$A-29$

$A-30$

$A-31$

$A-32$

A- 33

A -34
Title

Page

$A-34$

$A-35$

Schematic 2

A- 36

$A-38$

$A-39$

$A-41$

Schematic

A -42

$A-44$

A -45

$A-49$

Schematic

$A-50$

A- 53

Schematic

A -54

A -57

$A-58$

$A-61$

Schematic

$A-62$

A- 64 
LIST OF ILLUSTRATIONS

(Conti.nued)

Figure

Number

Title

Page

A-35 Energy Flow Diagram for Saddle Hill Trust Lot 36

$A-65$

A-36 Saddle Hill Trust Lot 73 Solar Energy

System Schematic

$A-67$

A-37 Energy Flow Diagram for Saddle Hill Trust Lot 73

$A-68$

A-38 Saddle Hill Trust Lot 77 Solar Energy

System Schematic

$A-70$

A-39 Energy Flow Diagram for Saddle Hill Trust Lot 77

$A-71$

A-40 South Bridge Tower Solar Energy System Schematic

$A-73$

A-4l Energy Flow Diagram for South Bridge Tower

$A-74$

A-42 Spearfish High School Solar Energy, System

Schematic

$A-76$

A-43 Energy Flow Diagram for the Spearfish

High School

$A-77$

A-44 Summerwood M Solar Energy System Schematic

$A-80$

A-45 Energy Flow Diagram for Summerwood $M$

$A-81$

A-46 Telex Communications Solar Energy System Schematic

$A-83$

A-47 Enerqy Flow Diagram for Telex Communications

$A-84$

A-48 Terrell E. Moseley Solar Energy System

Schematic

$A-87$

A-49 Energy Flow Diagram for Terrell E. Moseley

$A-88$

$A-50$

Vitro Test site Solar Energy System Schematic

$A-90$

$A-51$

Energy Flow Uiagram for the Vitro Test Site

$A=91$ 


\section{LIST OF TABLES}

Table

Number

Title

Page

National Solar Data Network Solar System Characteristics

Measured, Design Expected, and Predicted Values

3 Measured Summary Performance Data Versus Design Expected and f-Chart Predicted Results 


\section{INTRODUCTION}

This report relates field measured performance to the designer predicted performance. The field measured data was collected by the National Solar Data Network (NSDN) over a period of six years. Data from 25 solar. systems was selected from a data pool of some 170 solar systems.

The scope of the project extends beyond mereiy presenting comparisons of data. There is an attempt to provide answers which will move the solar industry forward. As a result of some industry and research workshops, several concerns arose which can be partially allayed by careful study of the NSDN data. These are:

- What types of failures occurred and why?

- How good was the design versus actual performance?

- Why was predicted performance not achieved in the field?

- Which components should be integrated with a system type for good performance?

Since the designs span several years and since design philosophies are quite variable, we have also compared the measured results to f-Chart 5.1 results (see Appendix B). This comparison is a type of normalization in that all systems are modeled with the same process. An added benefit of this normalization is a further validation of the f-Chart model on a fairly large scale. The systems were modeled using equipment design parameters, measured loads, and $f-C h a r t$ weather data from nearby cities. 
THIS PAGE

WAS INTENTIONALLY

LEFT BLANK 


\section{SECTION I}

\section{SITE SELECTION AND DESCRIPTION}

The NSDN has monitored data from 170 solar systems. However, such a large pool of data did not fit the resources of this project nor is all of the data appropriate to use. Therefore, several selection criteria were developed which could be applied to each site to objectively judge the value of the data.

These selection criteria are listed below:

- The solar systems must have average or above average collector efficiency and solar energy used. The average was determined from all of the NSDN systems monitared with over four months of usable data.

- Design predictions had to be known and available.

- The solar system could either supply hot water or space heating or both. Solar cooling systems were eliminated because the technology is not well enough developed to be cost-effective.

The final selection was made to create a diverse mix of sizes and types of solar systems. The selected systems range in size from 42 square feet to 21,760 square feet of collector area. The solar systems provide Domestic Hot Water (DHW) heating, process hot water heating, space heating of homes, commercial buildings, and institutions, and a combination of space heating and hot water heating for homes, businesses, and institutions. The solar collectors are both air and liquid collectors. The liquid collectors encompass a thermosiphon system, single and double glazing, and flat-black or selective surfaced absorbers.

Table I shows several of the important physical characteristics of the selected solar systems. Complete descriptions of the solar systems are given in Appendix A. These descriptions list the major components and operating modes. There are system schematics showing the relative piping or ducting to the subsystems and the NSDN sensor placements. There are also energy flow diagrams showing the major energy flows during the time periods of interest for this study. 
Table 1. NATIONAL SOLAR CATA NETWORK SOLAR SYSTEM CHARACTERISTICS

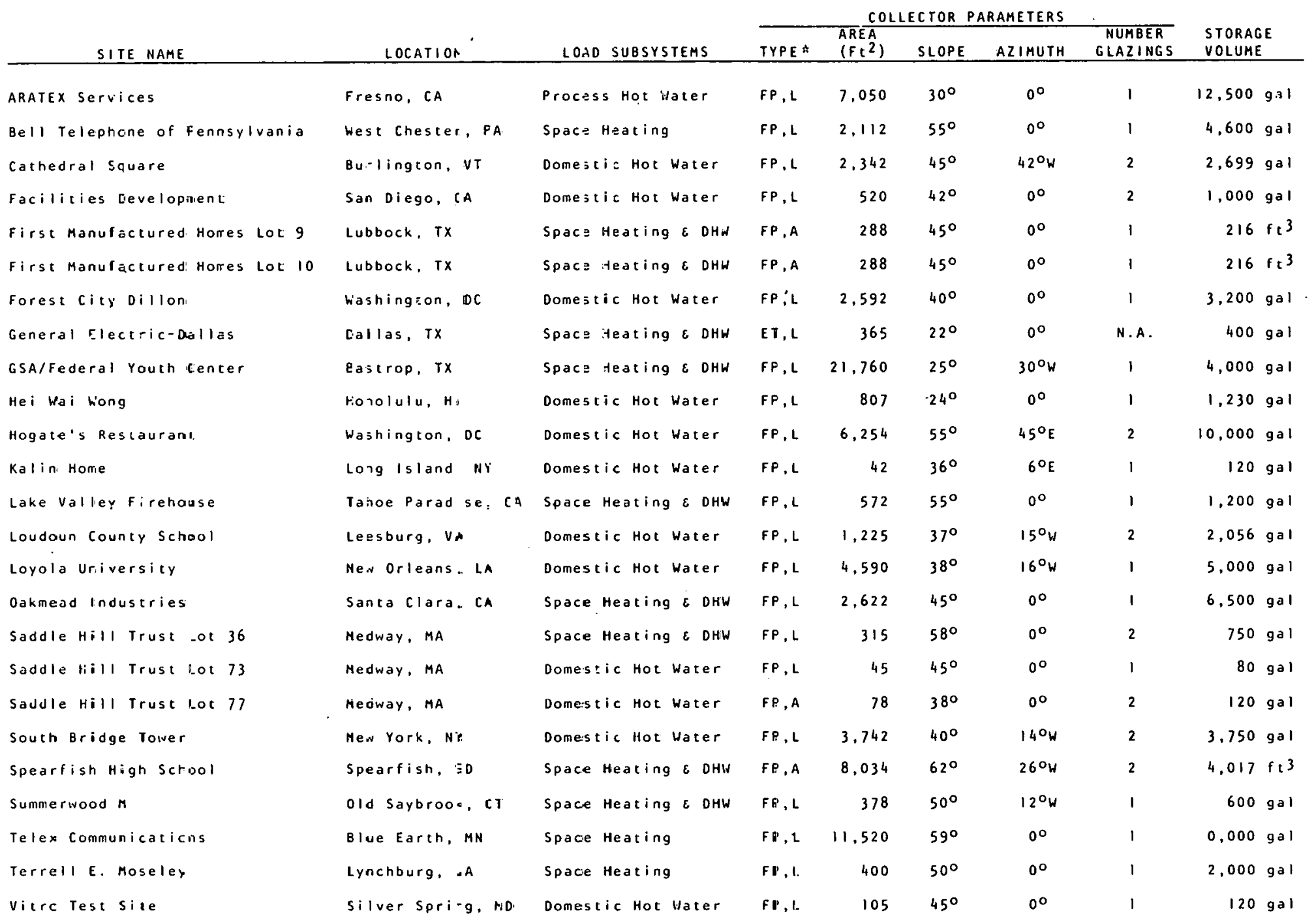

\footnotetext{
$\begin{aligned} \because A & =\text { Air } \\ L & =\text { Liquid }\end{aligned}$

ET = Evacuated-Tute

N.A. Clenozes not apolizab e.
} 


\section{SECTION II}

\section{COMPARISON OF DESIGN AND PREDICTED PERFORMANCE VERSUS ACTUAL PERFORMANCE}

The main point of comparison will be based on solar fraction 1 and system efficiency 2 . Solar fraction is used because both the f-chart predictions and most design numbers are available this way.

The solar system efficiency is a more useful number, since it is independent of load. This index of comparison will also be shown. For the f-Chart predictions, solar energy delivered to the load is derived from the predicted solar fraction and the measured load.

The NSDN records do not contain any explanation of how the design solar fractions were predicted. In order to provide a common basis for the predicted (design) values, a solar system model was used. We chose f-chart for this because it is more widely available and used more than most other solar system models. The version of f-Chart used was 5.1 implemented on an Apple 11 computer.

Although this simpler predictive model may appear restrictive because solar systems are not modeled as accurately as possible, the smaller amount of input data and the ease of input permitted a much larger sample of solar systems. A larger sample of solar systems was desirable in order to provide greater statistical significance.

Table 2 shows a comparison of the measured solar fractions, designer expected solar fractions, and f-chart predictions using measured load data and f-Chart supplied SOLMET weather data. The table also contains measured collector efficiency and solar energy utilization. These parameters are referred to on pages 9 and 10 .

The measured data comes from the NSON site files and usually represents 12 months of monitoring. Solar fractions range from seven percent to $98 \%$. Note that a high solar fraction is not indicative of high system efficiency. The solar fraction merely shows what portion of the system load is provided by solar energy. Comparing the predicted solar fractions to the measured solar fractions can help determine if a solar system is functioning well.

As the reader glances through Table 2 , it is quite evident that the systems generally performed more poorly than predicted. This is true whether one compares design predictions or $f-c h a r t$ predictions to the measured solar fractions. These statements are illustrated by Figure 1 and Figure 2, which show how much each measured solar fraction differs from the design or predicted solar fraction.

\footnotetext{
TSolar Fraction $=$ Solar Energy Supplied to Load $\div$ Load $\times 100 \%$. 2System Efficiency = Solar Energy Supplied to Load $\div$ Solar Energy Incident on Collector $\times 100 \%$.
} 
Table 2. MEASURED, JESIGN EXPECTED, GND PREDICTED JALUES

(All values in percentages)

\begin{tabular}{|c|c|c|c|c|c|}
\hline SITE & $\begin{array}{c}\text { MEASURED } \\
\text { SOLAF. FRACTI ON }\end{array}$ & $\begin{array}{l}\text { DESIINN EXPECTED } \\
\text { SOLAR FRACTION }\end{array}$ & $\begin{array}{l}\text { F- CHART PREDICTED } \\
\text { SOLAR FRACTION }\end{array}$ & $\begin{array}{l}\text { COLLECTOR } \\
\text { EFFICIENCY }\end{array}$ & $\begin{array}{l}\text { SOLAR ENERGY } \\
\text { UTILIZATION }\end{array}$ \\
\hline ARATEX Services & 21 & 20 & 49 & 30 & 83 \\
\hline Bell Telephone: of Pennsylrania & 64 & 57 & 59 & 26 & 100 \\
\hline Cathedral Square & 28 & 51 & 18 & 31 & 82 \\
\hline Facilities Development & 45 & 58 & 57 & 43 & 85 \\
\hline Forest City Dillori. & 43 & 59 & 49 & 28 & 93 \\
\hline First Manufactured Hones -ot 9 & 66 & 75 & 71 & 40 & 64 \\
\hline First manufactured Homes Lot 10 & 73 & 75 & 93 & 26 & 61 \\
\hline General Electric-Dallas & 29 & 64 & 65 & 31 & 41 \\
\hline GSA/Federa: Ycuth Center & 16 & 46 & 48 & 16 & 98 \\
\hline He i Wai Wong & 98 & 100 & 96 & 32 & 72 \\
\hline Hogate's Restaurant & 43 & 64 & 46 & 35 & 93 \\
\hline Kalin Home & 52 & 60 & 30 & 50 & 100 \\
\hline Lake Valley firehouse & 50 & 50 & 81 & 35 & 61 \\
\hline Loudoun County School & 60 & 26 & 64 & 21 & 62 \\
\hline Loyola University & 37 & 52 & 54 & 29 & 85 \\
\hline Oakmead Industries & 52 & 36 & 67 & 40 & 52 \\
\hline Saddle llill Trust Lot 36 & 53 & 50 & 35 & 40 & 99 \\
\hline Saddle Hill Trust Lot 73 & 56 & 54 & 49 & 52 & 73 \\
\hline Sadéle Hill T'rust Lot 77 & 42 & 43 & 56 & 28 & 51 \\
\hline South Bridge Tower & $\cdot 7$ & 24 & 15 & 47 & 78 \\
\hline Spearfish High School & 54 & 53 & 62 & 27 & 64 \\
\hline Summerwood M & 58 & 84 & 35 & 42 & 80 \\
\hline Telex Communicatiors & 82 & 79 & 83 & 28 & 76 \\
\hline Terrell E. Moseley & 80 & 69 & 77 & 28 & 87 \\
\hline Vitro Test Site & 14 & 24 & 23 & 23 & 94 \\
\hline
\end{tabular}


Figure 1 depicts the difference in actual versus design solar fraction. One system, Loudoun County School, outperformed the design prediction by $34 \%$. Of the 25 solar systems, 12 , or $48 \%$ were able to meet or exceed design expectations. Two of the solar systems, or eight percent, were less than $10 \%$ below design expectations, while 11 , or $44 \%$ of the systems, were well below design expectations. Note that we have considered any system within two percent of the design goal as meeting the design goal.

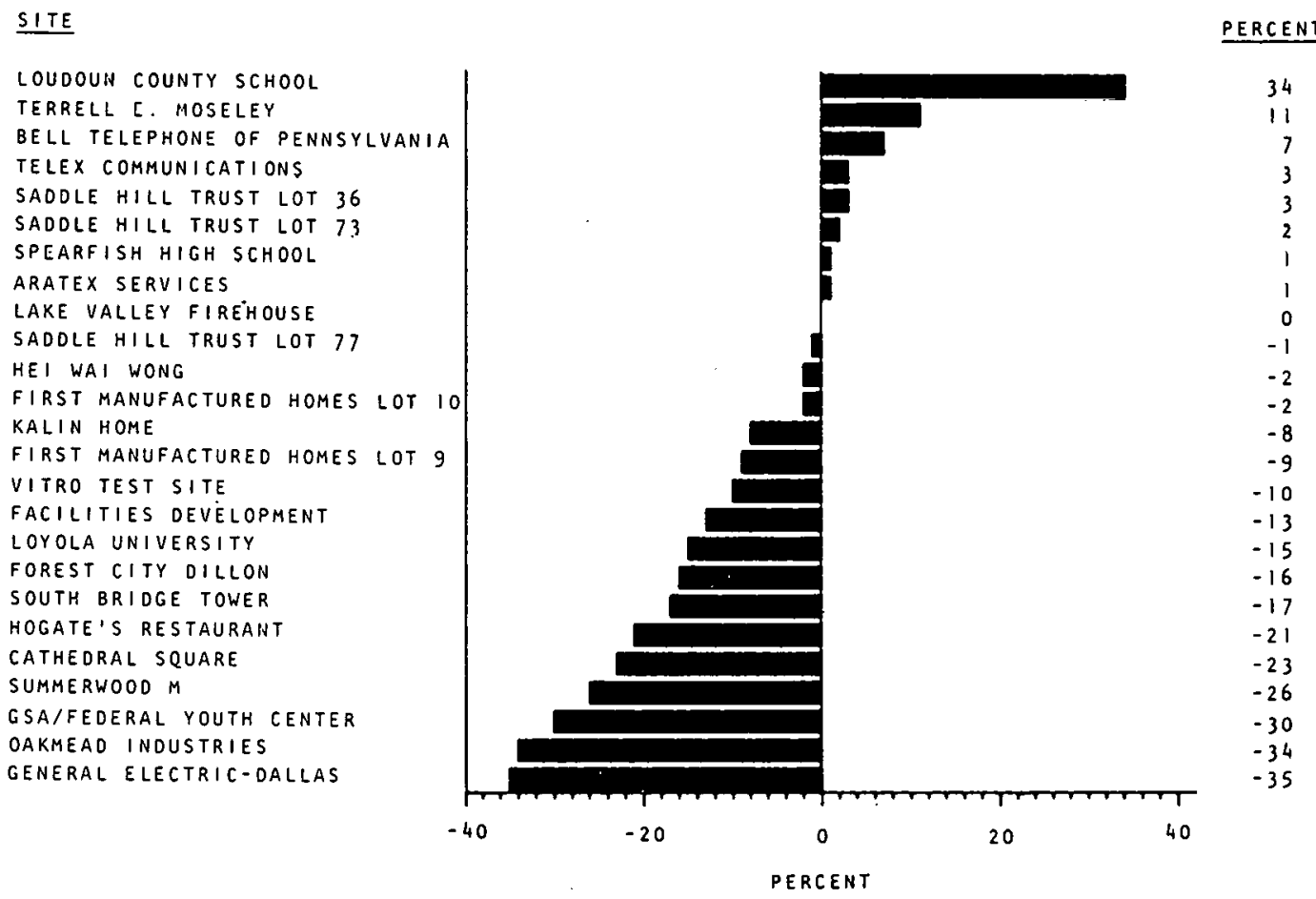

Figure 1. Bar Chart of Actual'Solar Fraction Minus Design Expected Solar Fraction

Figure 2 is similar to Figure l because the difference between two solar fraction percentages is shown. However, figure 2 shows the difference between the measured solar fraction and the f-Chart predicted solar fraction using measured loads.

In Figure 2, there are nine systems which meet or exceed design expectations, and six of the sites are common to both groups. Also, there are seven sites which are less than $10 \%$ below design and there are nine sites which are more than $10 \%$ below design predictions. Only one site is common to both Figure 1 and Figure 2 from the less than $10 \%$ below-design group, but five sites are common to the below-10\% group. 

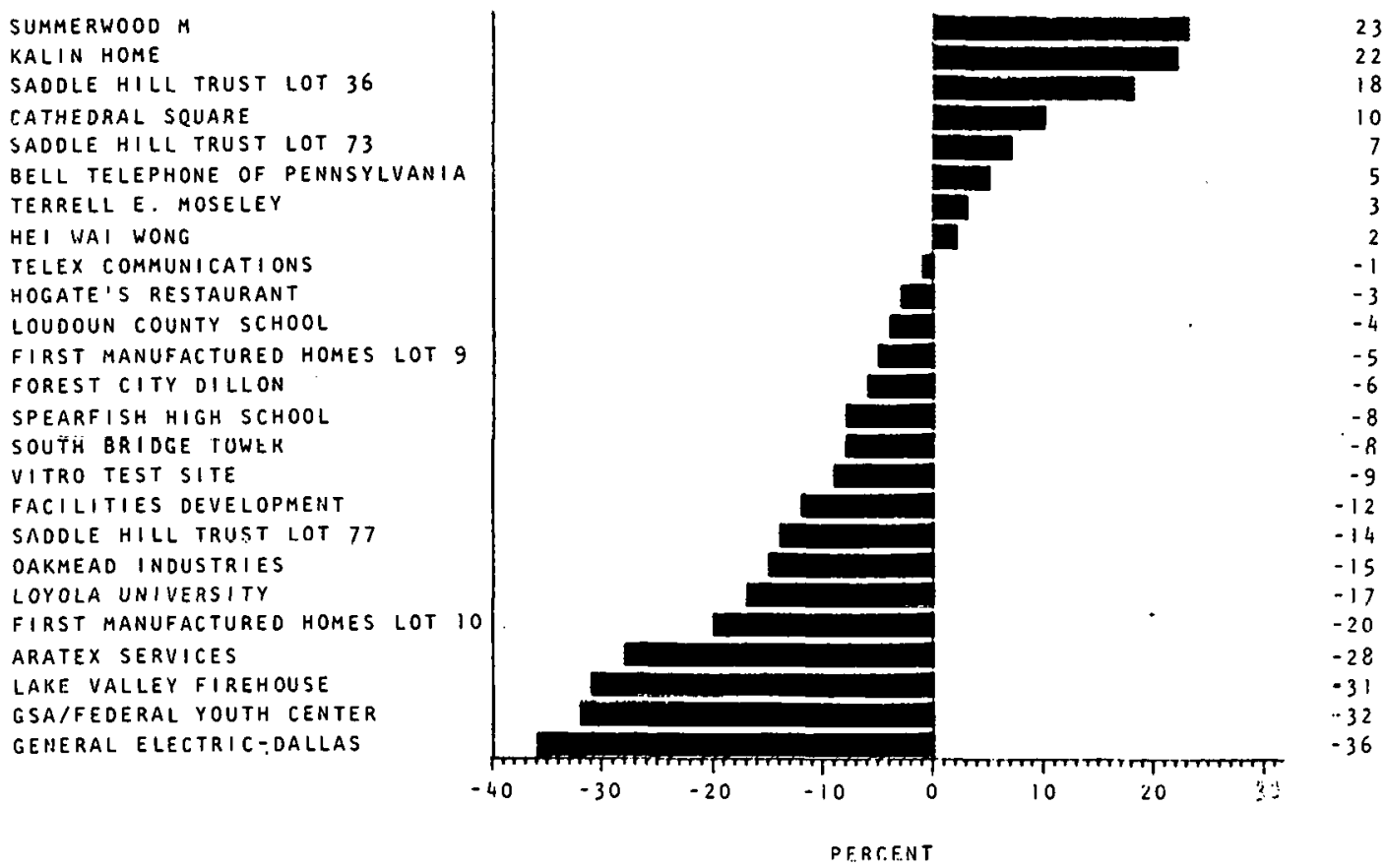

Figure 2. Bar Chart of Actual Solar Fraction Minus f-Chart Predicted Solar Fraction

Using the solar fraction as a basis of comparison is very good for an owner interested in the energy savings or economics. Solar fraction evaluates the percent of load not purchased, su savings can be directly calculated. However, solar fraction is load dependent, whereas the solar syslem efiliciency ls sunihillu dependent.

A system efficiency number is used to compare these solar systems because this value is more consistent from slle lu site. system etticiency ls delilled as the solar energy delivered divided by the total solar energy incident on the array. The design system efficiency is developed from the suldifiaction of the load times the design load divided by the total long-term solar energy incident on the array area. Likewise, a system efficiency call be determined from the f-chart solar fraction.

Figure 3 shows the difference in the measured system efficiency minus the design system efficiency. Design system efficiency data was not available for 0akmead Industries and Hogate's Restaurant. Figure 3 shows eight solar energy systells which meet or exceed the design expectations. (The criteria is that a solar system meets or exceeds the design expected performance if the difference between measured and design system efficiency is greater than negative two percent.) Looking back at Figure 1 , there 


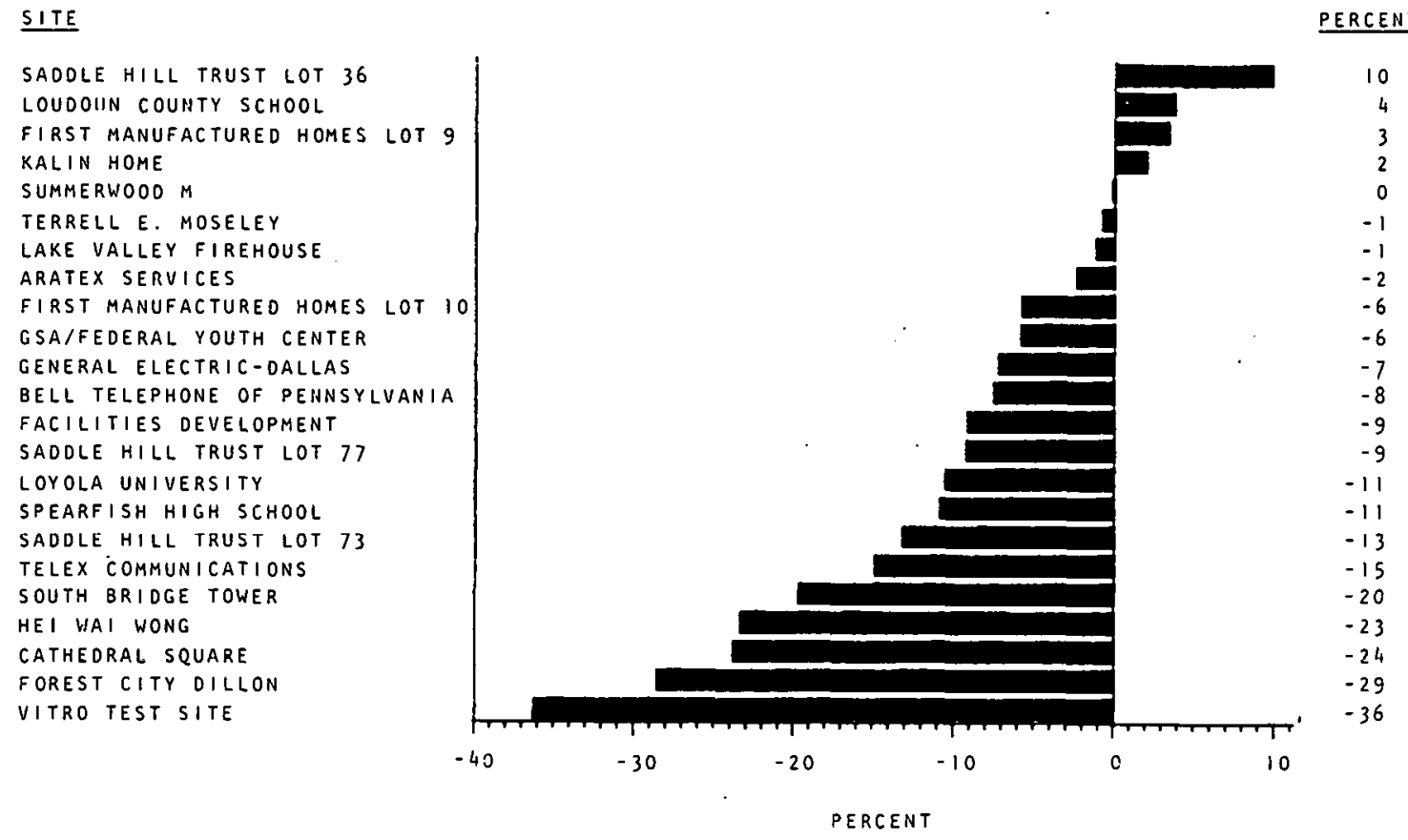

Figure 3. Bar Chart of Actual System Efficiency Minus Design Expected System Efficiency

are only five sites, ARATEX Services, Lake Valley firehouse, Loudoun County School, Saddle Hill Trust Lot 36 , and Terrell E. Moseley, which also met or exceeded the design solar fraction.

As one peruses Figure 3, quite naturally the question is asked, "Why did so many solar systems fail to meet the design goals?" This question will be answered subsequently. However, first there may be solar systems which have performed below expectations, but where the design goals arestill realistic. The present criteria of system efficiency does not catch the poorer performers. These sites must be detected by scrutinizing the f-chart predictions, solar energy utilization, collector efficiency, and specific facts from the site history relating to problems with the collection, storage, and energy transport subsystems.

The two other criteria used to evaluate solar system performance mentioned above were collector efficiency and solar energy utilization, also shown in Table 2. To avoid any confusion, collector efficiency is defined as the percentage of total solar insolation (incident on the gross collector array) which is collected. Another aspect of the collector efficiency is the manufacturer's single-panel test curve. This curve is the result of tests by an. independent laboratory which comply with ASHRAE Standard 93-77 (see Reference 3 ). These tests establish the maximum efficiency, 
$y$-intercept or $F_{R} \tau \alpha$ for $f$-Chart and the slope of the curve or losses (FRUL for f-Chart). A recently published report, "Component Report: Performance of Solar Arrays and Collector Controllers in the National Solar Data Network" (Reference 4), compares these test and measured results for many of the same solar systems.

The other criteria mentioned above is solar energy utilization. It is defined as the solar energy delivered to the load divided by the solar energy collected. This concept is useful to determine the efficiency of transport and use of the solar energy after is has been collected. This value is restricted to measured parameters only, since design data is not available and f-Chart does not output the amount of solar energy collected.

As the individual site analyses proceeded, it became evident that there were three groups of solar systems. These are:

- Design Goals Met or Exceeded

- Design Goals Realistic, Performance Less Than Expected

- Design Goals Optimistic

These groups are discussed in detail in the following sections. If the first two groups are added together, there are 14 solar systems out of the 25 which have realistic, achievable design goals.

A. DESIGN GOALS MET OR EXCEEDED

The group of sites which had realistic design goals and performed up to the design expectations is listed below. The basls of comparison for these eight sites is the system efficiency parameler discussed earlicr.

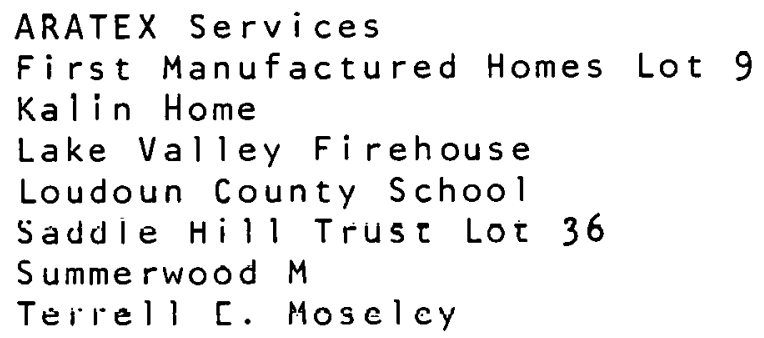

The ARATEX Services solar system had a measured system efticiency of $30 \%$, which is two percent less than design expected. Measured collector performance was quite good, with a $30 \%$ efficiency. The measured solar energy utilization of $83 \%$ was also very good, and the measured solar fraction of $21 \%$ was one percent above the design solar fraction. The f-chart predicted solar fraction was $49 \%$ and the predicted system efficiency was $51 \%$, or $19 \%$ above the design predictions. Although the long-term solar insolation was $14 \%$ sunnier than the measured insolation, the f-chart predictions are still too optimistic. 
The First Manufactured Homes Lot 9 site had good performance with a measured system efficiency of $25 \%$ versus the design expected system efficiency of $22 \%$. The system efficiency predicted from the f-chart solar fraction was $24 \%$. The measured solar fraction for this site is nine percent below the design expected solar fraction, whereas the f-Chart predicted solar fraction is $71 \%$, or five percent greater than measured. Slightly better collector performance and long-term weather which is $16 \%$ sunnier than the measured weather account for the difference between $f$-chart and the measured values.

The Kalin Home solar system had excellent measured performance. The measured system efficiency was $50 \%$ and the collector efficiency was an amazing 50\%. (The collectors performed seven percent above the manufacturer's single-panel test curve.) The measured solar fraction of $52 \%$ is eight percent below the expected design solar fraction, but, at $50 \%$, the measured system efficiency is two percent above the design expected system efficiency. The f-chart predicted 501 ar fraction was only $30 \%$, or $22 \%$ below the measured value. Likewise, the system efficiency predicted from the f-chart solar fraction was $22 \%$. Since the measured collector performance was seven percent above the manufacturer's single-panel test result, the f-chart results would be expected to be smaller, but not to the extent given here. There is no reason to believe the $f$-Chart input data was in error, but there is no other explanation for the discrepancy. The long-term weather for the f-chart prediction was eight percent above the measured value.

The performance of the Lake Valley Firehouse solar system was good, at a system efficiency of $22 \%$ and a collector efficiency of $35 \%$. The design expected system efficiency was $23 \%$ and the solar fraction was $50 \%$, the same as the measured solar fraction. The f-Chart predicted solar fraction was $81 \%$, $31 \%$ greater than measured. Comparing the system efficiency predicted from the f-chart solar fraction with the measured system efficiency, the f-chart system efficiency of $28 \%$ is six percent greater than measured. The f-Chart predictions are above the measured values because the long-term solar insolation data used by f-Chart is $28 \%$ sunnier than the measured insolation.

The Loudoun County School solar system performed moderately, but well above design expectations. Measured solar fraction was $60 \%$ compared to $26 \%$ design expected and $64 \%$-Chart predicted solar fraction. Comparing system efficiencies, measured was $13 \%$ versus nine percent design expected and nine percent for $f$-chart. Since the measured collector efficiency of $21 \%$ was $10 \%$ less than the manufacturer's single-panel test curve, it seems likely that the design expected performance was very conservative. The f-chart results were low when one would expect higher than measured values because the long-term weather was sunnier than measured and because the collector performance was low. There is no apparent explanation for these differences. The Loudoun. County School performance was reduced by large losses from buried pipes between the collector and the school mechanical room: 
The measured performance at Saddle Hill Trust Lot 36 was very good. Collector efficiency was $40 \%$ and measured solar fraction was $53 \%$. Note that this performance was restricted to the wintertime when the loads were higher. Although the measured solar fraction is only three percent above the design expected, the measured system efficiency of $46 \%$ is $10 \%$ above the design expected. This difference from measured to design expected performance is reduced to four percent in system efficiency if the measured summer months are included. The f-chart solar fraction of $35 \%$ is $18 \%$ below the measured solar fraction and f-Chart system efficiency is $10 \%$ below measured. One reason the performance at Saddle Hill Trust Lot 36 is so good is because the measured solar insolation is $20 \%$ greater than the long-term insolation used by f-chart. Also, the system has very high utilization of solar energy collected and collector efficiency was five percent above the manufacturer's single-panel test curve.

The Summerwood $M$ solar system has excellent performance during the winter when the loads are high. Measured collectur efriciency was $42 \%$ which is $16 \%$ greater than the manufacturer's single-panel test result. The measured solar fraction of $58 \%$ was $26 \%$ below the design expected value. However, the measured system efficlency of $29 \%$ was the same as the design expected system efficiency. The f-Chart predicted solar fraction of $35 \%$ was $23 \%$ less than measured. The measured system efficiency was three percent greater than the f-Chart predicted efficiency using the solar fraction values.

Measured solar energy utilization was $80 \%$ of the measured collected solar energy during the winter. The yearly value for solar energy utilization was $58 \%$. The reduced amount of solar utilization or solar energy delivered to the load on a yearly basis is due to the small summer hot water heating loads.

The Terrell E. Moseley solar. system performed well, with a high solar fraction $(80 \%)$ and $24 \%$ measured system efficiency. This performance was $11 \%$ above the design expected solar fraction and only one percent below design expected system efficiency. The f-Chart predictions were similar to the measured performance at a $77 \%$ solar fraction and $19 \%$ system efficiency predicted from f-chart results. The long-term solar insolation was eight percent below the measured insolation. Solar energy utilization by the Terrell E. Moseley system was very good, but the collectors performed $21 \%$ below the manufacturer's single-panel test curve. Accurate design forecasting and the balancing combination of higher solar insolation with lower collector performance provided good results in this case. 


\section{B. DESIGN GOAL REALISTIC, PERFORMANCE LESS THAN EXPECTED}

The sites which had realistic design expectations but performed below their potential are listed below. Generally, some component of the system was performing at a reduced output due to control malfunction or excessive wear. These six sites are:

Bell Telephone of Pennsylvania

First Manufactured Homes Lot 10

General Electric-Dallas

GSA/Federal Youth Center

Oakmead Industries

Saddle Hill Trust Lot 77

The measured performance of $64 \%$ solar fraction and $27 \%$ system efficiency at the Bell Telephone of Pennsylvania site was below the design expected performance. However, there were problems with the air vents on the solar system which restricted system filling.

After these air vents were replaced, the system performance slightly exceeded the design expected performance. The f-chart predicted solar fraction was five percent below the measured value, but the predicted system efficiency equalled the measured value. Note that the measured solar insolation was $11 \%$ sunnier than the long-term insolation.

The First Manufactured Homes Lot 10 solar system performed much less effectively than its sister system on Lot 9 . The measured solar fraction of $73 \%$ at Lot 10 was greater than the $66 \%$ solar fraction measured at Lot 9 . However, the measured system efficiency of $16 \%$ at Lot 10 was much lower than the measured value of $25 \%$ at Lot 9 , and substantially below the design expected value of $22 \%$. At Lot 10 , the measured load was $16.5 \mathrm{million}$ BTU compared to $30.3 \mathrm{million}$ BTU at Lot 9. This smaller load was the reason for the improved solar fraction at Lot 10 . The real problem at Lot 10 was the much lower collector efficiency of $26 \%$ compared to the $40 \%$ collector efficiency at Lot 9. The smaller load at Lot 10 did result in storage temperatures $6^{\circ} \mathrm{F}$ to $7^{\circ} \mathrm{F}$ warmer in the winter months. Another reason for the reduced performance at Lot 10 was the fact that air flow was $27 \%$ less than design.

The f-Chart predicted solar fraction at Lot 10 was. $93 \%$, but the f-chart system efficiency was still only $16 \%$. This is due to the smaller load at Lot 10 , because the same system at Lot 9 produced an f-Chart system efficiency of $24 \%$. If the collector performance at Lot 10 was improved so that all or most of the load would be served with solar energy, then the system efficiency would be nearly $21 \%$ or within one percent of the design expected value.

The General Electric-Dallas solar system had good collector performance, but poor utilization of collected solar energy. The measured solar fraction of $29 \%$ was $35 \%$ below the design expected value. The measured system efficiency of $10 \%$ was eight percent below the design expected value. An improvement of $37 \%$ in the solar energy delivered to the load would result in a system efficiency equal to the design expected value. The f-Chart predicted solar 
fraction is $65 \%$, similar to the design expected value, and the predicted system efficiency is $28 \%$, which is $10 \%$ above the design expected value. The control interface between the solar and load subsystems is the suspected cause of the low utilization of solar energy.

The GSA/Federal Youth Center solar system had very high solar energy utilization but poor collector performance. This resulted in a solar fraction of $16 \%$ and a system efficiency of $14 \%$. The design expected solar fraction was $46 \%$ and the system efficiency was $20 \%$. The f-chart solar fraction is $48 \%$, but the predicted system efficiency is $45 \%$ compared to the $20 \%$ design expected system efficiency. The large difference between the f-chart and design expected system efficiency is suspected to be due to an overstatement of collector efficiency by the manufacturer's singlepanel test curve. The measured collector performance was degraded due to stagnation damage after installation and subsequent treezing. The stagnation damage was caused when the collectors were installed several months before the system was turned on. The freeze damage was caused by a mislocated check valve which prevented drainback. Both of these problems can be attributed to poor i.nstallation practices.

The Oakmead Industries solar system had a measured collector efficiency of $40 \%$. This is slightly better than the manufacturer's single-panel test result. The design solar fraction of $86 \%$ is $34 \%$ greater than measured. There was no design system efficiency available. Although the design expectations appear optimistic, design solar fraction could be met if the solar utilization could be increased to $85 \%$. The present measured solar energy utilization of $52 \%$ is suspected to be due to the oversized storage tank which was often at temperatures too low for utilization by the space heating subsystem.

The f-chart predicted solar fractioi, was $67 \%$, $15 \%$ better than measured. Likewise, the f-chart system efficiency predicted from the solar fraction was $24 \%$, or four percent better than the measured data. Some of the increase in f-Chart predicted performance was due to greater solar insolation in the long-term weather records. The increased solar energy delivered to the loads is undoubtedly the major cause for better predicted performance at oakmead Industries.

At Saddle Hill Trust Lot 77 , site performance was reduced primarily because of transport losses. The measured solar fraction of $42 \%$ compares favorably with the design solar fraction of $43 \%$. However, the measured system efficiency was only $15 \%$, or nine percent below the design expected value. The f-Chart predicted solar frac$t i$ on was $56 \%$ and the predicted system efficiency of $21 \%$ is six percent above the measured value and three percent below the design expected value. Since the measured solar energy utilization was only $51 \%$ and collector efficiency was exactly as expected from the manufacturer's single-panel test curve, transport and storage losses were the cause of the poorer performance. These losses are principally due to leaks in the ductwork. Therefore, the design goals are realistic and they can be achieved if the duct leaks are sealed. 
This group of sites has design goals which appear to be unattainable by the installed systems. There may have been changes in system size after the designs were completed but we are not aware of any. The primary basis of comparison is the system efficiency augmented by f-chart predictions, collector efficiency, and solar energy utilization. All of these sites have good performance. The 11 sites considered are listed below:

Cathedral Square

Facilities Development

Forest City Dillon

Hei Wai Wong

Hogate's Restaurant

Loyola University
Saddle Hill Trust Lot 73

South Bridge Tower

Spearfish High School

Telex Communications

Vitro Test site

The Cathedral Square solar energy system had good performance with a $28 \%$ measured solar fraction and $17 \%$ measured system efficiency. On the other hand, the design solar fraction was $51 \%$ and the design system efficiency was $41 \%$. The f-chart solar fraction was $18 \%, 10 \%$ less than the measured value and quite opposite to the design solar fraction. Similarly, the f-chart predicted system efficiency was $14 \%$, or three percent less than measured.

These f-Chart results are even more surprising when one considers that the long-term solar insolation was $17 \%$ sunnier than the measured insolation. The measured collector efficiency of $31 \%$ is only one percent below the manufacturer's single-panel test result. The design results are clearly optimistic, because, even if $100 \%$ of the collected solar energy based on the long-term solar insolation were used, the system efficiency would still only be $31 \%$. It appears that a $51 \%$ design solar fraction is just not possible with the present solar system.

The Facilities Development solar system has been a consistently high performer with no major problems. At Facilities Development, collector efficiency was $43 \%$ and the solar energy utilization was $85 \%$. However, the measured system efficiency was nine percent less than design expected. The measured solar fraction was $13 \%$ less than predicted. If there were no losses, then measured system efficiency would still be two percent smaller than predicted. The design expectations are certainly optimistic. Although the f-chart predicted solar fraction is $12 \%$ greater than the measured solar fraction, the f-Chart system efficiency predicted from the solar fraction is only three percent greater than the measured system efficiency. The f-Chart results appear only slightly optimistic and that may be due to the $15 \%$ greater long-term solar insolation.

At the Forest City Dillon site, the solar fraction was $43 \%$ and solar energy delivered to the load was $93 \%$ of the collected energy. This performance is quite good, but the collector efficiency of $28 \%$ was $22 \%$ below the manufacturer's single-panel test curve. The system efficiency of $26 \%$ was fair, but eight percent below f-chart predictions and $29 \%$ below the design experted value. The difference 
between design solar fraction and measured solar fraction was $16 \%$ versus a six percent difference in the f-chart predicted and measured solar fraction. The design expected performance was very optimistic even compared to $100 \%$ utilization of the solar energy collected.

The Hei Wai Wong site performed well, although the collector efficiency of $32 \%$ was still $12 \%$ below the manufacturer's singlepanel test value. The solar fraction of $98 \%$ was two percent below the design predicted and two percent above the f-chart prediction. However, the design expected results were quite optimistic when one compares system efficiencies. The measured system efficiency of $23 \%$ was $23 \%$ below the design expected result, but two percent abovc thc f-chart result. Seventy-two percent nf the ronllected energy was delivered to the load. At this site, the f-chart predictions and measured results compare very well. The design expected results appear to be optimistic because the actual load was $50 \%$ of the design expected load.

The Hogate's Restaurant solar system performed with a collector efficiency of $35 \%$, which is good but nine percent less than the manufacturer"s single-panel test result. The measured solar fraction of $43 \%$ was also very good, but $21 \%$ below the design predictions. Design system efficiency was unavailable. The large difference in solar fraction between measured and design expected indicates an optimistic design. Since the f-chart solar fraction of $46 \%$ was only three percent above the measured value, this is a further indication that the design expected performance was optimistic. Noting that the measured solar energy utilization was $93 \%$ and that the long-term insolation was $13 \%$ greater than the measured value, it may be instructive to estimate what the possible highest solar fraction could be. Taking the highest possible values for solar energy incident, solar collector efficiency, and solar energy utilization, one can estimate that a 6l\% solar fraction is possible. This is still three percent below the design expected solar fraction.

The Loyola University solar system had a collector efficiency of $29 \%$, seven percent below the manufacturer's single-panel test result. However, the solar fraction off $37 \%$ was $15 \%$ below the design expected value and $17 \%$ below 1 -Chart predictions. This lower performance was partially due to sunnier long-term weather and below-expected collector performance. The measured solar energy utilized was $85 \%$ of thc collccted solar energy. The design is optimistic unless the collector array efficiency can be improved. The system efficiency predicted from the f-chart solar fraction was $30 \%$ versus the $34 \%$ system efficiency expected by the designer. The f-Chart predicted system efficiency is seven percent above the $23 \%$ measured system efficiency. Although the Loyola University solar system performed quite well, the measured performance was below the predicted f-chart performance because the measured solar insolation was $83 \%$ of the f-Chart long-term insolation and because the collector performance was below expected. 
At the Saddle Hill Trust Lot 73 site, overall performance was very good. Collector performance was particularly high with a collector efficiency of $52 \%$, seven percent better than the manufacturer's single-panel test result. Solar energy utilization was also quite good with $73 \%$ of the collected energy being used by the load. The system efficiency of $38 \%$ was excellent, but was still 13\% below the design expected. The measured solar fraction was two percent above design expected, however. The f-Chart results were similar to, the measured values, but with a lower solar fraction of $49 \%$ and a lower system efficiency of $35 \%$. Perhaps the difference was due to the lesser amount of sunshine for the longterm weather data. The design expected performance is optimistic at Saddle Hill Trust Lot 73 because the design system efficiency is too high. Also, since the long-term average weather is less sunny, the fine performance of the particular measured year may not be repeated. Therefore, the f-Chart results are quite likely representative of long-term average results.

The South Bridge Tower solar system had a high collector efficiency of $47 \%$, due to cool inlet water temperatures during the winter months. The measured solar fraction of seven percent was $17 \%$ below the design expected solar fraction and eight percent below the f-Chart predicted solar fraction. Comparing system efficiencies, the measured system efficiency of $26 \%$ was $20 \%$ below design expected and $30 \%$ below the system efficiency predicted from the f-Chart solar fraction. The design expected performance is quite optimistic, but the reason may lie in the overstated collector performance from the manufacturer's single-panel test. Although measured collector efficiency was very high, it was $29 \%$ below the performance predicted from the single-panel test. If one uses the f-chart long-term insolation, which is $23 \%$ sunnier than the measured insolation, and the measured collector efficiency, the estimated system efficiency is three percent above the measured system efficiency. Apparently the South Bridge Tower solar system design expectations and f-Chart predictions are very inflated due to the erroneous single collector panel test results.

The Spearfish High School solar system performed more moderately with a measured collector efticiency of $27 \%$. Thls was eiglit percent below the manufacturer's single-panel test result. The measured solar fraction of $54 \%$ actually was one percent greater than the design expected solar fraction, but the measured system efficiency of $22 \%$ was $11 \%$ below the design expected system efficiency. This comparison implies that the design expected solar energy delivered to load would be nearly twice the measured value. Comparing f-chart predictions, the f-Chart solar fraction of $62 \%$ was eight percent greater than measured, but the system efficiency predicted from the f-chart solar fraction was three percent less than measured. The long-term solar insolation was about one percent less than the measured insolation, so this was not a factor. Although the design expected solar fraction is the same as the measured solar fraction, the design loads were more than twice the measured loads. Hence, the expected solar contribution based on solar fraction was also greatly inflated. 
The Telex Communications solar system had good performance. collector efficiency was $28 \%$, but was still two percent above the manufacturer's single-panel test result. Seventy-six percent of the collected solar energy was utilized. The measured solar fraction of $82 \%$ was excellent and one of the highest. This solar fraction was three percent above the design value. The f-chart solar fraction of $83 \%$ was similar to the measured value. The design goals are optimistic due to design expected system efficiency, which is $15 \%$ greater than measured, and $10 \%$ greater than f-chart.

The Vitro Test Site had relatively poor collector efficiency of $23 \%$ versus the manufacturer's single-panel test result of $46 \%$. Due in part to the reduced collector efficiency, the measured solar fraction was only $14 \%, 10 \%$ below the design expected value. However, the measured system efficiency of $22 \%$ was $36 \%$ below the design expected system efficiency because the estimated design load was 50\% too high and collector performance was low. Measured solar energy utilization was very good, with $94 \%$ of the collected solar energy being used. The f-chart predictions were also higher than the measured results because the manufacturer's single-panel test results were used. The f-chart solar fraction of $23 \%$ was nine percent greater than the measured solar fraction. The system efficiency predicted from the f-Chart solar fraction was $39 \%, 17 \%$ higher than the measured value. The optimistic design expectations for the vitro Test site were partially due to lower than expected collector performance and overestimation of the design load. 


\section{SECTION III}

\section{SUMMARY AND CONCLUSIONS}

The data presented in Section ll illustrates the comparison of measured performance with design expected and f-Chart predicted performance. This section presents the aggregated results and the conclusions.

Table 3 shows the summary performance data of measured versus design expected and f-chart predicted results. The data is the average sum of the difference between the measured performance and design expected or f-Chart predicted performance.l Measured values which are less than the design expected or f-chart predicted results yield a negative number.

Table 3. MEASURED SUMMARY PERFORMANCE DATA VERSUS DESIGN EXPECTED AND F-CHART PREDICTED RESULTS

$$
\text { (All values in percentages) }
$$

\begin{tabular}{lcccc} 
& \multicolumn{2}{c}{ SOLAR } & FRACTION & \multicolumn{2}{c}{ SYSTEM EFFICIENCY } \\
\cline { 2 - 4 } CATEGORY & DESIGN & f-CHART & DESIGN & f-CHART \\
\hline All Sites & -8.0 & -6.4 & -9.0 & -4.0 \\
All Sites Except & -5.5 & -2.5 & -10.0 & -2.0 \\
Poor Performers & & & & \\
Sites Which Meet & 0.7 & 3.7 & 2.0 & 6.0 \\
Or Exceed Design & & & -18.0 & -7.0
\end{tabular}

Examining the average differences from Table 3 , one can see that the difference between measured and design expected data is usually negative. This means. that the design expected results exceeded the measured results. Statistically, this difference is significant for the system efficiency values. If we exclude the below average performers, the differences are smaller for solar fraction but slightly larger on system efficiency.

For those sites with expected performance and realistic design expectations, the average measured performance exceeded the design performance only slightly.

Value $=\frac{\sum \text { (Measured Value - Design or f-Chart Value) }}{\text { Number of Values }}$ 
However, in the category labeled Optimistic Design, there is no real difference between all. the sites and the ones labeled optimistic. The system efficiency from the optimistic category was much higher than when all sites were included. This indicates that the solar fraction parameter is more independent of the groups. The system Efficiency is much worse for the Optimistic Design group because of the greater variability of insolation. This is a strong indication that this category is indeed overdesigned. Recall that most of the error appeared to be due to overestimation of the loads.

The summary results for the f-Chart predicted performance are similar to the design expected values, but somewhat. closer to the measured values. In fact, there is no significant difference between the f-chart predictions and the measured values for system Efficiency for All Sites. This means that, on the average, f-Chart predictions match the measured results. However, bear in mind that these f-chart predictions are based on measured loads for the input data. Interestingly, there is also no significant difference between the design expectations and $f$-Chart predictions for system Efficiency for All Sites. The exclusion of below-average measured performance merely brings the f-Chart predictions closer to the measured performance.

For those sites which meet or exceed design expectations, the f-Chart predictions are surprisingly below the measured performance. There is no explanation as to why this might be.

The sites where the design expected performance was optimistic also have f-chart predictions which are optimistic, but not to the same degree as for the design expected performance. In several instances, the f-chart predictions were somewhat inflated because the long-term solar insolation exceeded the measured insolation. For all sites in this report, the long-term insolation exceeds the measured insolation by six percent.

The reader should note that, although the average measured and design expected or f-chart predicted performance values are not greatly different, the range of values represented in the data is quite wide. From Figures 1,2 , and 3 , it is obvious that the differences in solar fraction range from $+30 \%$ to $-30 \%$, and the differences in system efficiency range from + four percent to $-36 \%$. $1 \mathrm{t}$ is unclear whether this large variability is a general characteristic of solar system performance, or whether it is due to differences in system types and system applications. Study of a larger sample of similar systems would help determine the true range of variability and perhaps the cause.

Design expected performance was found to be significantly greater than actual measured performance by an eight percent solar fraction or a nine percent system efficiency. The f-chart predicted performance with measured loads was not significantly different from the measured performance or the design expected performance. The f-Chart predictions tended to be greater than the measured performance because the average long-term insolation was $5.7 \%$ larger than measured insolation, and because the average measured collector performance was $6.3 \%$ below the manufacturer's test results. 
of the 25 selected solar systems, eight sites, or $32 \%$, met or exceeded the design goals, while 11 sites, or $44 \%$, had design goals which were not achievable. The other six sites, $24 \%$, had realistic design goals but below average performance.

The below average measured performance was caused by poor solar energy utilization on three systems, poor collector performance on two systems, and faulty air vents on one system. The collectors appear to have degraded on one system due to excessive stagnation and freezing caused by a misplaced check valve. The other poor collector performance appears to be related to lower than designed air flow. The solar energy utilization problems were caused by low storage temperatures, high duct losses, and a suspected control problem.

Further research into the aspect of solar energy utilization is needed to round out the design process. Predictive models like f-chart appear to be particularly adept at determining how well the solar collector component will perform. The fact that several solar systems had poor utilization of the collected solar energy indicates a need to better understand the dynamics of integrating solar energy systems with conventional HVAC systems.

The conclusions of this study are summarized below.

- Design expected performance was statistically different from measured performance and eight percent greater in solar fraction, or nine percent greater in system efficiency.

- The f-Chart predictions were not statistically different from measured or design expected results.

- The long-term insolation data was about six percent sunnier than the measured insolation. This inflated the f-chart predictions.

- The manufacturer's collector test results were six percent above the measured collector efficiency on the average. This higher efficiency also inflated the f-chart predictions.

- Design expected loads were generally larger than the measured loads. This difference is believed to be the largest source of error in the design expected performance. 


\section{DESIGN DO'S AND DON'T'S}

The following 1 ist of design do's and don't's is suggested from the writer's interpretation of the data. What is proposed in the list is a checklist or "rules of thumb" pertaining to establishing the design concept of a solar system.

1. Do check predictions for reasonableness. Our suggestion here is to determine the average incident solar energy in BTU/ft2-day and the average solar energy delivered to loads in BTU/ft2-day. The ratio of these will yield a system efficiency. The measured NSDN solar systems had an average system efficiency of $25 \%$ and the f-Chart predicted average system efficiency was $29 \%$. Predicted system efficiencies nver $40 \%$ are suspect, al though two NSDN solar systems did achieve that level of performance.

2. Do check solar energy utilization. Recall that this is defined as solar energy used divided by solar energy collected. A ratio greater than one is impossible; ratios less than 0.6 should be checked because they are low.

3. Don't use conservative design practice to estimate loads. This was the greatest source of error in the design expected results. Therefore, loads should be carefully determined.

4. NSDN measured insolation data was usually below f-Chart SOLMET insolation data by about six percent on the average. This higher insolation causes some inflation in the predicted values. The designer must be aware of this.

3. Do try to find more than one. source of ASHRAE 93-77 collector cest results. Also, compare the chosen collector test curve with other generically similar collector curves to alert a designer to a suspect test curve if it is greatly different. 
SECTION IV

REFERENCES

*1. National Solar Data Network, Department of Energy, prepared under Contract Number DE-AC01-79CS30027, Vitro Laboratories, Silver Spring, Maryland, January 1980.

2. Beckman, W.A., S.A. Klein, and J.A. Duffie, Solar Heating Design by the f-Chart Method, John Wiley $\varepsilon$ sons, New York, 1977 .

3. ASHRAE Standard 93-77, Methods of Testing to Determine the Thermal Performance of Solar Collectors, The American Society of Heating, Refrigeration and Air Conditioning Engineers, Inc., 1977 .

*4. Component Report: Performance of Solar Collector Arrays and Collector Controllers in the National Solar Data Network, July 1984, SOLAR/0015-84/32, Vitro Corporation, Silver Spring, Maryland.

*5. Solar Energy System Performance Evaluation, ARATEX Services, December 1979 through November 1980, SOLAR/2008-81/14, Vitro Laboratories, Silver Spring, Maryland.

*6. Solar Energy System Performance Evaluation, Bell Telephone of Pennsylvania, November 1979 through March 1980, SOLAR/2012$80 / 14$, Vitro Laboratories, Silver Spring, Maryland.

*7. Solar Energy System Performance Evaluation, Cathedral Square, January 1980 through December 1980, SOLAR/1060-81/14, Vitro Laboratories, Silver Spring, Maryland.

*8. Solar Energy System Performance Evaluation, Facilities Developmeni, January 1980 through December 1980, SULAR/1017-81/14, Vitro Laboratories, Silver Spring, Maryland.

*9. Solar Energy System Performance Evaluation, First Manufactured Homes Lot 9 and Lot 10 , September 1981 through February 1982 , SOLAR/1047-82/24 and SOLAR/1105-82/24, Vitro Laboratories, Silver Spring, Maryland.

*10. Solar Energy System Performance Evaluation, Forest City Dillon, January 1981 through December 1981, SOLAR/1041-82/14, Vitro Laboratories, Silver Spring, Maryland.

*Copies of these reports may he ohtained from Terhnical Information Center, P.0. Box 62, Oak Ridge, Tennessee 37831 . 
*11. Solar Energy System Performance Evaluation, General ElectricDallas, October 1980 through March 1981, SOLAR/2094-81/14, vitro Laboratories, Silver Spring, Maryland.

*12. Solar Energy System Performance Evaluation Update, GSA/Federal Youth Center, October 1982 through April 1983, SOLAR/2037$83 / 14$, Vitro Corporation, Silver Spring, Maryland.

*13. Solar Energy System Performance Evaluation, Hei Wai Wong, November and December 1979, and April through August 1980, SOLAR/1014-80/14, Vitro Laboratories, Silver Spring, Maryland.

*14. Solar Energy System Performance Evaluation, Hogate's Restaurant, January 1980 through December 1980, SOLAR/2028-81/14, vilio Laboratories, Silver Spring, Maryland.

*15. Solar Energy System Performance Evaluation, Kalin Home, September 1981 through March 1982, SOLAR/1117-82/14, Vitro Laboratories, Silver Spring, Maryland.

*16. Solar Energy System Performance Evaluation, Lake Valley Firehouse, March 1981 through June 1981, S0LAR/2020-81/14, Vitro Laboratories, Silver Spring, Maryland.

*17. Solar Energy System Performance Evaluation, Loudoun County School, July 1979 through June 1980, SOLAR/2016-80/14, Vitro Laboratories, Silver Spring, Maryland.

* 18. Solar Energy System Performance Evaluation, Loyola University, February 1981 through June 1981, SOLAR/1055-81/14, Vitro Laboratories, Silver Spring, Maryland.

*19. Solar Energy System Performance Evaluacion, 0akillead Industries, June 1981 through April 1982, SOLAR/2076-82/14, Vitro Laboratories, Silver Spring, Maryland.

*20. Solar Energy. System Performance Evaluation, Saddle Hill Trust Lot 36, 0ctober 1979 through May 1980, SOLAR/1038-80/14, vitro Laboratorles, Silver Spring, Maryland.

*21. Solar Energy System Performance Evaluation, Saddle Hill Trust Lot 73, January 1980 through December 1980, SOLAR/1039-81/14, vitro Laboratories, Silver Spring, Maryland.

*22. Solar Energy System Performance Evaluation, Saddle Hill Trust Lot 77, September 1979 through August 1980, SOLAR/1040-80/14, vitro Laboratories, Silver Spring, Maryland.

*Copies of these reports may be obtained from Technical Information Center, P.0. Box 62, 0ak Ridge, Tennessee 37831 . 
*23. Solar Energy System Performance Evaluation, South Bridge Tower, January 1981 through February 1982, SOLAR/1101-82/14, Vitro Laboratories, Silver Spring, Maryland.

*24. Solar Energy System Performance Evaluation, Spearfish High School, September 1980 through June 1981, SOLAR/2078-81/14, Vitro Laboratories, Silver Spring, Maryland.

$* 25$. Solar Energy System Performance Evaluation, Summerwood Associates, House M, June 1980 through May 1981, SOLAR/1102-81/14, Vitro Laboratories, Silver Spring, Maryland.

*26. Solar Energy System Performance Evaluation, Telex Communications, November 1979 through April 1980, SOLAR/2033-80/14, Vitro Laboratories, Silver Spring, Maryland.

*27. Solar Energy System Performance Evaluation, Terrell E. Moseley, Inc., October 1980 through April 1981, SOLAR/2011-81/14, Vitro Laboratories, Silver Spring, Maryland.

*28. Solar Energy System Performance Evaluation, Vitro Test Site, January 1982 through December 1982, SOLAR/2093-83/14, Vitro Corporation, Silver Spring, Maryland.

*Copies of these reports may be obtained from Technical Information Center, P.0. Box 62, Oak Ridge, Tennessee 37831. 
APPENDIX A

SYSTEM DESCRIPTIONS 


\section{ARATEX SERVICES}

The ARATEX Services (formerly Work-Wear) site is an industrial laundry located in Fresno, California. The system was designed so that collected and recycled solar energy would sat isfy $20 \%$ of a 30,000-gallon per day hot water laundry process demand. Output waters are designed to be maintained at about $180^{\circ} \mathrm{F}$; however, conservation efforts have reduced this temperature to $165^{\circ} \mathrm{F}$.

The solar collector array consists of $140 \mathrm{flat-plate,} \mathrm{single-}$ glazed Ying Collectors Model SP4l20 (Ying Manufacturing Corporation, Gardena, California), 90 of which were reglazed with Tedlar, and recoated during a refurbishment project begun in september 1979.

The Ying solar collectors normally have one UV stabilized layer of clear polycarbonate plastic, 0.02 inches in thickness, as a cover. Transmittance of this cover is 0.91 . Flat-black paint was used as a surface for the aluminum absorber plate.

Ying controls were used to control the operation of the solar collectors.

The collector area is 7,050 square feet. The collector array faces due south and the collector angle is 30 degrees from the horizontal.

The system, shown schematically in Figure $A-1$, has three modes of operation for process water heating with solar energy and recycled thermal energy.

Mode 1 - Collector-to-Storage - During this mode of operation, water is pumped from solar thermal storage through the collector array and back into storage. This mode. is activated when the temperature of the collector array outlet exceeds the storage temperature by 4.5 degrees and continues until this differential temperature drops below 1.5 degrees. There is a $12-m i n u t e$ delay for circulation pump $P 2$ to turn on or off. This control function eliminates sporadic pump operation during fluctuations of insolation, saving electrical operating energy and increasing the lite of the collector pump.

Mode 2 - Hot Water Demand - This mode is activated when there is a demand by the laundry for hot water. City water entering the hot water system is preheated using thermal energy from wastewater in the 16,500-gallon holding tank. The temperature of the city water is raised to a range of $95^{\circ} \mathrm{F}$ to $110^{\circ} \mathrm{F}$ before entering solar thermal storage. As water is drawn from solar thermal storage, it passes through a steam heat exchanger (HX2) where auxiliary energy is added to maintain the 4,000-gallon laundry hot water service storage tank at about $180^{\circ} \mathrm{F}$. Additional energy is supplied from steam condensate flowing through heat exchanger $H \times 3$. Under conditions of elevated demand, valve $V 3$ opens to provide inlet water preheated only by the heat recovery subsystem. 
Mode 3 - Storage-to-Wastewater - When the water in the solar thermal storage tank reaches $180^{\circ} \mathrm{F}$, it can be circulated by reverse flow through heat exchanger $H X I$ in the heat recovery subsystem, thus storing any excess solar energy in the wastewater holding tank. This mode is used to prevent overheating the 12,500-gallon fiberglass storage tank and allows the wastewater holding tank to be used as a secondary storage tank. 


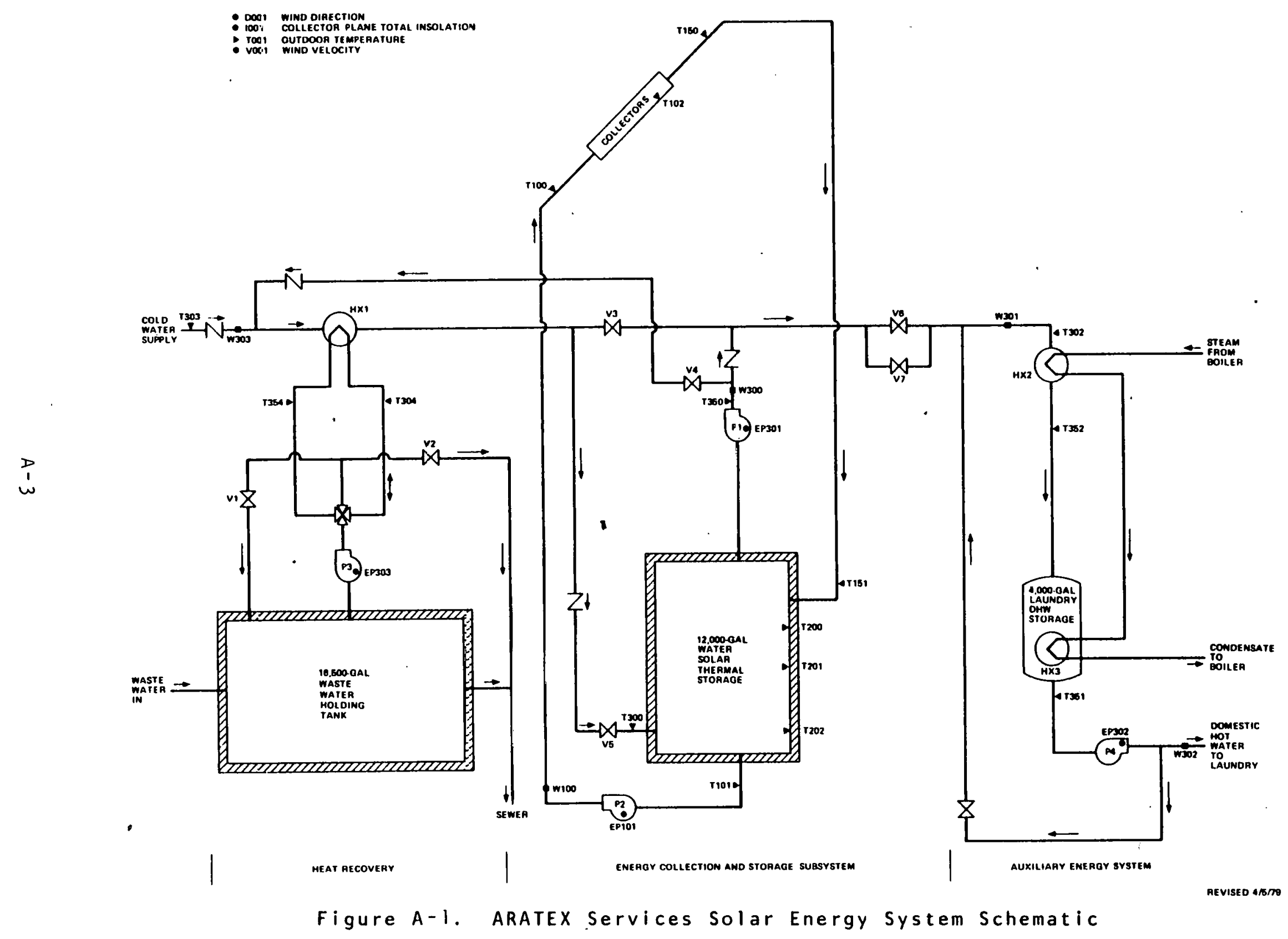




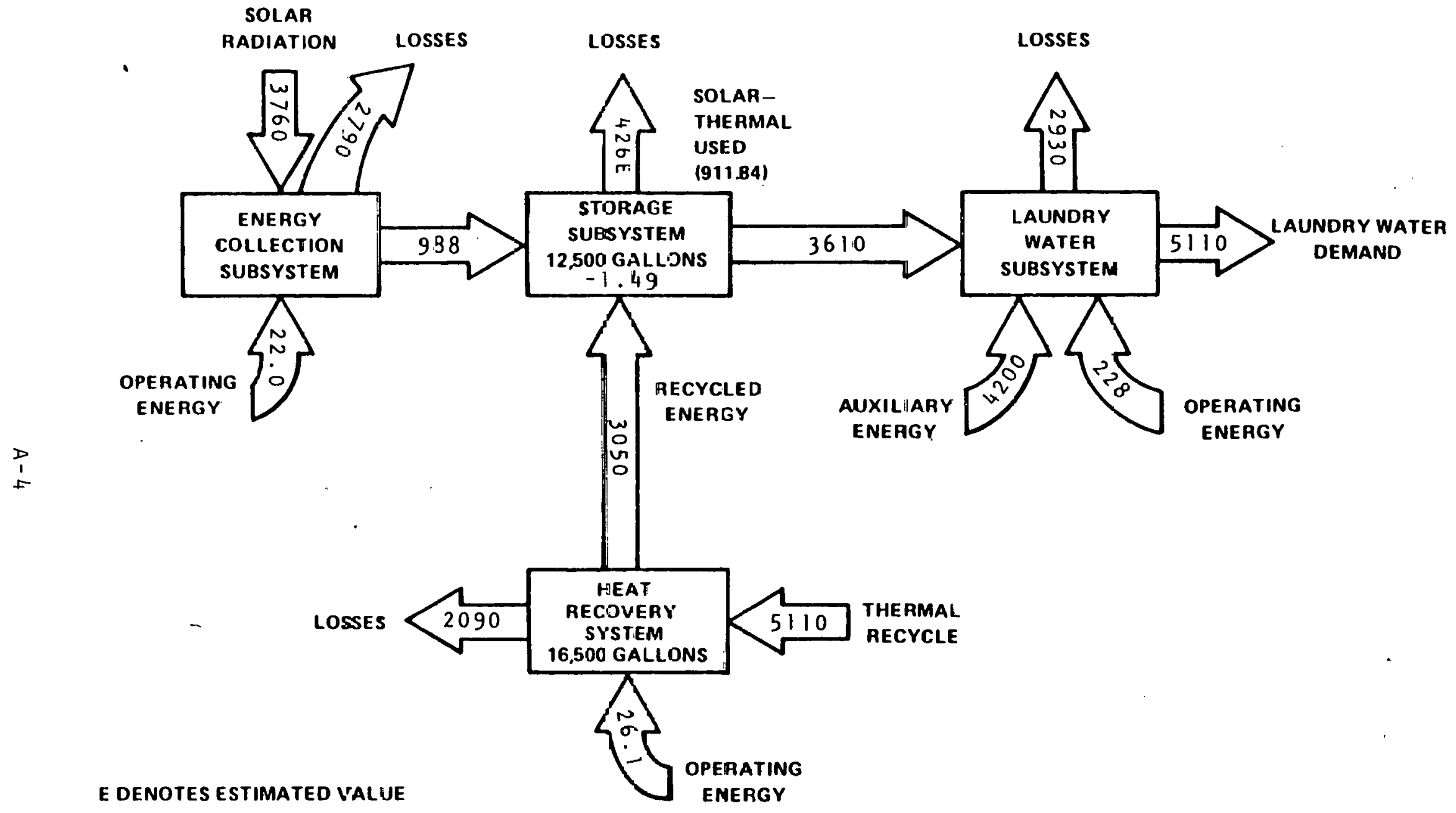

Figure A-2. Energy Flow Diagram for ARATEX Services December 1979 through November 1980

(Figures in million BTU) 


\section{BELL TELEPHONE OF PENNSYLVANIA}

The Bell Telephone of Pennsylvania site is a one-story office and warehouse building in West Chester, Pennsylvania. The solar energy system is designed to supply approximately $60 \%$ of the annual space heating requirements for the building. The site has an array of Heliotherm flat-plate collectors (DC 24 SC) with a gross area of 2,112 square feet which faces south at an angle of 55 degrees from the horizontal.

The collector paneis have a single, 0.10-inch-thick cover and a selective surface manufactured by Heliotherm. The absorber surface has a solar absorptivity of 0.95 and an infrared emissivity of 0.10 . Total solar transmissivity of the glazing is 0.92 . The absorber surface is composed of 0.04 -inch Roll-Bond CDA 122 copper by 01 in Brass Company. The fluid circulated through the collectors is water. The collector panels are 0.10-inch-thick covered with plexiglass "G" by Rohm \& Haas.

The site utilizes a Honeywell R74l2A differential controller to operate the solar collectors. This controller has the capability of adjustment of differential set points on-site as needed.

Solar-heated water is stored in a 6,000-gallon capacity tank, which is believed to contain only 4,600 gallons. The tank is located above ground in the mechanical room. Thermal energy is distributed to the loads by circulating water from the storage tank through forced-air heat exchangers and through 20 individual heat pump evaporators. When solar energy is insufficient to meet the requirements for space heating, auxiliary energy is supplied to the circulating water by electric resistance heating in the boiler.

The system, shown schematically in Figure A-3, has three instrumented modes of solar operation.

Mode 1 - Collector-to-storage - This mode is entered when the sensed collector absorber plate temperature exceeds the temperature in the middle of storage by at least $180 \mathrm{~F}$. Water from the tank is then circulated through the collectors until this temperature differential is less than $3^{\circ} \mathrm{F}$. The collector subsystem has a draindown feature to prevent freezing. Overheat protection is provided by automatic draining of the collector array whenever the collector output temperature exceeds $190^{\circ} \mathrm{F}$.

Mode 2 - Storage-to-Space Heating - This mode is entered with a demand for heating from manually preset thermostats in either the office corridors or the warehouse area. Water is circulated by pumps $P 3$ and $P 4$ between the storage tank and the Air-Handling Unit (AHU) heat exchangers and the Forced Flow Heater (FFH) units. The AHU and FFH units are activated to provide heat to the warehouse area and the corridors, respectively. Pumps $P 3$ and $P 4$ are deactivated whenever the space heating demands are satisfied at each respective area. 
Mode 3 - Storage-to-Space Heating (Heat Pumps) - This mode is entered when there is a demand for space heating from individual offices and the sensed temperature of the water to the heat pumps is below a nominal $700 \mathrm{~F}$. Valve vio blends water from the storage tank with the heat pump return flow as required. Flow from the storage tank ceases when the heat pump fluid operating temperature again reaches the $700 \mathrm{~F}$ set point. When the sensed storage tank temperature is less than 700F, the boiler becomes the thermal energy source for the heat pumps by the opening of valve $v 8$ and the closing of valve $v 9$. 


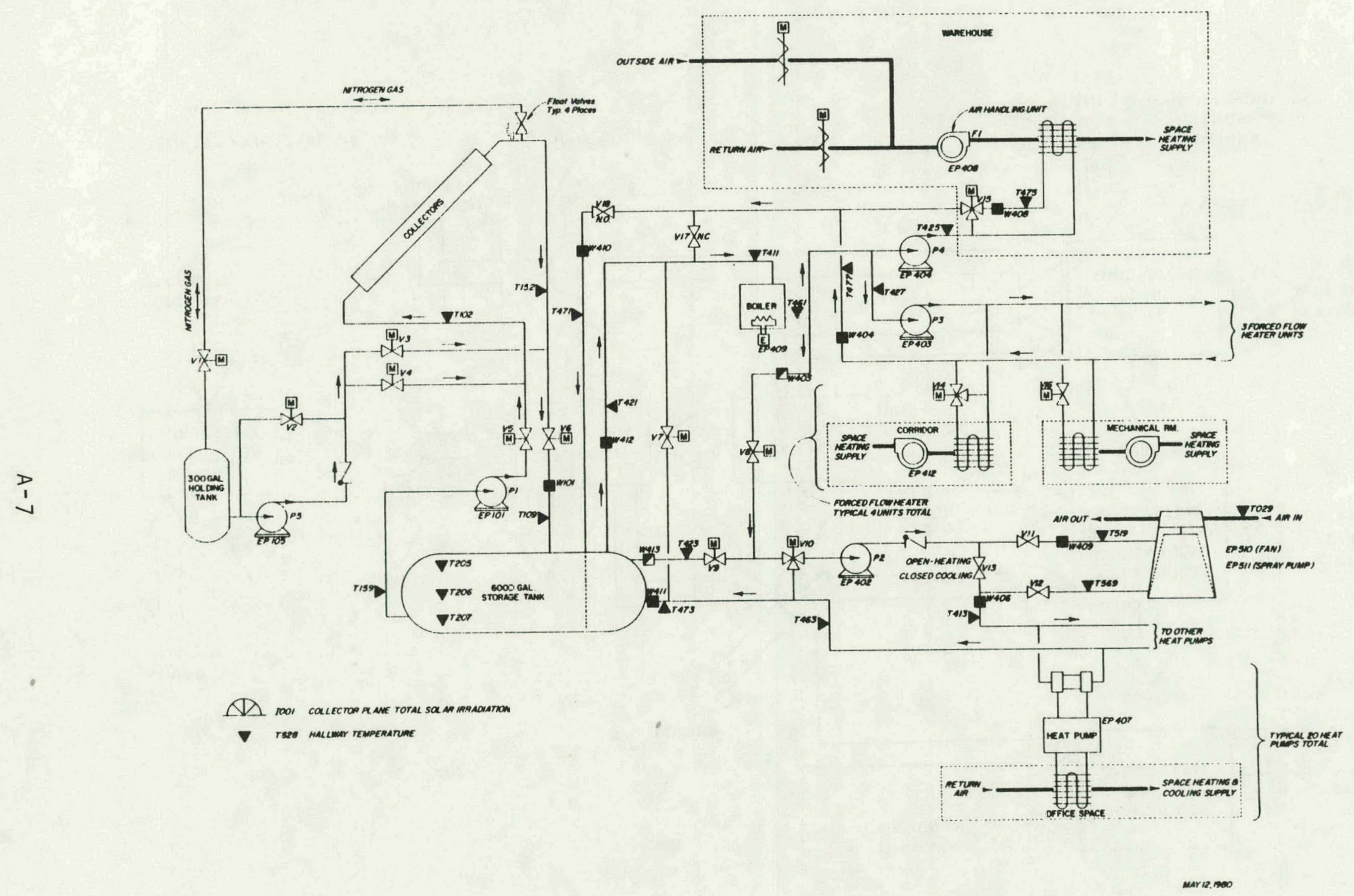

FigureA-3. Bell Telephone of Pennsylvania Solar Energy System Schematic 


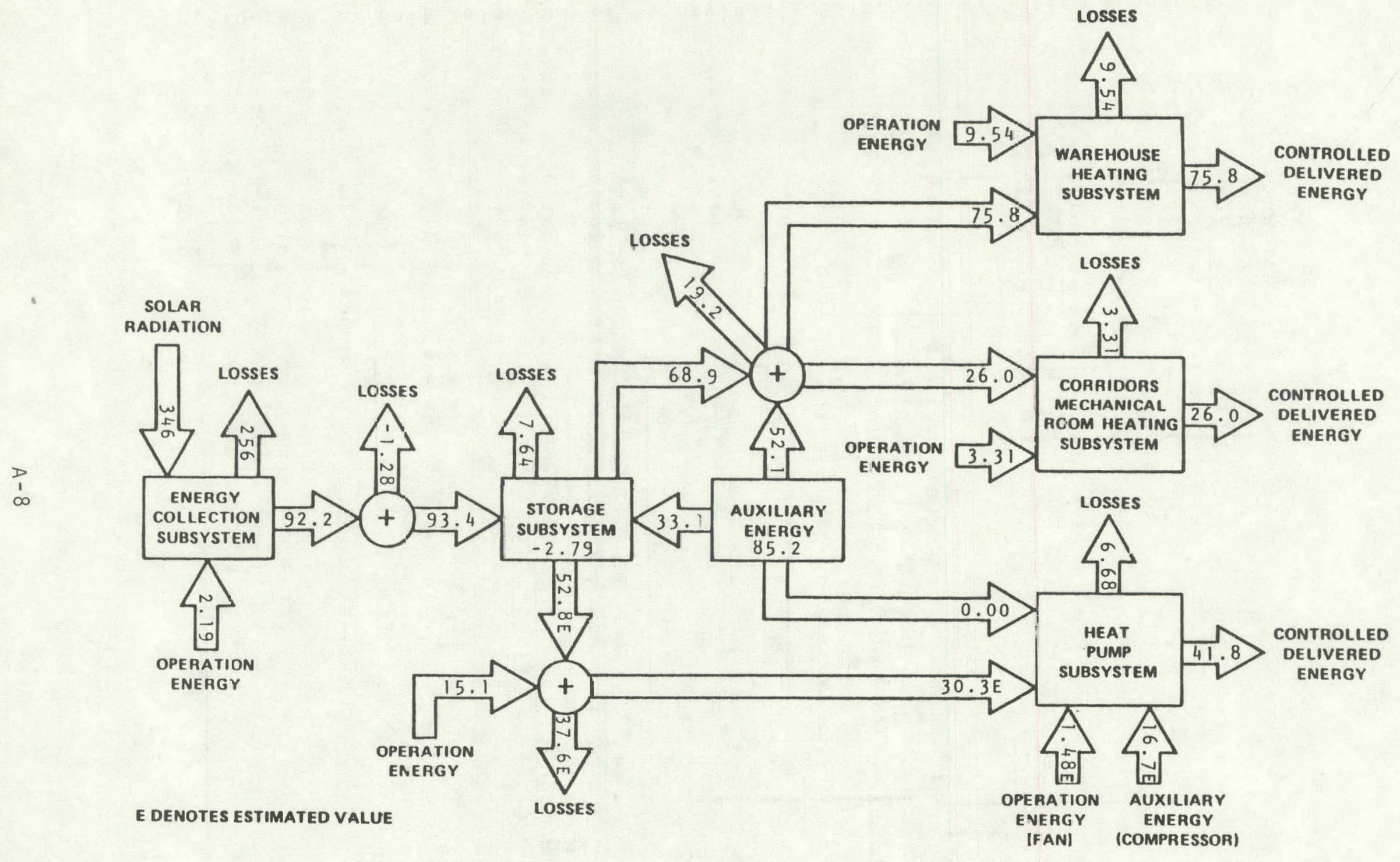

Figure A-4. Energy Flow Diagram for Bell Telephone of Pennsylvania November 1979 through March 1980

(Figures in million BTU) 


\section{CATHEDRAL SQUARE}

The Cathedral Square site is a lo-story building located in Burlington, Vermont. The building has 101 apartments, each containing approximately 500 square feet of living space. Solar energy is used to preheat the Domestic Hot Water (DHW). The solar energy system has an array of flat-plate collectors, Daystar 2l-B, with an effective area of 1,798 square feet, requiring a gross area of 2,342 square feet. The array faces 42 degrees west of due south at an tilt of 45 degrees from the horizontal.

The collector array consists of 80 Daystar 21-B collectors. The collectors have a 3/16-inch low-iron content, tempered glass cover plate with a net aperture of 21 square feet. The absorber plate is copper with copper tubing and repainted black. The absorber has an absorbitivity of 0.98. Special features include a folded polymer heat trap with transmissivity of 0.94 and an integrated temperature delimiter which maintains internal collector temperatures below $270^{\circ} \mathrm{F}$. The optical efficiency is 0.83 . (This model is no longer manufactured by Daystar.)

A Rho Sigma Model 106 differential controller is used to control the operation of the solar collectors. Thermistor sensors measure a $100 \mathrm{~F}$ "on" differential and a $3^{\circ} \mathrm{F}$ "off" temperature differential between storage and the collector array.

A $67 \%$ propylene glycol/water solution is the transfer medium that delivers solar energy from the collector array to a water storage heat exchanger. The transfer medium that delivers solar energy from storage to the hot water heat exchanger is water. Solar energy is stored in a 2,699-gallon solar storage tank. Energy is exchanged from the solar storage tank to the 865-gallon conventional DHW storage tank when there is a sufficient temperature difference between the two tanks. When there is a hot water demand, cold supply water flows past the solar storage heat exchanger into the DHW storage tank. Two gas-fired boilers supply any auxiliary thermal energy required to satisfy the hot water load.

The solar system, shown schematically in Figure A-5, has two modes of operation.

Mocie 1 - Collector-to-storage - This mode activates when the collector temperature exceeds the solar thermal storage temperature by approximately loof. Pumps in the collector heat exchangerl storage loop are activated. The propylene glycol/water solution flows through the collector array and the collector heat exchanger, and water flows through the heat exchanger and solar thermal storage tank. When the collector temperature is within approximately $30 \mathrm{~F}$ of the solar energy storage temperature, the pumps are deenergized and the mode is terminated. 
Mode 2 - Storage-to-Preheat - This mode activates when the temperature of the solar thermal storage exceeds the temperature on the discharge side of the DHW preheat exchanger by approximately $10^{\circ} \mathrm{F}$. Pumps in the solar thermal storage to DHW preheat exchanger loop are activated. The water flows from solar thermal storage through the DHW heat exchanger and back to storage. The city water is preheated, on demand, as it passes through the DHW preheat heat exchanger. This mode terminates when the temperature of the hot water on the discharge side of the DHW preheat heat exchanger is within approximately $3^{\circ} \mathrm{F}$ of the temperature of solar thermal storage. 


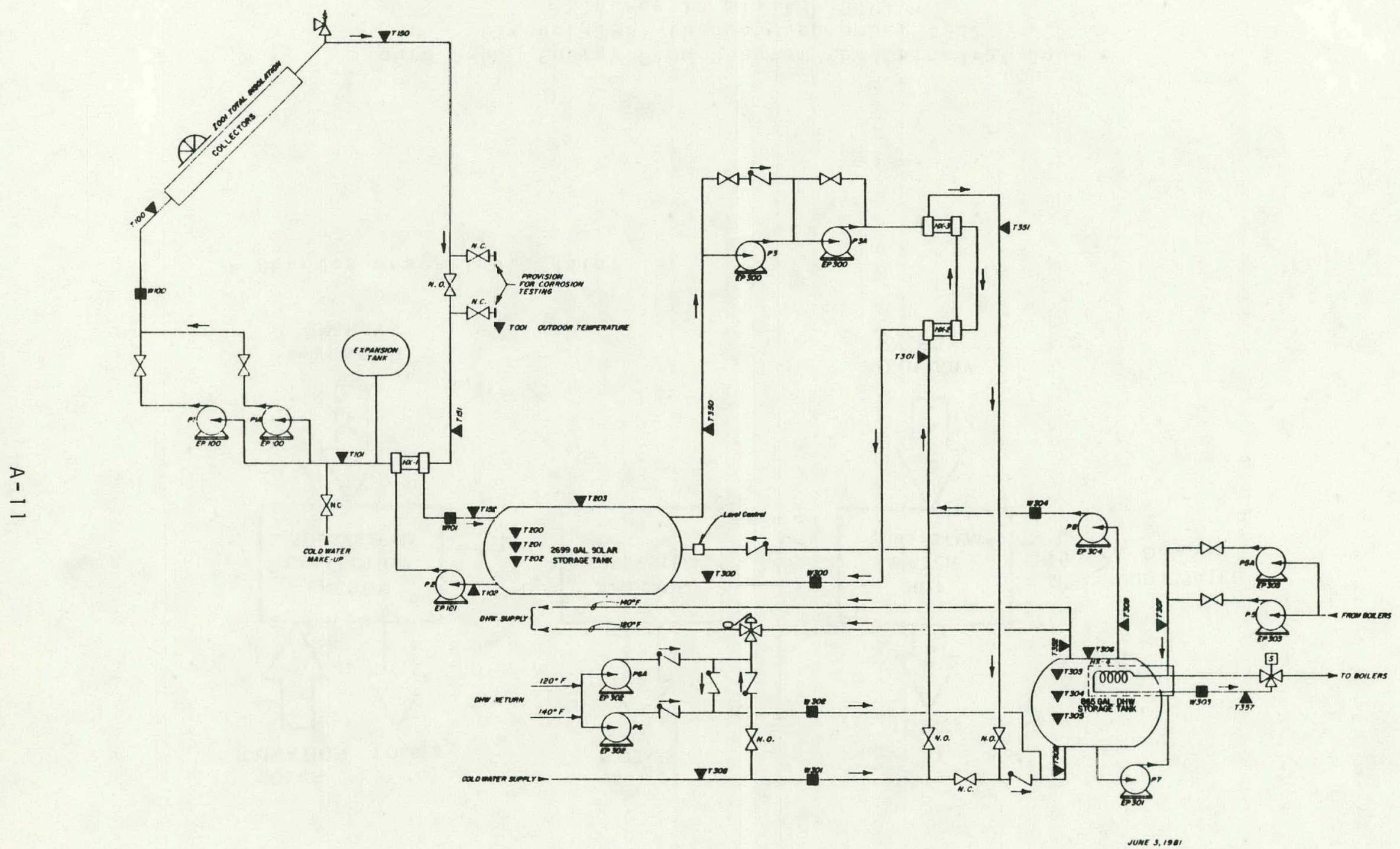

Figure A-5. Cathedral Square Solar Energy System Schematic 


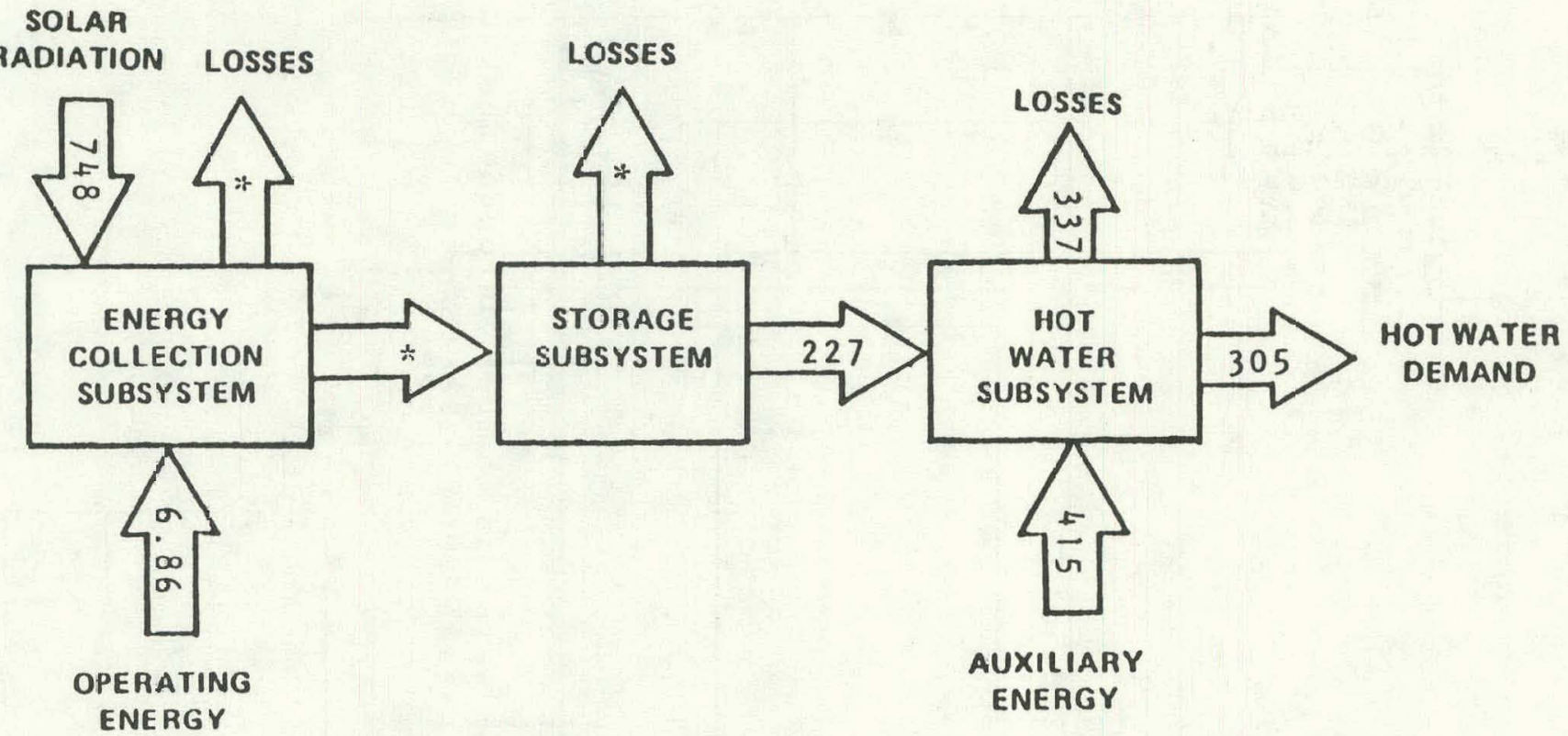

* Denotes unavailable data.

Figure A-6. Energy Flow Diagram for Cathedral Square October 1981 through September 1982

(Figures in million BTU) 


\section{FACILITIES DEVELOPMENT}

The Facilities Development Company site is a three-story multifamily condominium consisting of 31 units in San Diego, California. Solar energy is used for preheating Domestic Hot Water (DHW) for the complex. The solar energy system has an array of flat-plate Revere collectors with a gross area of 520 square feet. The array faces south at an angle of 42 degrees to the horizontal.

The Revere Sun-Aid No. 211 collector panels have two glass covers and a nonselective absorber surface. The absorber surface has a solar absorptivity of 0.96 and an infrared emissivity of 0.11 . Total solar transmissivity of the glazing is.0.86. The absorber surface is composed of black painted copper. The fluid circulated trhough the collectors is water.

The differential controller is a Heliotrope General Model. DTT200 with freeze protection cycle, $9^{\circ} \mathrm{F}$ "on" temperature differential and 30 F "off" differential.

Potable water is the transfer medium that transports solar energy from the collector array to an underground insulated 1,000-gallon glass-lined Santa Fe storage tank. Preheated water from the storage tank is supplied, on demand, to 31 conventional Ruudglas 52gallon DHW tanks. When sollar energy is insufficient to satisfy the load, electric heating elements within the individual DHW tanks are energized.

The system, shown schematically in Figure A-7, has two modes of solar operation.

Mode 1 - Collector-to-Storage - This mode activates when the water temperature in the collectors is $9^{\circ} \mathrm{F}$ higher than the temperature of the storage tank. Water is pumped through the collectors and circulates back to storage until the temperature difference is $3^{\circ} \mathrm{F}$ or less.

Mode 2 - Storage-to-DHW Tank - This mode activates when there is a demand for hot water replenishment by an individual DHW tank.

Water from storage circulates through a supply service loop to the individual DHW tank and returns through a service line to storage. The water temperature in each DHW tank is thermostatically controlled. When required, additional energy is supplied by electric heating elements within each tank. 


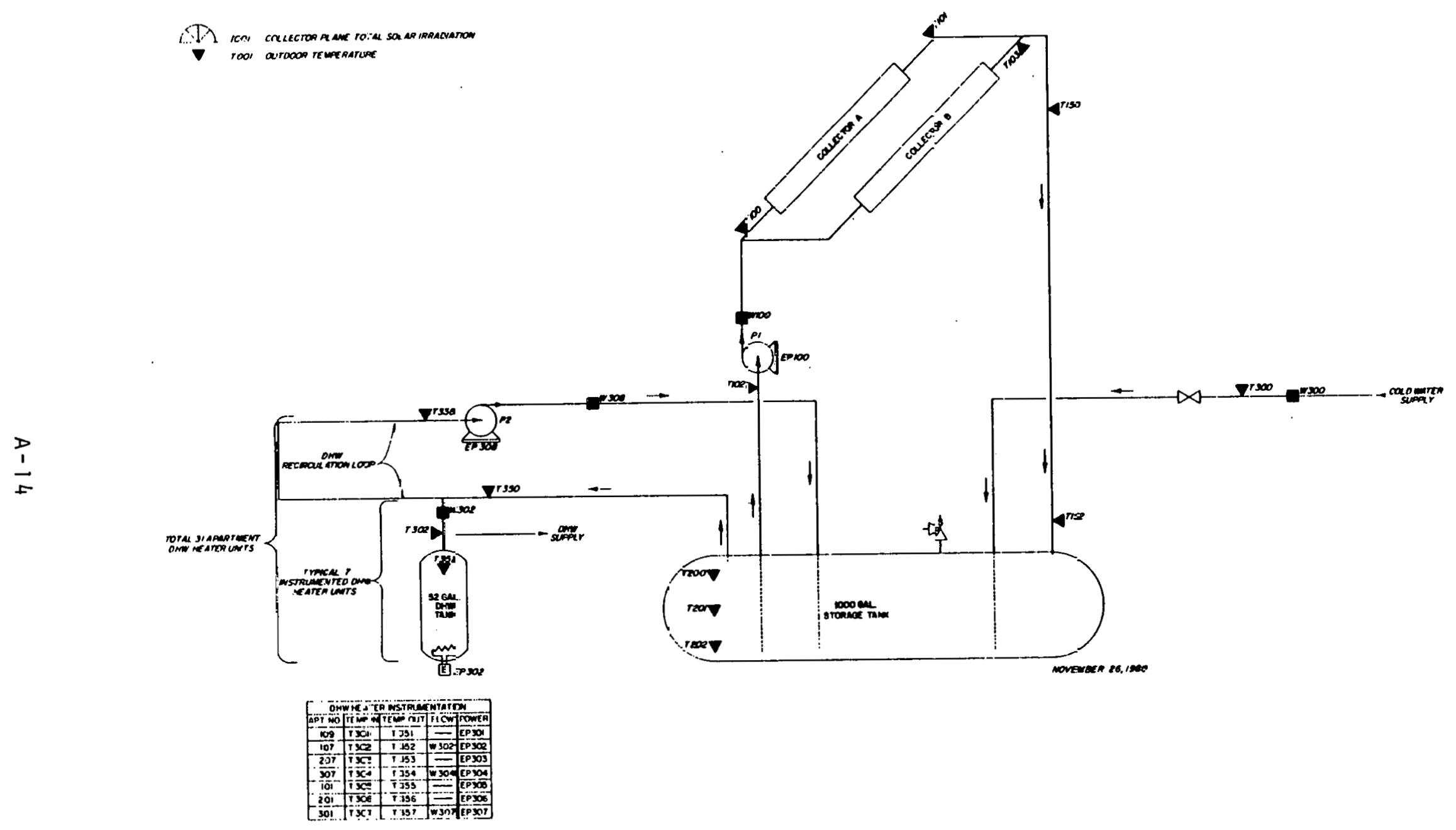

Figure A-7. Facilities Development Solar Energy System Schematic 


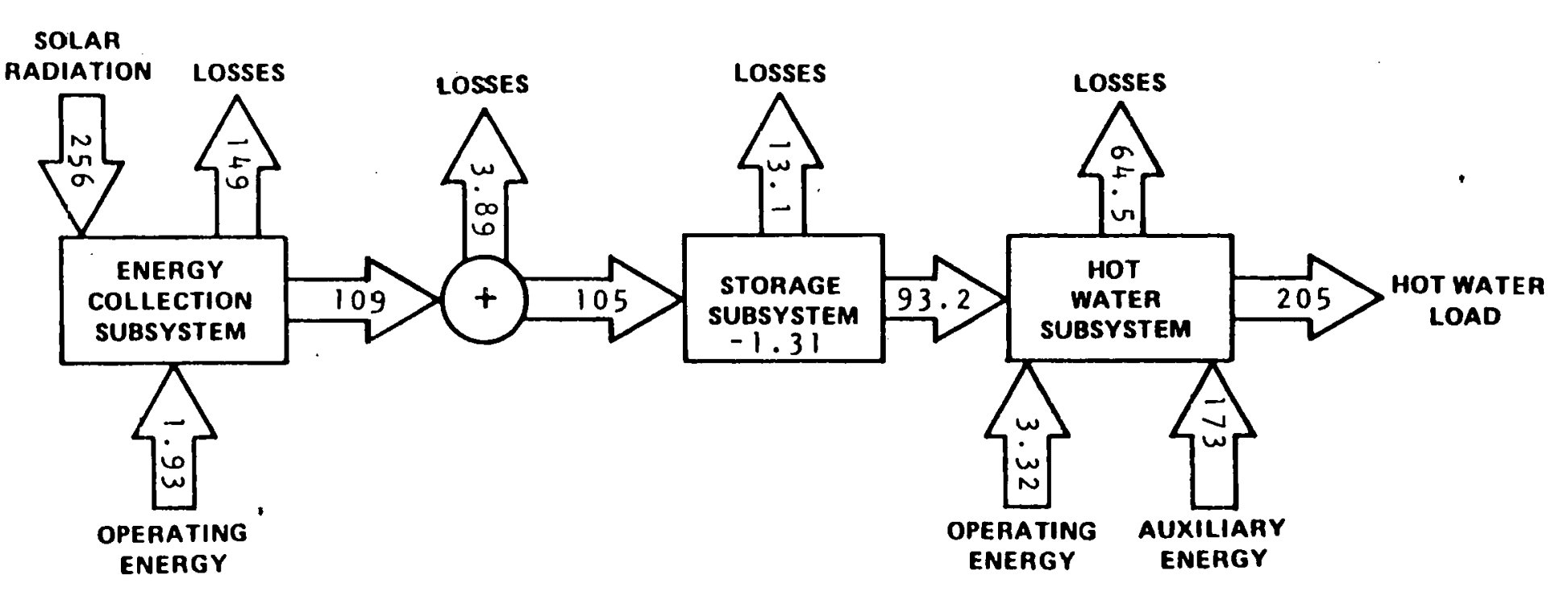




\section{FIRST MANUFACTURED HOMES LOT 9}

The First Manufactured Homes Lot 9 site is a single family residence located in Lubbock, Texas. First Manufactured assembles houses in a factory and wheels them to the desired location. The building has 1,280 square feet of living area. Solar energy is used for space heating and preheating Domestic Hot Water (DHW). The solar energy system has an array of nine Payne \#175A408SCS flat-plate collectors, with a gross area of 288 square feet. The array faces south at an angle of 45 degrees from the horizontal.

The collectors have a single $3 / 16-i n c h$ low-iron glass cover with 0.90 solar transmittance. The absorber is corrugated aluminum sheet, painted flat black. This surface has an absorptivity of 0.90 and an emissivity of 0.85 . Insulation behind the absorber is one and one-half inch fiberglass. All collectors are ducted in parallel.

The control unit is a B.D. Payne Company 851 BSSC solar controller, using thermistor sensors. This unit controls all functions of the solar and auxiliary systems.

The collectors use air to collect and deliver solar energy to 20,520 pounds of rock located in a storage bin located within the house. An air-to-liquid heat exchanger, located near the collector array outlet, is used to heat water in an 82-gallon preheat tank.

Solar energy is supplied to meet the space heating requirements either directly from the collector array or from the rock storage bin. Solar heated water from the 82-gallon preheat tank is supplied to the cold water inlet of a 42-gallon DHW tank. The space heating subsystem uses a heat pump for auxiliary heating (manufactured by B.D. Payne, \#541B028SHP). Both the space heating subsystem and the DHW subsystem utilize electric resistance heaters for auxiliary thermal energy.

The system, shown schematically in Figure A-9, has five modes of operation.

Mode 1 - Collector-to-Storage - When the temperature of the collectors is at least $25^{\circ} \mathrm{F}$, greater than the bottom of the storage bin and the building is not demanding heat, the controller will energipe the solar hlower and the collector air director motor, Solar energy will then be supplied to the storage bin until the temperature differential drops below $10^{\circ} \mathrm{F}$.

Mode 2 - Direct Solar-to-Space Heating - For this operating mode, three conditions must be met. The first is that a $25^{\circ} \mathrm{F}$ temperature differential must be maintained between the collector sensor and the sensor in the bottom of the storage bin. The second is that the sensor located near the top of the rock storage bin must measure a temperature of $80^{\circ} \mathrm{F}$ or higher. The third is that the first stage of the building thermostat must demand heat. 
When these three conditions have been met, the controller will energize the space heating blower, the solar blower, the solar air director in the collector ducts, and the solar air director in the space heating ducts.

NOTE: The water heating mode will take place concurrently with Mode 1 and Mode 2 when the control sensors indicate that solar energy is available to preheat the domestic hot water.

Mode 3 - Storage-to-Space Heating - To heat the indoor conditioned space using stored solar energy, three conditions must be met. The first is that the building thermostat must demand heat. The second is that the sensor in the top of the rock storage bin must have a temperature greater than $80^{\circ} \mathrm{F}$, indicating sufficient energy in the storage bin. The third is that the temperature differential between the collector sensor and the sensor in the bottom of the bin must be less than $25^{\circ} \mathrm{F}$, indicating that direct solar energy from the collector is not available.

When these three conditions are met, the controller will energize the indoor space heating air director and blower.

If heat from the storage bin is unable to meet the building demand, the second stage of the building thermostat will energize the electric resistance auxiliary heaters. These will supply auxiliary energy concurrently with the addition of energy from the rock storage bin. To prevent excessive heat pump pressures, the heat pump compressor is locked off whenever some or all the heating requirements can be supplied with solar energy.

Mode 4 - Preheating Domestic Hot Water - When the temperature of the collectors is at least $25^{\circ} \mathrm{F}$ greater than the preheat tank, system controls energize. the solar blower and DHW pump. This mode will continue until the water temperature in the preheat tank reaches $160^{\circ} \mathrm{F}$, or the temperature differential drops below $10^{\circ} \mathrm{F}$. The water preheating mode receives the highest priority; therefore, it can activate during the summer when no solar energy is added to the rock storage bin.

Mode 5 - Auxiliary Space Heating - When solar energy is not available from either the collectors or storage, heating will be provided by the heat pump. If the outside ambient temperature is below $0^{\circ} \mathrm{F}$ or if the heat pump cannot supply the heating demand, the electric resistance heaters energize to supply auxiliary heating. 


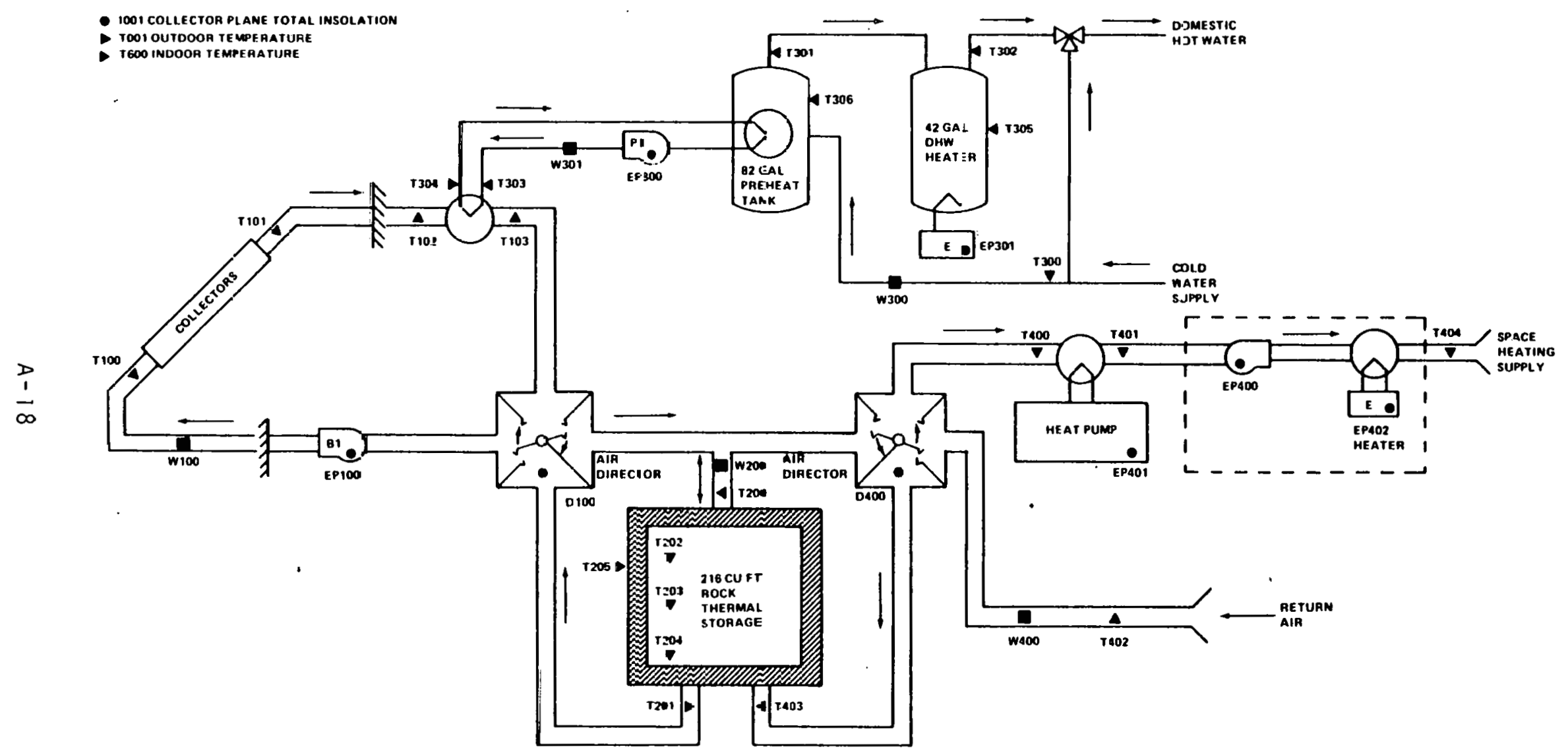

Figure A-9. First Manufactured Hones Lot 9 Solar Energy System Schematic 


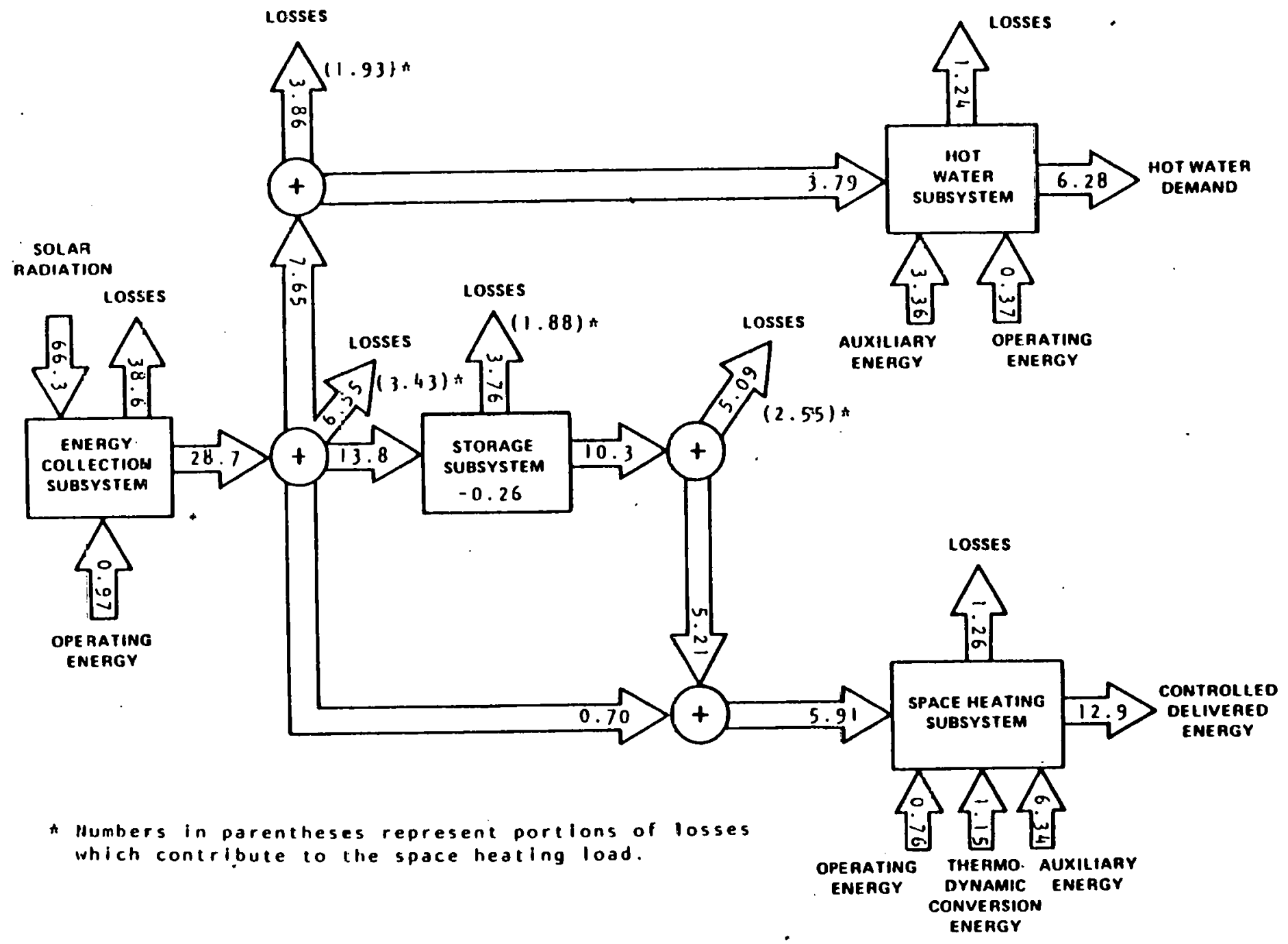

Figure A-10. Energy Flow Diagram for First Manufactured Homes Lot 9 October 1981 through February 1982

(Figures in million BTU) 


\section{FIRST MANUFACTURED HOMES LOT 10}

The First Manufactured Homes Lot 10 site is a single family residence located in Lubbock, Texas. The building has 1280 square feet of living area. Solar energy is used for space heating and preheating Domestic Hot Water (DHW). The solar energy system has an array of nine Payne \#175A408SCS flat-plate collectors, with a gross area of 288 square feet. The array faces south at an angle of 45 degrees from the horizontal. The collectors use air to collect and deliver solar energy to 20,520 pounds of rock located in a storage bin located within the house. An air-to-liquid heat exchanger, located near the collector array outlet, is used to heat water in an 82-gallon preheat tank.

The collectors have a single $3 / 16-1$ nch low-iron glass cover with 0.90 solar transmittance. The absorber is corrugated aluminum sheet, painted flat black. This surface has an absorptivity of 0.90 and an emissivity of 0.85 . Insulation behind the absorber is one and one-half inch fiberglass. All collectors are ducted in parallel.

The controller is a B.D. Payne Company 851 BSSC solar controller identical to the one used in First Manufactured Homes Lot 9.

Solar energy is supplied to meet the space heating requirements either directly from the collector array or from the rock storage bin. Solar heated water from the 82 -gallon preheat tank is supplied to the cold water inlet of a $42-g a l l o n$ DHW tank. Both the space heating subsystem and the OHW subsystem utilize elcctric resistance heaters for auxiliary energy.

The system, shown schematically in Flgure A-11, has five modes of operation.

Mode 1 - Collector-to-storage - When the temperature of the collectors is at least $25^{\circ} \mathrm{F}$ greater than the bottom of the storage bin and the building is not demanding heat, the controller will energize the solar blower and the collector air director motor. Solar energy will then be supplied to the storage bin until the temperature differentlal drops below $10^{\circ} \mathrm{F}$.

Mode 2 - Direct Solar-to-Space Heating - For this operating mode, threc conditions must be met. The first is that a $25^{\circ} \mathrm{F}$ temperature differential must be maintained between the collector sensur and the sensor in the bottom of the storage bin. The second is that the sensor located near the top of the rock storage bin must measure a temperature of $80^{\circ} \mathrm{F}$ or higher. The third is that the first stage of the building thermostat must demand heat.

When these three conditions have been met, the controller will energize the space heating blower, the solar blower, the solar air director in the collector ducts, and the solar air director in the space heating ducts. 
NOTE: The water heating mode will take place concurrently with Mode 1 and Mode 2 when the control sensors indicate that solar energy is available to preheat the domestic hot water.

Mode 3 - Storage-to-Space Heating - To heat the indoor conditioned space using stored solar energy, three conditions must be met. The first is that the building thermostat must demand heat. The second is that the sensor in the top of the rock storage bin must have a temperature greater than $80^{\circ} \mathrm{F}$, indicating sufficient energy in the storage bin. The third is that the temperature differential between the collector sensor and the sensor in the bottom of the bin must be less than $25^{\circ} \mathrm{F}$, indicating that direct solar energy from the collectors is not available.

When these three conditions are met, the controller will energize the indoor space heating air. director and blower.

If heat from the storage bin is unable to meet the building demand, the second stage of the building thermostat will energize the electric resistance auxiliary heaters. These will supply auxiliary energy concurrent with the addition of energy from the rock storage bin.

Mode 4 - Preheating Domestic Hot Water - When the temperature of the collectors is at least $25^{\circ} \mathrm{F}$ greater than the preheat tank, system controls energize the solar blower and DHW pump. This mode will continue until the water temperature in the preheat tank reaches $160^{\circ} \mathrm{F}$, or the temperature differential drops below $100 \mathrm{~F}$. The water preheating mode receives the highest priority; therefore, it can activate during the summer when no solar energy is added to the rock storage bin.

Mode 5 - Auxiliary Space Heating - When solar energy is not available from either the collectors or storage, heating will be provided exclusively by the electric resistance heaters. 


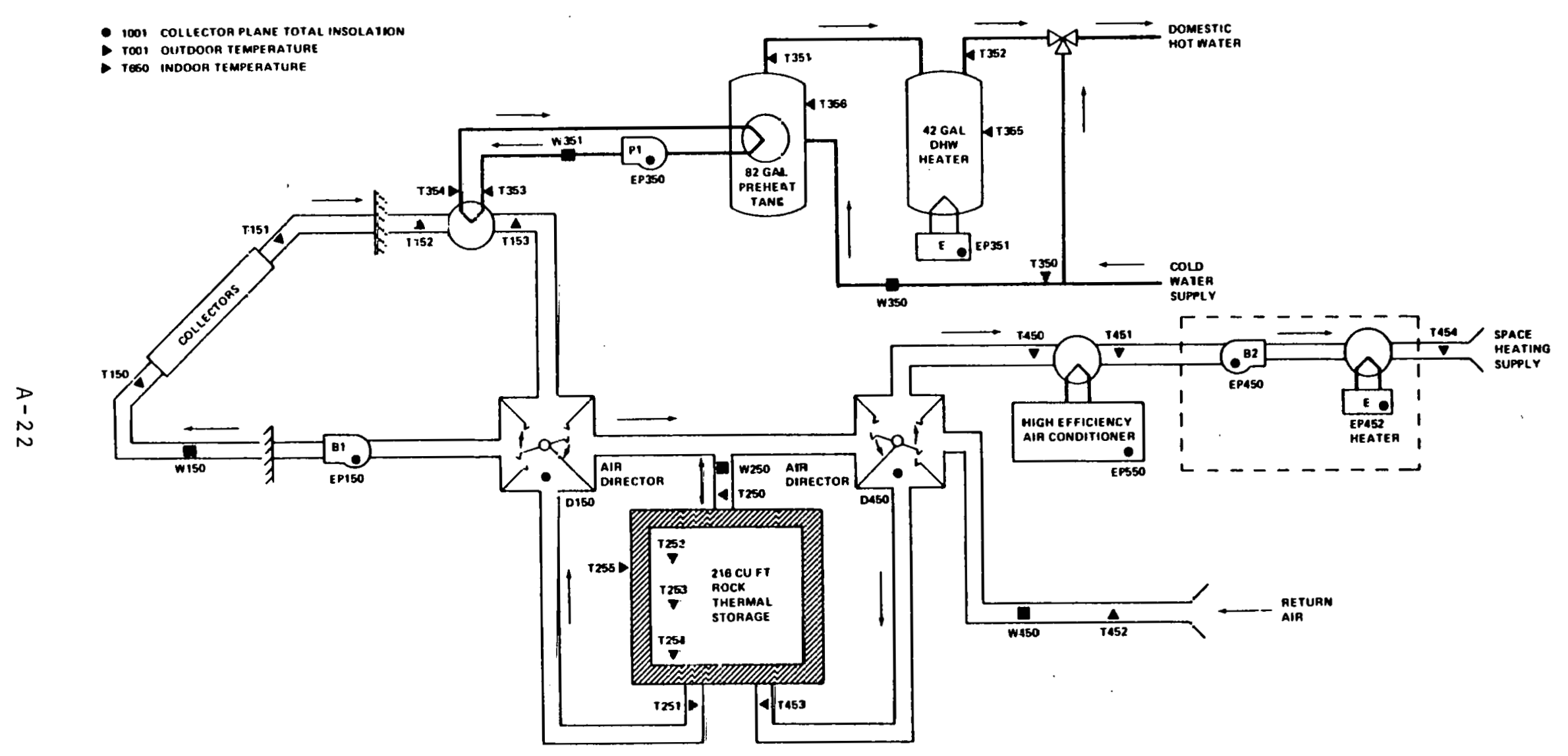

Figure A-11. First Manufactured Homes Lot 10 Solar Energy System Schematic 


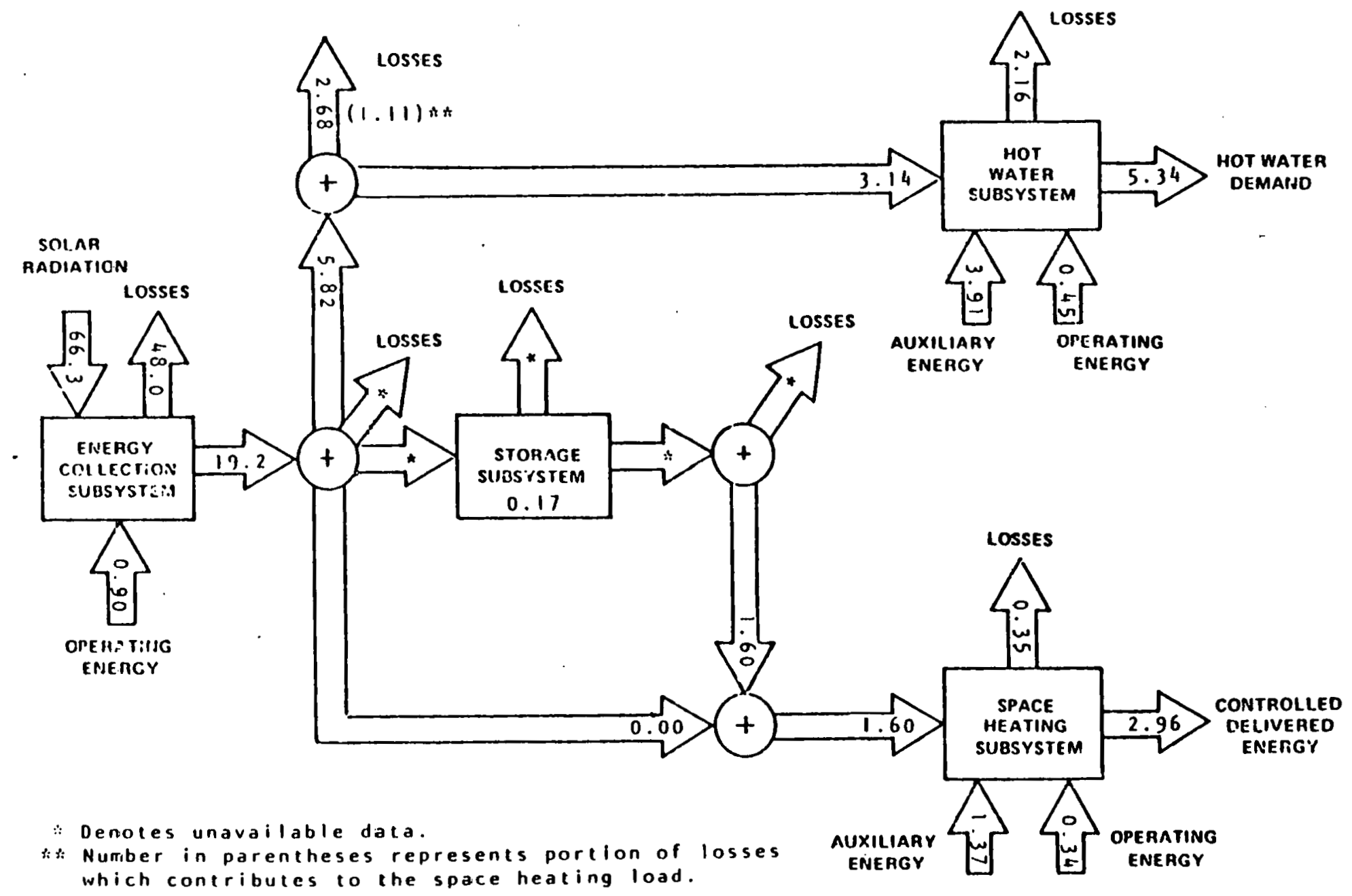

Figure A-12. Energy Flow Diagram for First Manufactured Homes Lot 10 October 1981 through February 1982

(Figures in million BTU) 


\section{FOREST CITY DILLON}

The Forest City Dillon site is a high-rise apartment building in Washington, D.C. The building has 188 apartments and a total of 124,000 square feet of living space. Solar energy is used to preheat the Domestic Hot Water (DHW).

The solar energy system has 12 arrays of flat-plate collectors with a gross area of 2,592 square feet. The arrays face south at an angle of 40 degrees from the horizontal. The collectors are manufactured by Lennox, Model LSC-18-1S. A light hydrocarbon solution is the transfer medium that delivers solar energy from the collector arrays to a hot water heat exchanger.

The collector panels have one glass cover and a selective absorber surface. The absorber surface has a solar absorptivity of 0.94 and an infrared emissivity of 0.10 . Total solar transmissivity of the glazing is 0.96 . The absorber surface is composed of a steel absorber plate with, a black chrome coating. The fluid circulated through the collectors is Brayco 888 oil.

The control system is manufactured by Rho Sigma, Model RS 104.

Preheated water is stored in a 3,200-gallon storage tank and supplied, on demand, to a conventional 400-gallon hot water tank. When solar energy is insufficient to satisfy the total load, three oil-fired boilers provide auxiliary thermal energy.

The system, shown schematically in Figure $A-13$, has only une mode nf solar operation.

Mode 1 - DHW. Prelieating - This mode activates when the temperoturc of the collector solar fluid exreeds the water temperature of the preheat storage tank by approximately $25^{\circ} \mathrm{F}$. Pumps Pl and $\mathrm{P} 2$ are activated. The solar fluid passes through a heat exchanger, where heat is transferred to circulating water. The preheated water then flows through the storage tank until the prelieated water temperature approximates the solar fluid temperature within 10 to $15^{\circ} \mathrm{F}$. Pumps $P 1$ and $P 2$ then shut off.

As hot water is drawn from the DHW tank, it is rcplenished with preheated water from the storage tank. When necessary, the water can be heated further by an oil-firest heat exchanger. This conventional heat exchanger is in a DHW circulation loop containing pump P4. Pump P4 is activated when the DHW storage temperature drops below the $135^{\circ} \mathrm{F}$ service-water temperature requirement.

Pump P5 activates when the recirculation return temperature drops below a nominal $1300 \mathrm{~F}$. If the storage temperature is greater than the recirculation return temperature by a nominal $50 \mathrm{~F}$, then.recirculation flow is passed through storage to utilize solar energy. 


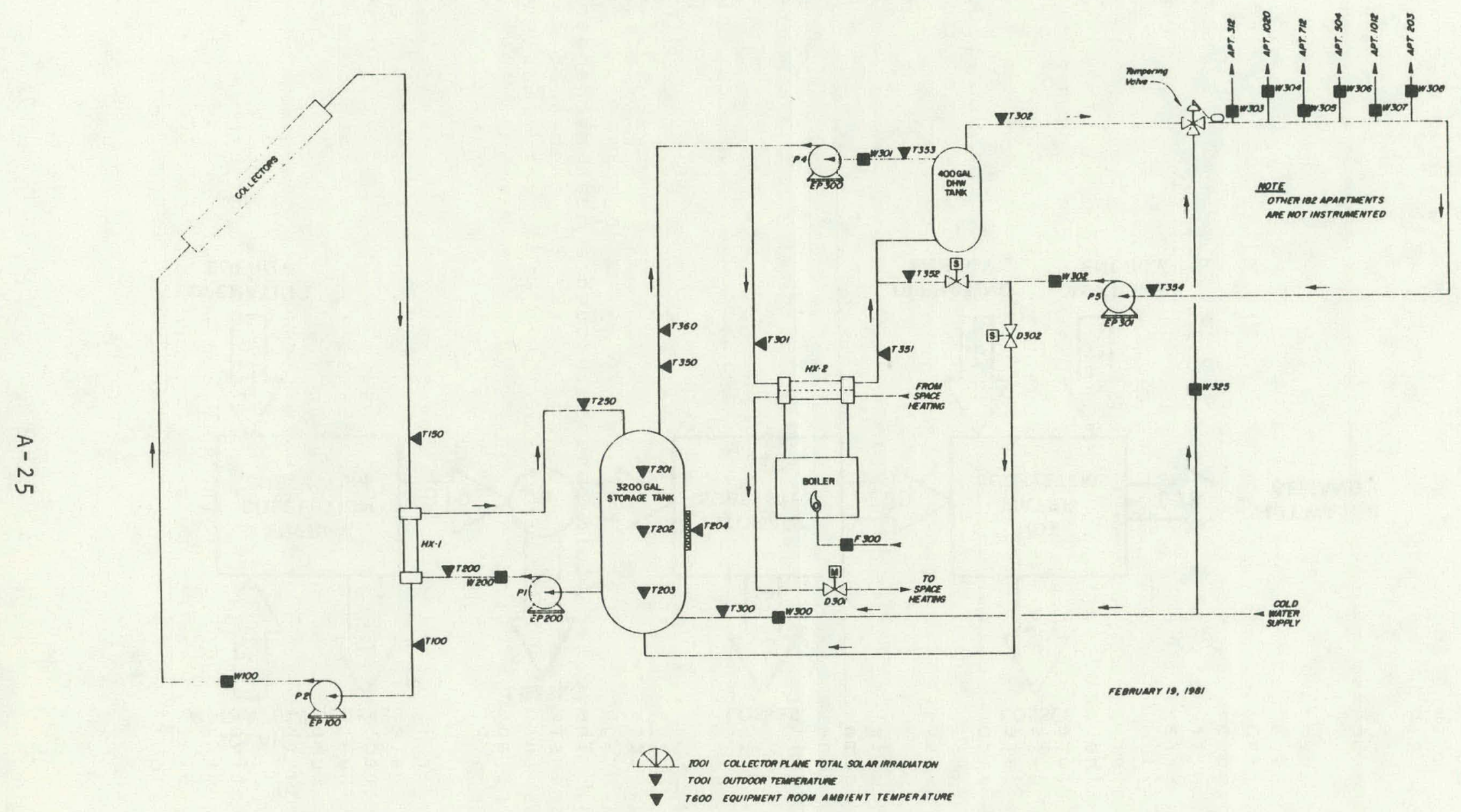

Figure A-13. Forest City Dillon Solar Energy System Schematic 


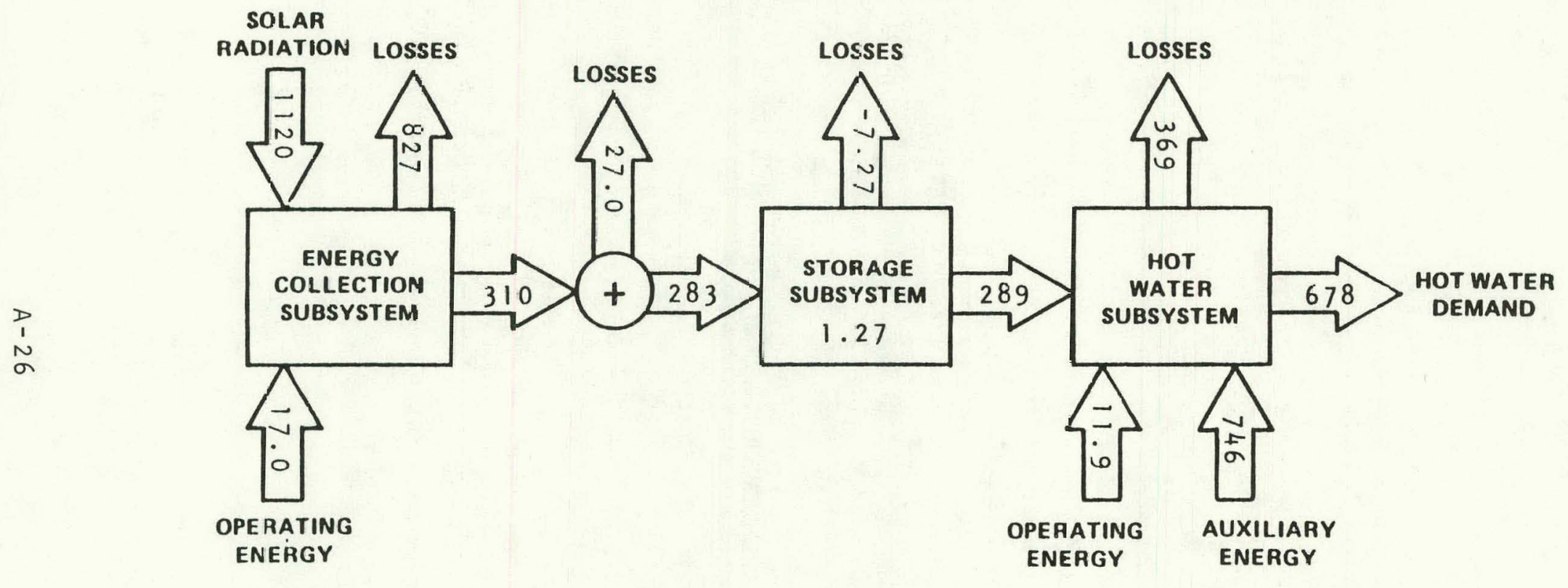

Figure A-14. Energy Flow Diagram for Forest City Dillon January 1981 through Decenber 1981

(Figures in million BTU) 


\section{GENERAL ELECTRIC-DALLAS}

The General Electric-Dallas site is a single family residence located in Dallas, Texas. The solar energy system is designed to provide space cooling, space heating, and Domestic Hot Water (DHW) for the residence. The system contains a 400-galion storage tank and a 365-square-foot collector array containing 21 panels of General Electric Solartron vacuum tube solar collectors, Model TC-100.

The General Electric TC-100 solar collectors utilize florescent lamp tubes fabricated into a thermos bottle unit. Collected energy is removed from the tubes by an independent hydronic copper system. The concentrating ratio is 1.1 , with an aluminized glass surface and a vapor deposited surface on the copper tubes.

Solar cooling is provided by a solar-driven Rankine engine which, in turn, drives a vapor compressor chiller/heat pump. An electric motor is used for auxiliary power to the chiller. Solar heating is provided by circulating solar heated water from storage to a waterlair heat exchanger. Auxiliary heating is provided by the heat pump and an electric strip heater. Solar preheating of. DHW uses a heat exchanger located in the solar storage tank. Auxiliary energy is provided by a gas-fired boiler.

The system shown schematically in Figure A-15, has six modes of solar operation. However, because complete control documentation is presently unavailable, much of this description was written using control logic as seen from data analysis. Thus, control set points should be taken as approximate values only.

Mode 1 - Collector-to-Storage - When the insolation rate reaches 100 BTU/ft2-hr, pump Pl is turned on, initiating collector loop flow. Pump P2 is turned on when the collector outlet temperature rises $10^{\circ} \mathrm{F}$ above the temperature of the storage tank. This pumps water from storage through the heat exchanger located in the collector loop.

Mode 2 - Solar Cooling - When the temperature of storage reaches $270^{\circ} \mathrm{F}$ and there is a demand for cooling, pump P3 is activated. Valve $V 4$ is positioned so that water from storage is pumped directly to the Rankine engine. The Rankine engine is used to drive the vapor compressor chiller. The chilled water from the chiller is then delivered to a heat exchanger in the air duct where the air is chilled and delivered to the space.

Mode 3 - Auxiliary Cooling - If, after 15 minutes of Rankine operation, the Rankine is unable to meet the power demand of the compressor, or, if the storage temperature is less than $2700 \mathrm{~F}$, the Rankine is decoupled from the chiller and an auxiliary electric motor is used to power the chiller. 
Mode 4 - Space Heating, Outside Air Temperature $400 \mathrm{~F}$ - When there is a demand for space heating, valve V4 is positioned to allow solar storage flow to a heat exchanger located in the air duct. If the temperature of storage is greater than $105^{\circ} \mathrm{F}$, then pump P3 is activated and solar heated water from storage is delivered to the heat exchanger. If the temperature of storage drops below $90^{\circ} \mathrm{F}$, this flow will stop. If solar heating is unable to meet the heating demand, the chiller/heat pump is activated and used to heat the space. If this combined energy source is still unable to meet the heating demand, the strip heater located in the air duct is used to meet the deficit.

Mode 5 - Space Heating, Outside Air Temperature Less Than $40^{\circ} \mathrm{F}$ This mode is similar to that mentioned above except that the heat pump is not used. Heating is provided by solar energy and heat serip only.

Mnde 6 - Preheating Domestic Hot Water - Supply water for DHW is preheated by passing through a heat exchanger located in the solar storage tank. Valve $V 3$ is manually positioned to temper water returning from the heat exchanger with incoming supply water so that the temperature of the water delivered to hot water storage does not exceed $150^{\circ} \mathrm{F}$. The DHW storage tank is maintained at $1500 \mathrm{~F}$ by a gas-fired boiler. 
- 1009 COLlectop Plane total insolation

- roor outdoor rempenatuRe

- rO0z J-TON S/4 DHF

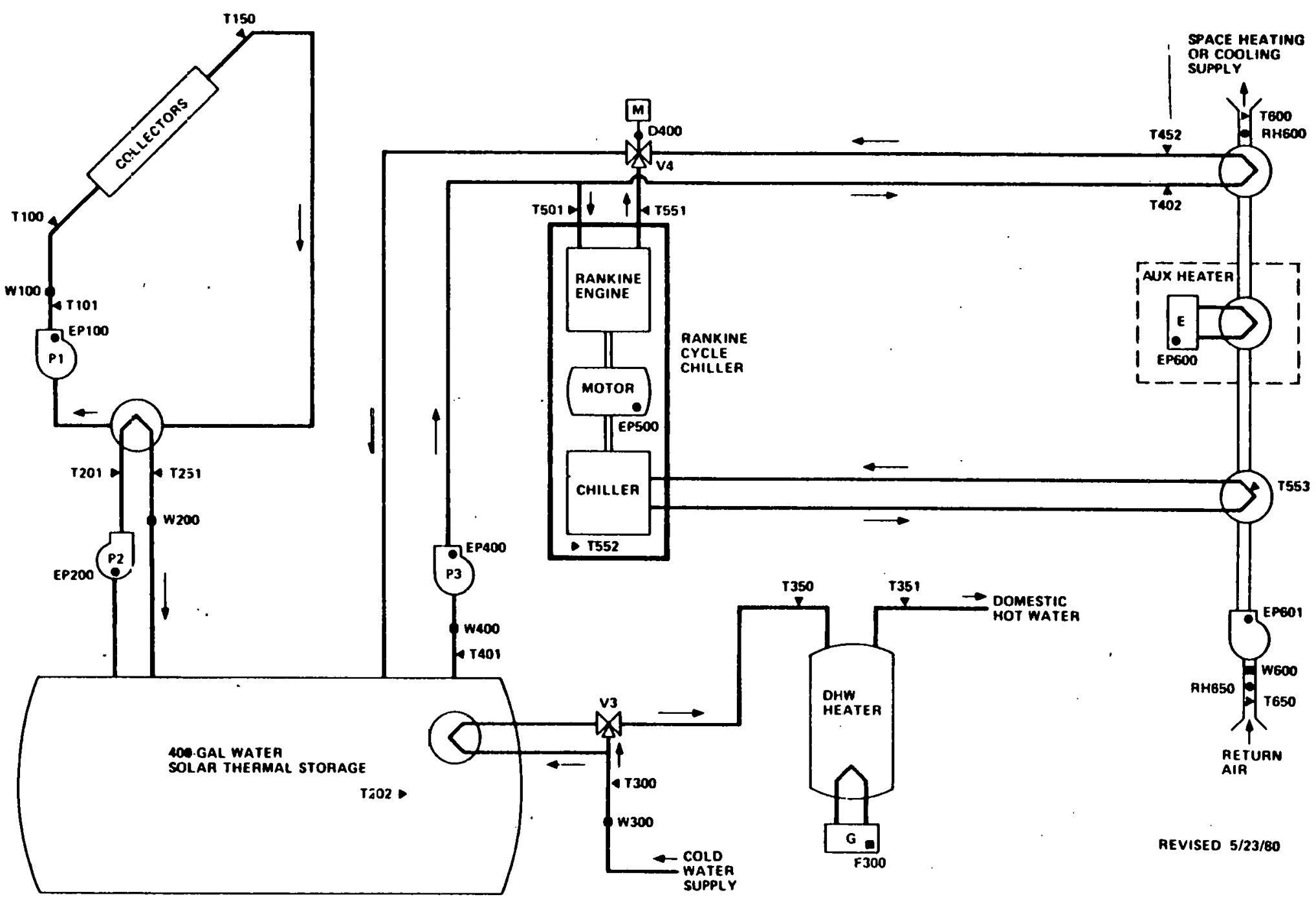

Figure A-15. General Electric-Dallas Solar Energy System Schematic 


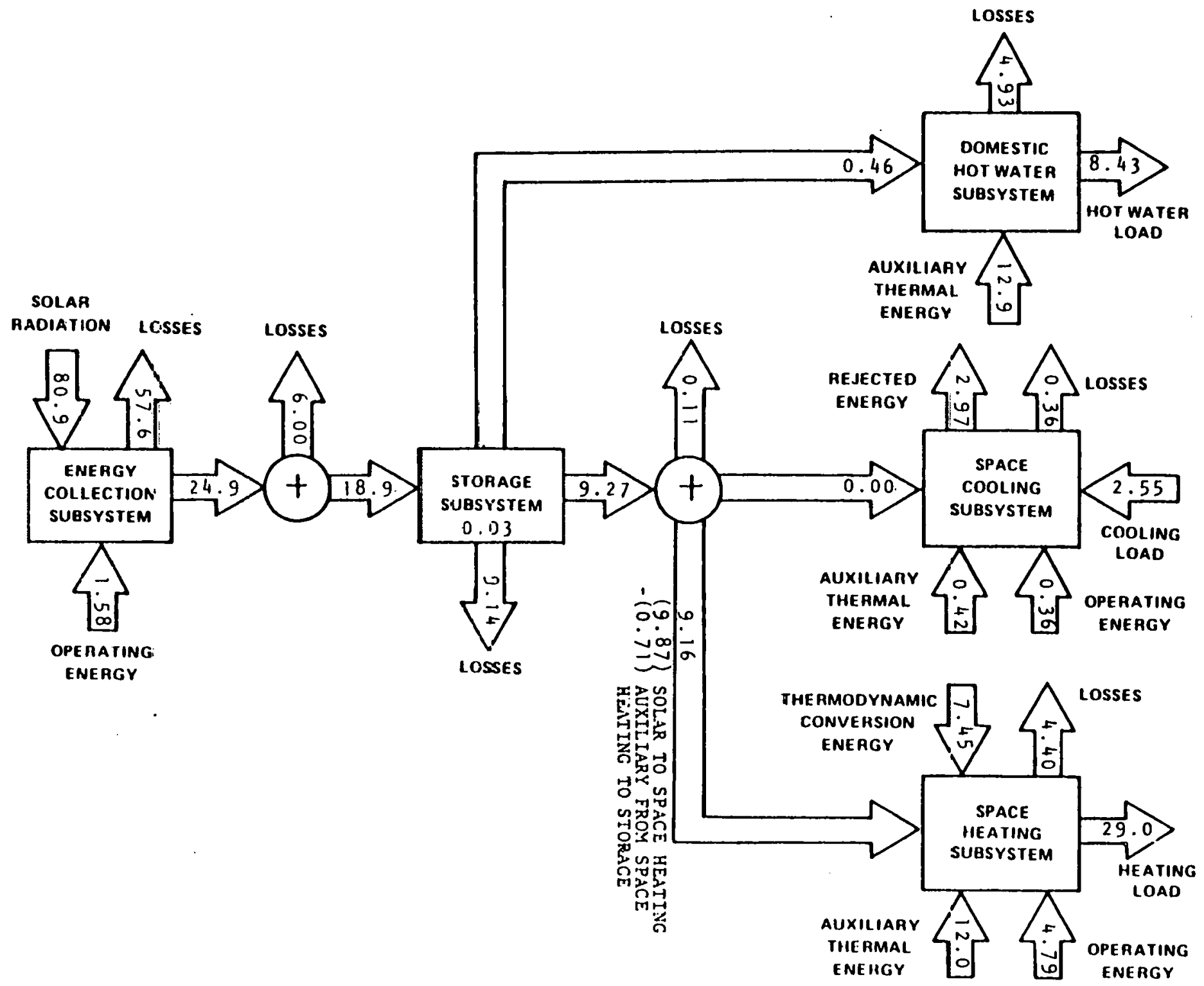

Figure A-16. Energy Flow Diagram for General Electric-Dallas octoser 1980 through Mar $=h \quad 1981$

(Figures in million BTU) 
GSA/FEDERAL YOUTH CENTER

The GSA/Federal Youth Center solar energy site is located in a prison near Bastrop, Texas. This facility consists of youth housing units, administration offices, prison industries, academic and vocational training, a clinic, recreation, and support services. The "downtown" buildings consist of administrative offices, cafeteria, recreational facilities, and a hospital. The combination of buildings to which solar energy makes a space heating and cooling contribution has a floor area of approximately 149,671 square feet. The solar energy system is designed to provide $46 \%$ of the annual heating demand, nine percent of the annual cooling demand, and $97 \%$ of the annual Domestic Hot Water (DHW) demand.

The solar energy system consists of 21,760 square feet of singleglazed, selective-coated collectors manufactured by Cole Solar Systems (Model 306-G1S). Orientation is 30 degrees west of south and 25 degrees from the horizontal. The 1,184 collectors are all located on the roof structures and are connected in a seriesparallel arrangement. This results in small groups of collectors (four to 10) connected in parallel which have a common output connected in series to the common input of a second identical group. Solar heated water is stored in two interconnected tanks outside the equipment room. Water returning from the collectors enters a 15,000-gallon storage tank. For freeze protection, the collector loop uses the drainback method.

The collector panels have a single $1 / 8-i n c h$ glass cover of tempered water-white glass. The absorber surface has a selective black chrome coating. The absorber riser tubes are copper soldered to the absorber. The heat transfer fluid circulated through the collectors is water. The drainback system design prevents freezing by pumping the water out of the collectors and into the hot storage tank.

The pneumatic control system was manufactured by Powers Regulator Company.

Domestic hot water heating is accomplished by drawing hot water from the smaller, hotter storage tank through a heat exchanger and returning it to the storage tank. The DHW recirculating loop to. the "downtown" buildings flows through this heat exchanger and the auxiliary DHW heater.

Space heating is provided by pumping water from the smaller storage tank through a separate heat exchanger. The space heating circulating loop from the dormitories flows through this heat exchanger, then to the auxiliary boilers where additional heat is added if necessary.

Space cooling is supported by circulating water from the smaller storage tank through an absorption chiller. Auxiliary energy may supplement or be used in place of the solar energy through use of 
fossil boilers and a heat exchanger. Further auxiliary cooling is provided through two centrifugal chillers.

The system, shown schematically in Figures $A-17$ and $A-18$, has four modes of solar operation.

Mode 1 - Collector-to-storage - This mode is entered when the temperature sensor on the collector absorber plate rises to $200 \mathrm{~F}$ above the temperature of storage tank 2. Collection is terminated when the differential temperature falls below $3^{\circ} \mathrm{F}$. Collector pump P32 may operate at three possible speeds, depending on the rate of solar energy absorption. As the temperature difference between the collector plate and the storage tank increases, the pump speed increases, Similarly, when possible, the pump speed decreases to the next level as the difterence in temperature falls. Whenever storage tank 2 temperature at the pump inlet exceeds $185^{\circ} \mathrm{F}$, the pump is turned off.

Mode 2 - Domestic Hot Woter Heating - DHW heating is accomplished by circulating water from storage tank 1 by either pump P29 or P 30 through heat exchanger HX2. Modulating valves maintain the water leaving the tube section below $145^{\circ} \mathrm{F}$ and a $3^{\circ} \mathrm{F}$ temperature los across the solar side of the heat exchanger. A valve also determines whether larger pump P30 or smaller pump P29 is necessary to provide circulation. Auxiliary DHW heating is supported by boiler 3 and pump $P 23$ which circulate water through a heat exchanger in the DHW heater. DHW heating in the dormitory section is accomplished by means of heat exchangers in the space heating loop in these buildings.

Mode 3 - Space Heating - Space heating is accomplished by circulating water from storage tank 1 by either pump P27 or P28 through heat exchanger HXI. Modulating valves maintain the water leaving the tube section below $145^{\circ} \mathrm{F}$ and maintain a $3^{\circ} \mathrm{F}$ temperature loss across the solar side of the heat exchanger. A modulating valve also determines whether larger pump P27 or smaller pump P28 is necessary to provide circulation. Auxiliary space heating during the winter is provided by using pumps Pl7 and Pl8 to circulate through boilers 1 and 2. During the summer, boiler 3 is used to provide auxiliary energy instead of boilers 1 and 2 . Circulation from the boiler is produced by pump P33 through heat exchanger HX4. A modulating valve maintains a water temperature of $1400 \mathrm{~F}$ leaving the tube section of the heat exchanger. When boiler 3 is used, circulation in the space heating loop is required during the summer since this loop also provides DHW in the dormitory buildings.

Mode 4 - Space Cooling - Space cooling is accomplished by using pump P3l to circulate hot water from the storage tank through the generator of the absorption chiller. The storage tank temperature necessary to start the absorption chiller varies from $182^{\circ} \mathrm{F}$ to $196^{\circ} \mathrm{F}$ and is determined from the sunshine forecast and the overnight low forecast. When the storage tank drops below $175^{\circ} \mathrm{F}$ or the load is not being met; valve $V 7$ opens, 68 closes, and pumps P3 1 and P26 start. This allows boilers 1 and 2 to supply energy 
to the absorption chiller. Two centrifugal chillers are also available for auxiliary space cooling. Solar heated water, used in this and the previous two modes, returns to the storage tanks through valve 66 . Valve $V 6$ compares the temperature of the returning water with the temperature of tank 1 , and, if the temperature of the returning water is below that of tank 1 , the water is diverted into tank 2 . 


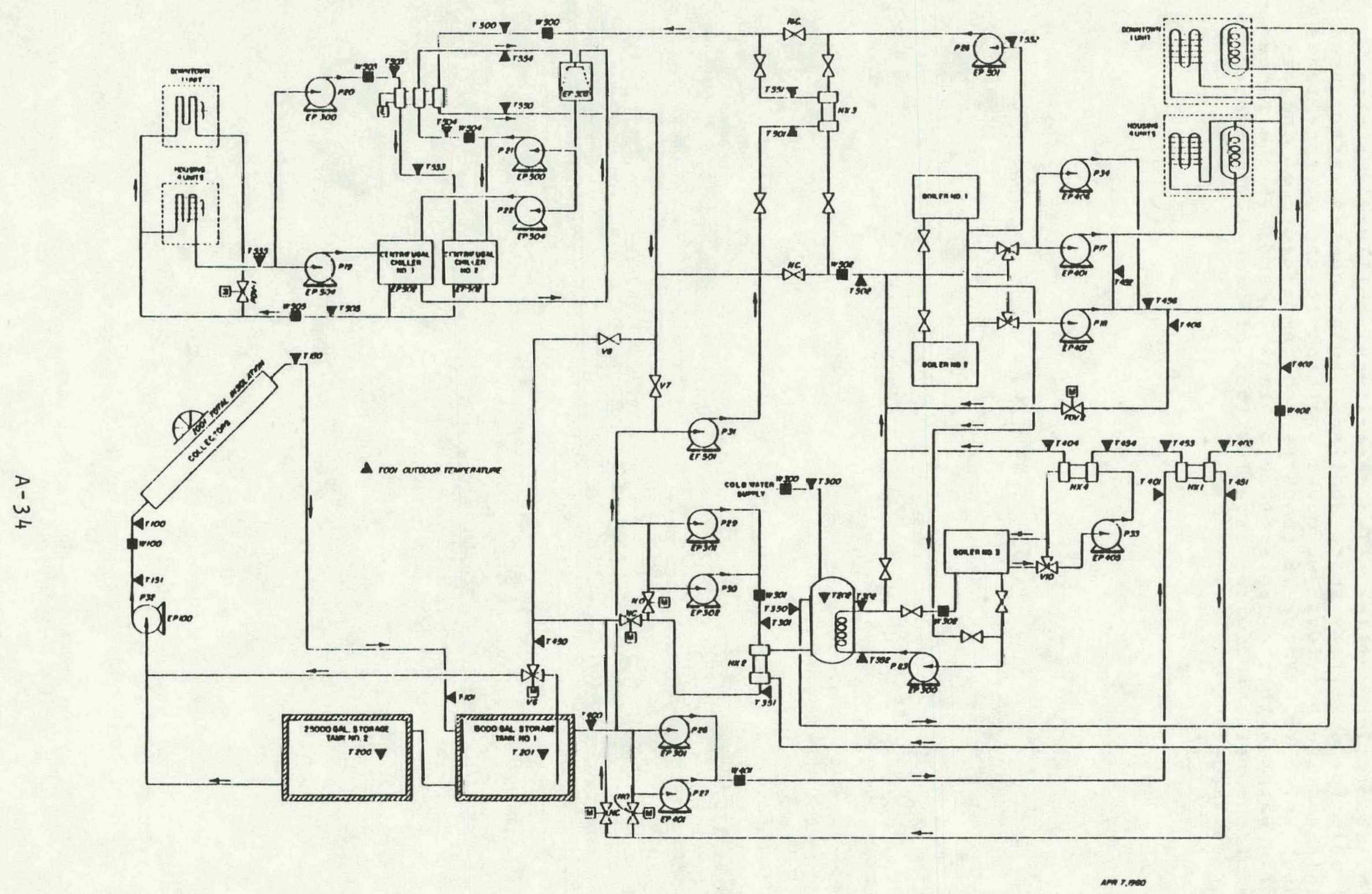

Figure A-17. GSA/Federal Youth Center Solar Energy System Schematic 1 


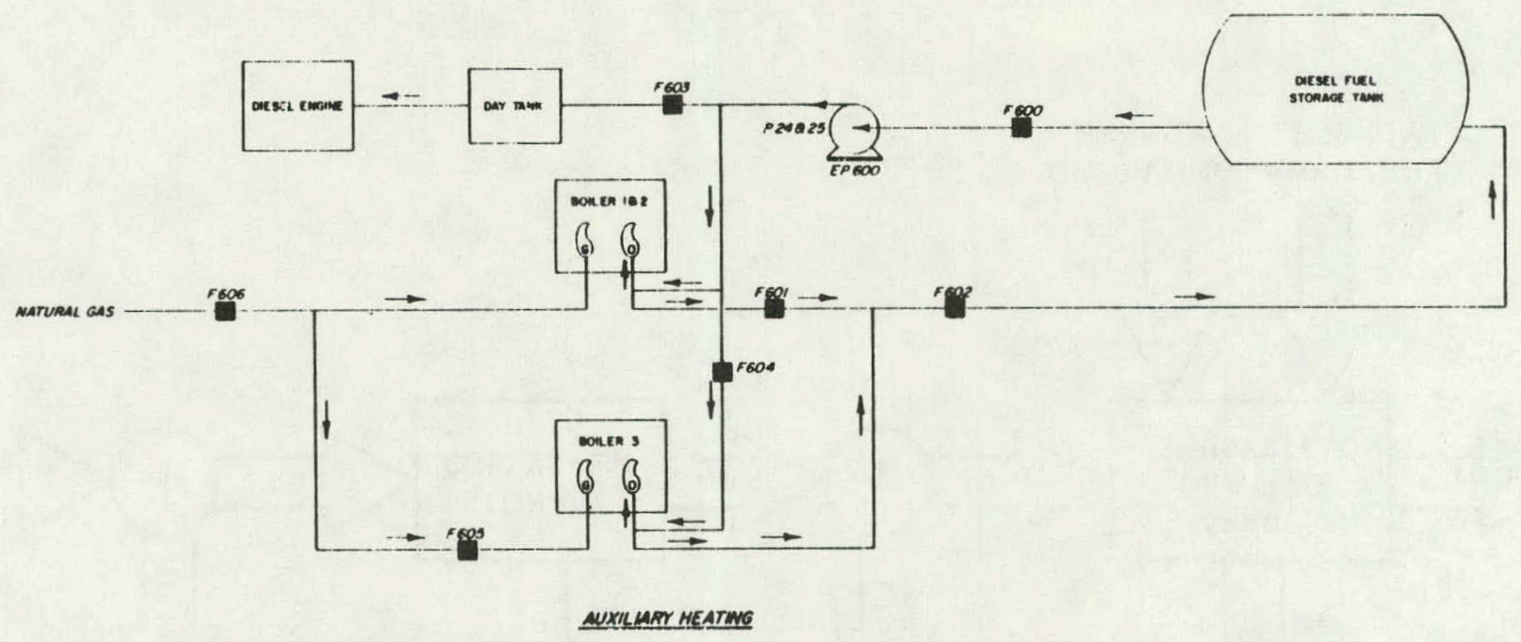

Figure A-18. GSA/Federal Youth Center Solar Energy System Schematic 2 


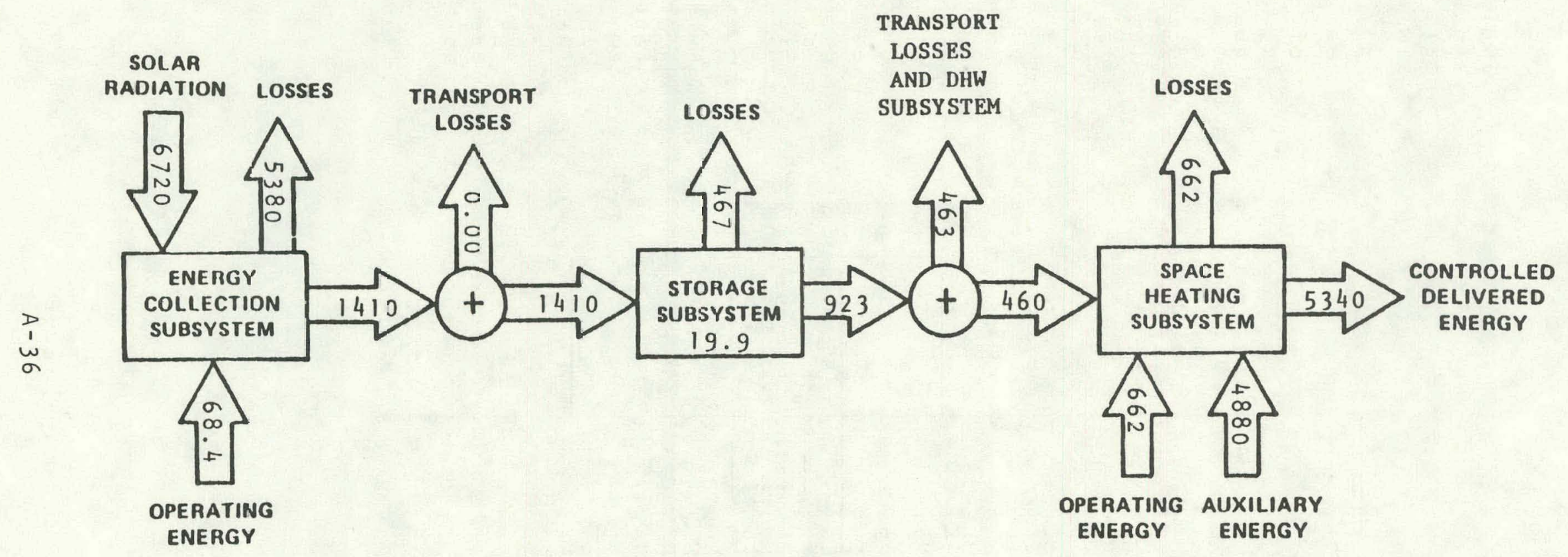

Figure A-19. Energy Flow Diagram for GSA/Federal Youth Center October 1980 through May 1981

(ECSS and Space Heating Subsystems only)

(Figures in million BTU) 


\section{HEI WAI WONG}

The Hei Wai Wong site is a four-story apartment building in Honolulu, Hawaii. Three separate solar energy systems are used to provide solar energy for hot water. One of these systems participated in the NSDN program. This system supplies hot water for six apartments and a laundry used by the occupants of the apartments. The six apartments are occupied by 12 adults and seven children.

The participating NSDN system consists of an array of 807 square feet of flat-plate collectors manufactured by Raypak, Inc. of Westlake Village, California. The collectors face due south at a tilt of 24 degrees from the horizontal.

The SG-18P collectors have one glass cover with a selective absorber surface. The absorber surface has a solar absorbitivity of 0.95 and an infrared emissivity of 0.71 . Total solar transmissivity of the glazing is 0.91 . The absorber surface is composed of aluminum.

No controls were used on the collector array.

Solar energy is stored in a 1,230-gallon tank filled with water. The tank is mounted on a tower on the roof, with the bottom of the tank slightly higher than the top of the collector plates. When the sun heats the water in the collectors to a temperature above that of the water in the tank, a thermosiphon current is created in the collector loop. Because the tank is higher than the collectors, the thermosiphon flow stops when the temperature of the water in the tank is higher than that in the collectors. No electrical power is used to operate the collector system.

The entire solar system operates at city water pressure. Hot water is supplied to the apartments and laundry from the top of the storage tank so that the hottest water available in storage is always used. Cold water supplied from the city water system is fed directly to the bottom of the collector panels. Hot water going to each apartment passes through individual 30-gallon electrical hot water heaters located in each apartment. These heaters boost the temperature of the hot water from the solar storage when solar energy is insufficient to satisfy the hot water requirements. Auxiliary heating of the hot water for the laundry is provided by an 85 -gallon gas hot water heater.

The solar energy system is shown schematically in Figure A- 20 . 


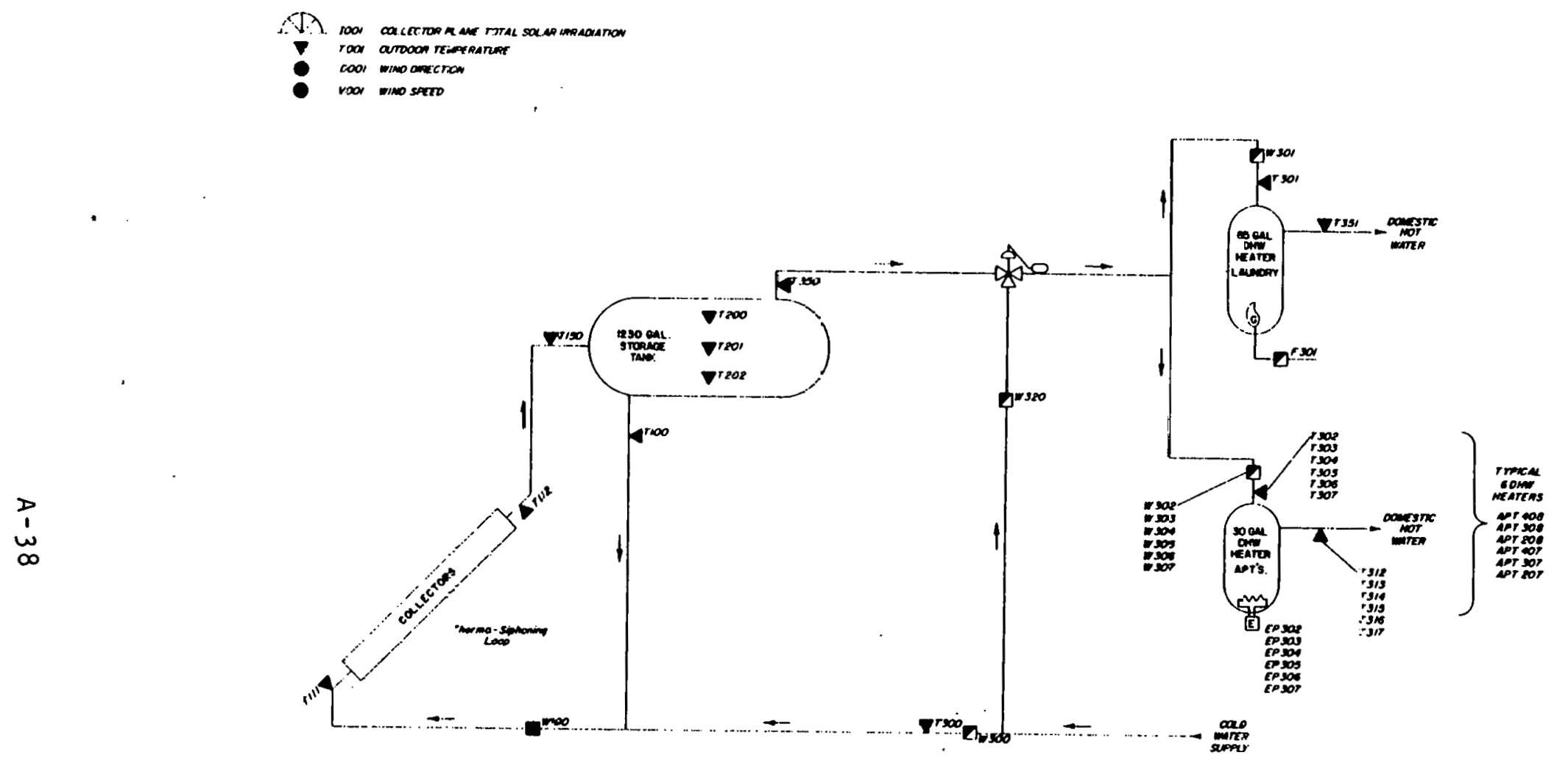

Figure A-20. Hei Wai Hong Solar Energy System Schematic 


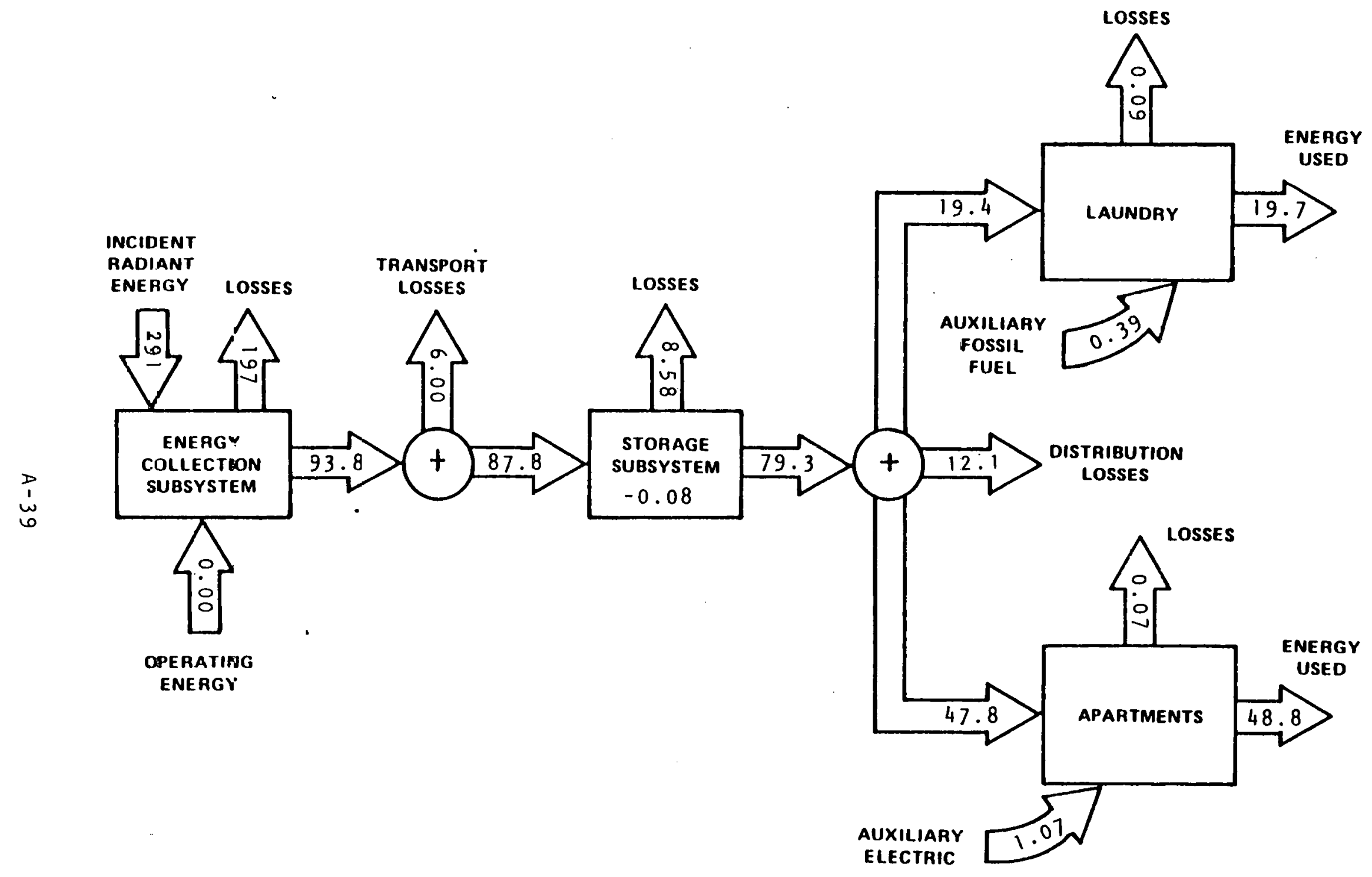

Figure A-21. Energy Flow Diagram for. Hei Wai Wong November and December 1979 and April through August 1980 (Figures in million BTU) 


\section{HOGATE'S RESTAURANT}

The solar energy system of Hogate's Restaurant in Washington, D.C. supplies part of the energy necessary to heat approximately 10,000 gallons of Domestic Hot Water (DHW) each day. The DHW is used by the restaurant's kitchen and must be maintained at a temperature of $150^{\circ} \mathrm{F}$.

The solar energy system was added to the existing water heating system and has an array of sunworks "Solector" flat-plate collectors with a gross area of 6,254 square feet. The array faces southwest at an angle of 55 degrees from the horizontal. The collector panels have double glass covers and a selective absorber surface. The absorber surface has a solar absorptivity of 0.87 and an infrared emissivity of 0.07 . Total solar transmissivity of the glazing is 0.07 . The absorber surface is composed of black nonelectrolytic thin-film oxide coaced copper. The fluld clrculated through the collectors is $40 \%$ propylene glycol/water. Insulation is 2.5 -inches thick, with an R-value of 10 .

Propylene glycol and water is the transfer medium that delivers solar energy from the collector array to storage and to the hot water load. Potable water is isolated from the heat transfer fluid by a liquid-to-liquid heat exchanger. Solar heated water is stored in two insulated 5,000-gallon tanks which are located in the garage. When solar energy is insufficient to satisfy the hot water load, a gas-fired boiler provides auxiliary energy for water heating.

The system, shown schematically in Figure A-2L, has two modes of operation.

Mode 1 - Collector-to-Storage - This mode activates when the temperature difference between the collector absorber plate and the water in the bottom of tank T2 exceeds the temperature setting in the controller. Pumps $P 1$ and $P 3$ turn on to circulate the solar heated water; pumps $P 2$ and $P 4$ are backup pumps. Water in the DHW preheat loop circulates from tank T2, through the heat exchanger to tank $T 1$, and returns to tank $T 2$. This mode terminates when the temperature difference between the collector plate and the cooler tank T2 is less than the control setting, or the temperature of tank $\mathrm{Tl}$ is higher than $180^{\circ} \mathrm{F}$.

Mode 2 - Storage-to-Load - This mode activates when there is a hot water demand. In this mode, makeup water from the cold water supply flows through valves V7 and V6, replacing the preheated water in tank T2. Before entering the DHW recirculation loop, preheated water from tank $T l$ may be mixed with cold water by tempering valve $V i$ to maintain the design temperature of $1500 \mathrm{~F}$. If there is insufficient solar energy in storage to maintain this design temperature, the water is heated to $150^{\circ} \mathrm{F}$ by the existing boiler. 


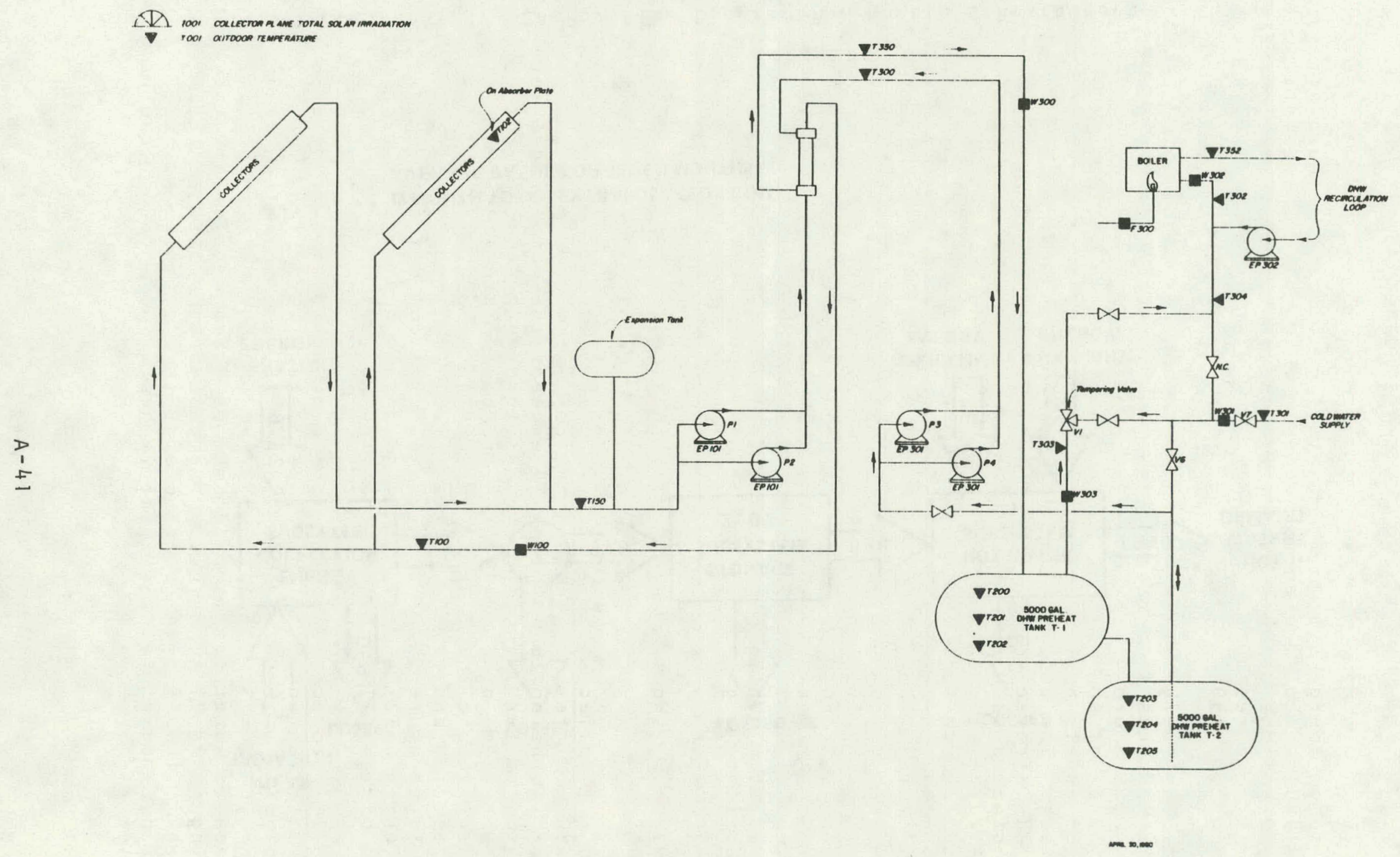

Figure A-22. Hogate's Restaurant Solar Energy System Schematic 


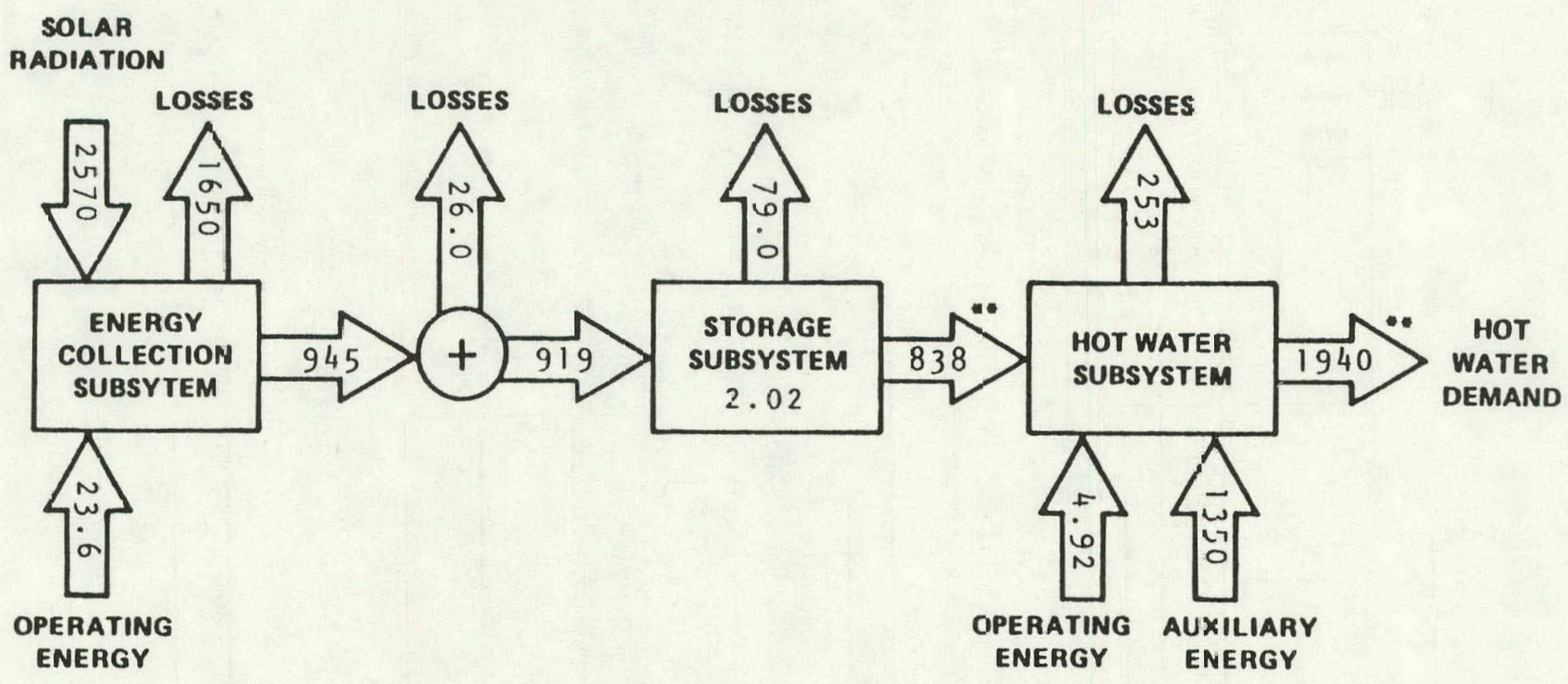

- 12 month total extrapola ted from AVERAGE VALUE FOR SEVEN MONTHS

Figure A-23. Energy Flow Diagram for Hogate's Restaurant January 1980 through December 1980

(Figures in million BTU) 


\section{KALIN HOME}

The Kalin Home is a single family residence in East Meadow, Long Island, New York. The home has approximately 1,300 square feet of conditioned space. Solar energy is used for preheating Domestic Hot Water (DHW) and is designed to provide $60 \%$ of the DHW requirements. The solar energy has an array of two flat-plate collectors, manufactured by Solar Thermal systems, a Division of Exxon Corporation, with a gross area of 42 square feet. The array faces six degrees east of south at an angle of 36 degrees from the horizontal.

The controller is a Rho sigma RS-120.

This system is a drainback solar system. Preheated water is supplied to a solar heat exchanger equipped $120-g a l l o n$ stone-lined DHW tank. An electrical heating element in the DHW tank provides auxiliary energy for water heating. This site utilizes off-peak power to heat DHW at night on only the upper two-thirds of the 120-gallon tank. The off-peak power is available from midnight to 7:00 a.m. daily. The homeowners are part of a 600-site LILCO (Long Island Light Company) solar project.

The system, shown schematically in Figure A-24; has two modes of solar operation.

Mode 1 - DHW solar heating occurs when the $1 / 12-h p$ pump switches on and fills the collector loop from the drainback reservoir. The system is activated when control sensors determine an $80^{\circ} \mathrm{F}$ to $12^{\circ} \mathrm{F}$ differential exists between the bottom of the water heater heat exchanger and the collector outlet. The pump turns off when the differential reduces to $2^{\circ} \mathrm{F}$.

Mode 2 - On an off-peak timer-relay, auxiliary DHW heating can be provided by a $4.5-\mathrm{kw}$ element heater fitted in the solar storage tank. This element is munitored for "on" time by a Martin timer. The off-peak auxiliary energy is available only from midnight to 7:00 a.m. Hot water from the tank is then tempered for use by the tempering valve with a set point of $120^{\circ} \mathrm{F}$ to $125^{\circ} \mathrm{F}$. 
DD YOOI TOTAL INSOLATION

7 TOOI OUTDOOR AMBIENT TEMPESATURE

- osero solar ciacuit breaker

$\nabla$ TGOO MECHANICAL ROOM TEMP

$D$
1
\pm
\pm

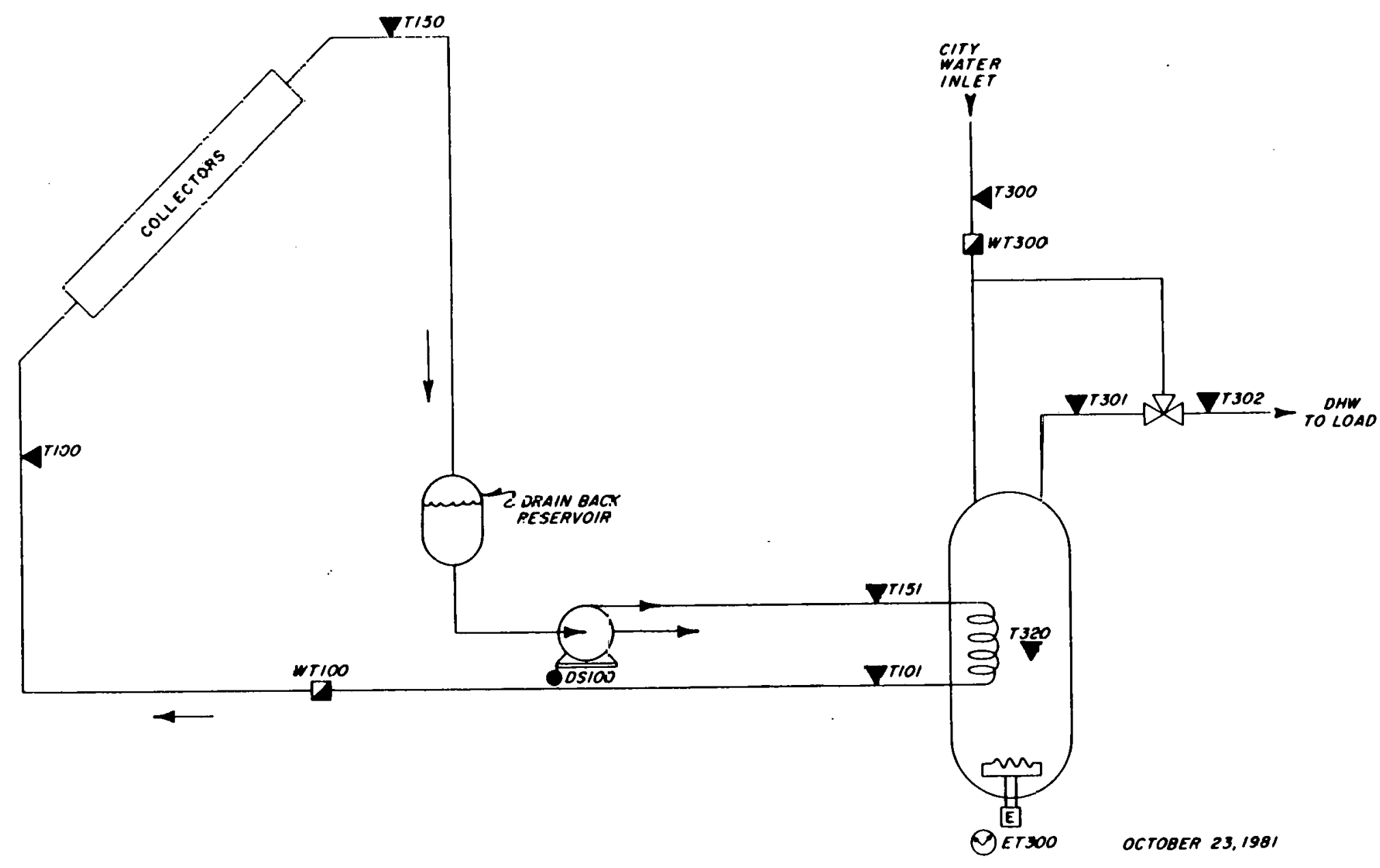

Figure A-2L: Kalin Home Solar Energi System Schematlc 


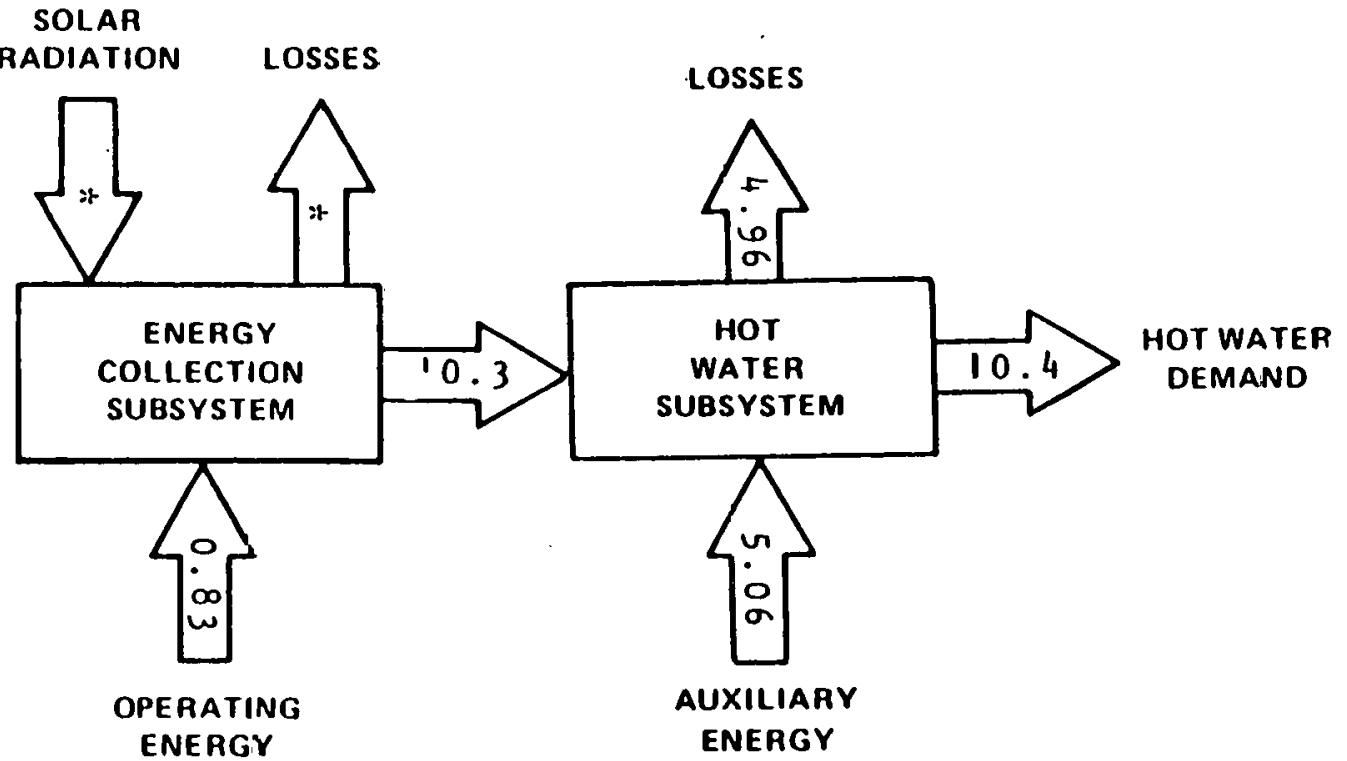

* Denotes unavailable data

Figure A-25. Energy Flow Diagram for the Kalin Höme october 1981 through September 1982

(Figures in million BTU) 


\section{LAKE VALLEY FIREHOUSE}

The Lake Valley Firehouse Number 2, located at Tahoe Paradise, California, is a small fire station using solar.energy to preheat Domestic Hot Water (DHW) and provide space heating and snow melting. The solar energy system is designed to supply approximately $50 \%$ of the space heating and DHW energy requirements for the building. The upstairs dayroom and kitchen are heated by baseboard radiators. The downstairs sleeping quarters and engine room are heated by pipes in the concrete floor. Auxiliary energy is provided by a 325,000 8TU/hr propane-gas-fired boiler, a 52-gallon propane-gas-fired DHW heater, and an upstalrs wood stove. In addition, a unique snow-melting capability is provided to the front ramp by circulating solar heated water through cuils beneoth a specially designed asphalt ramp. Since the ramp can use solar energy at much lower cemperatures than is practical for space heating, it is expected to increase the total solar. energy used by the system.

The solar energy system has an array of nine flat-plate collectors manufactured by Solargenics, Inc., Model 75-20. The array has a gross area of 572 square feet. The collector array, mounted on an A-frame structure in the backyard, faces south at an angle of 55 degrees from the horizontal. A $20 \%$ ethylene glycol solution is used as the medium for delivering solar energy from the collector array to the water thermal storage tank. The collector panels have one glass cover and a selective absurber surface. The absorber surface has a solar absorptivity of 0.91 and an infrared emissivity of 0.08 . Total solar transimissivity of the glazing is 0.91 , The absorber is composed of an aluminum plate with aluminum flow tubes coated with black chrome on dull nickel.

The water thermal storage tank is located aboveground. The tank has four inches of foam insulation with an $R$ factor of 30 and has a capacity of 1,200 gallons. The actual volume of water is varied from 600 gallons to 1,200 gallons, depending on the season. The DHW subsystem consists of a heat exchanger and a gas-fired DHW heater. Makeup water is preheated by passing through a heat exchanger located in the thermal storage tank prior to entering the DHW heater. Auxiliary energy is supplied by the DHW heater to maintain a DHW temperature of $1200 \mathrm{~F}$. Makeup water flows from the cold water supply through heat exchanger $H X I$ dind the DHW liuter under city water pressure. The space heating and snow-melting subsystems consist of a heat exchanger in the thermal storage tank, a gas-fired boiler for auxiliary heating, two circulation pumps, and heating coils.

The energy for space heating and snow melting is supplied from either the thermal storage tank or from the gas-fired boiler, but not from both simultaneously. While supplying energy from the gas-fired boiler, solar energy can be concurrently collected to heat water in the thermal storage tank and preheat DHW. If snow melting is desired while space heating is active, both loads must 
receive energy from the same source. Space heating cannot be performed with auxiliary energy while using solar energy to melt snow.

The system, shown schematically in Figure A-26, has the following five modes of operation.

Mode 1 - Collector-to-Storage - This mode is entered when the differential temperature between the collector surface and water in the storage tank is greater than l00 F. A Heliotrope General (Delta-T) differential controller then energizes pump Pl. Pump PI maintains circulation of water between the thermal storage tank and collectors until the differential temperature is less than $2^{\circ} \mathrm{F}$.

Mode 2 - Storage-to-Space Heating - This mode is entered when any of three thermostats indicates a demand for heating and the temperature of the water in the storage tank is greater than $75^{\circ} \mathrm{F}$. Pump P2 is energized and a solution of $28 \%$ ethylene glycol and $72 \%$ water is circulated from heat exchanger $\mathrm{HX} 2$ to any of three heating coils. Valve VI will allow flow from port $A$ to port $A B$. Valve V 2 will blend flow from ports $A$ and $B$ to port $A B$. Each of three areas requiring space heating has a thermostat-controlled solenoid valve which allows space heating to be controlled for each area.

Space heating in the upstairs dayroom and kitchen is supplemented with auxiliary energy from a wood stove. The amount of this auxiliary energy supplied for space heating is unknown.

Snow melting from the engine ramp is manually controlled as described in Mode 3. Operation of Mode 3 is possible concurrently with Mode 2 , but this is not typical.

Mode 3 - Storage-to-snow Melting - This mode is manually controlled Pump P3 is energized and a solution of $28 \%$ ethylene glycol and $72 \%$ water is circulated from heat exchanger $H \times 2$ to the heating coil embedded in an asphalt ramp. Valve V3 will blend flow from ports $A$ and $B$ to port $A B$.

This mode is inoperative when the auxiliary boiler supplies energy for space heating. Typically this mode would be entered when the temperature of the water in the storage tank was less than $100^{\circ} \mathrm{F}$ and there was no demand for space heating. Sufficient energy would still be available from water in the storage tank to melt snow from the asphalt engine ramp.

Mode 4 - Storage-to-Domestic Hot Water - This mode is entered when there is a demand for hot water. Makeup water flows from the cold water supply to the $0 H W$ heater through heat exchanger $H X l$ for preheating. Auxiliary energy from the DHW heater is supplied to maintain a DHW outlet temperature of $1200^{\circ} \mathrm{F}$.

Mode 5 - Auxiliary Boiler-to-Space Heating - This mode is entered when the thermostat indicates a demand for heating and the temperature of the water in the storage tank is less than $75^{\circ} \mathrm{F}$. Pump P2 is energized and a solution of $28 \%$ ethylene glycol and $72 \%$ water is 
transferred from the auxiliary boiler to the heating coil. Valve Vl will allow flow from port $B$ to port $A B$. Valve V2 will blend flow from ports $A$ and $B$ to port $A B$. Each of the three areas requiring space heating has a manually controlled solenoid valve which allows all space heating to be eliminated from any area.

Space heating in the upstairs dayroom and kitchen is supplemented with auxiliary energy from a wood stove. The amount of this auxiliary energy supplied for space heating is unknown.

Operation of Mode 3 is not possible concurrently with Mode 5. 


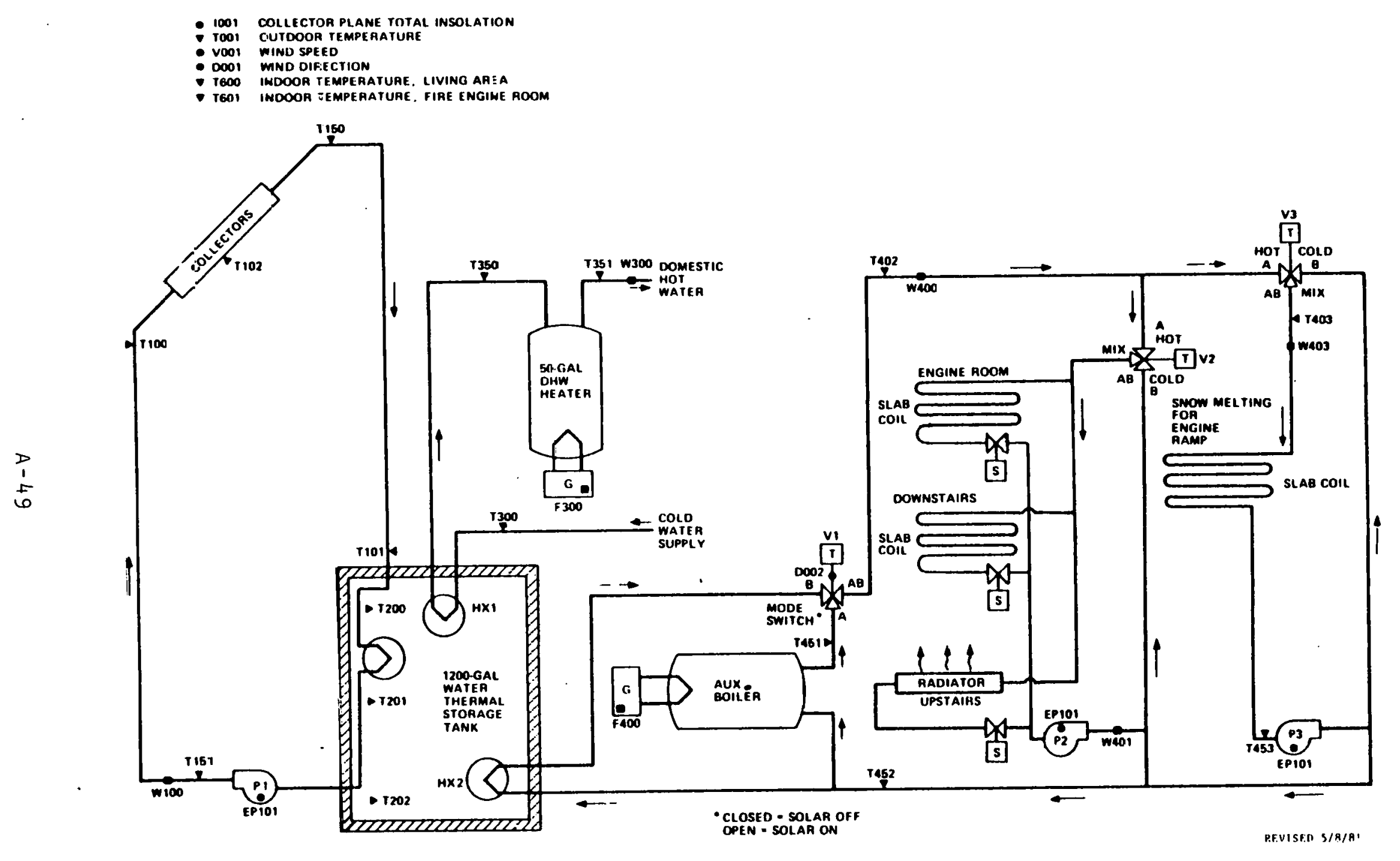

Figure A-26. Lake Valley Firehouse Solar Energy System Schematic 


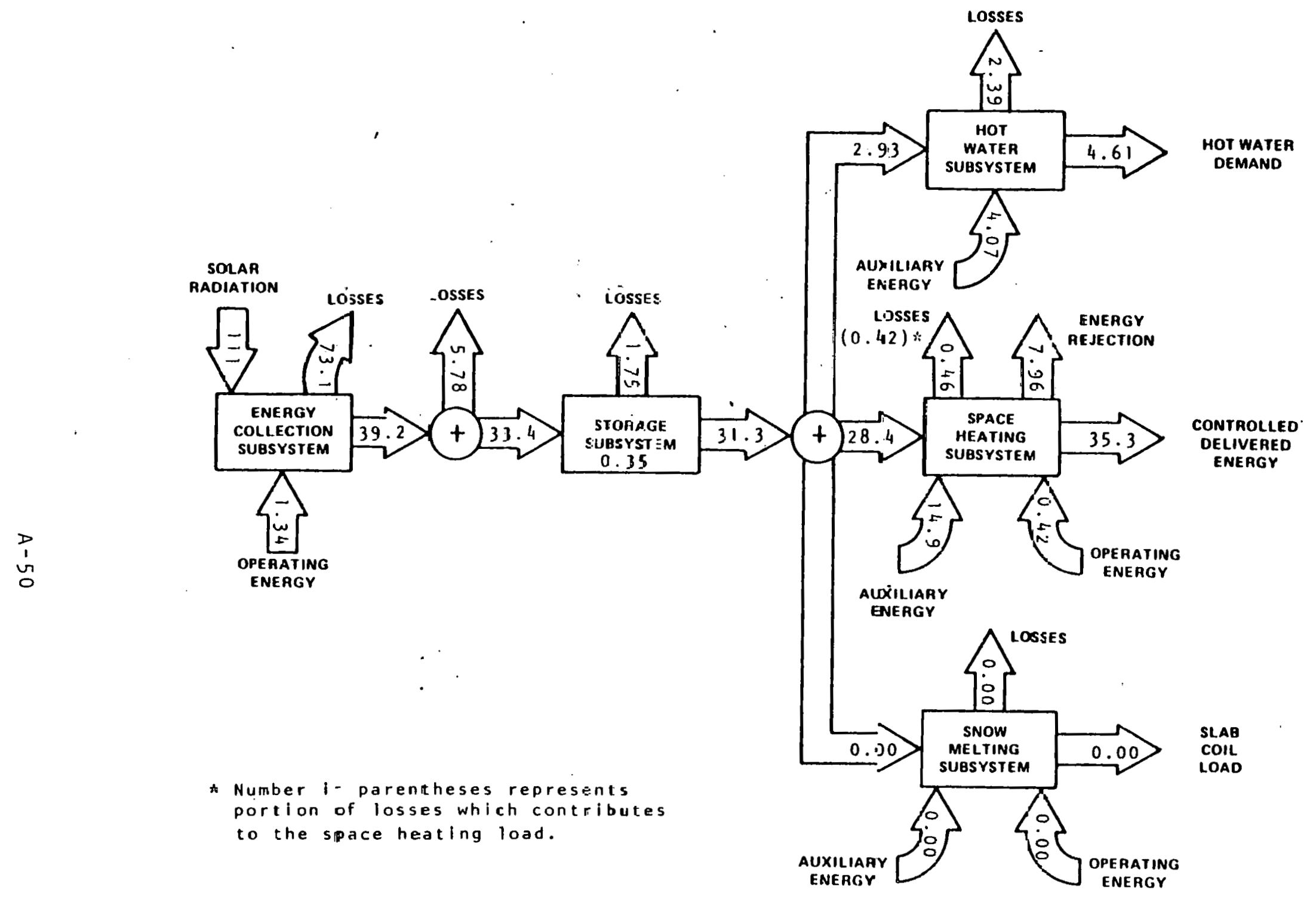

Figure A-27. Energy Flck Diagram for the Lake Valley Firehouse March lig81 through June 1981

(Figures in million BTU) 
The Loudoun County School site is the Charles S. Monroe Vocational Technical school located in Leesburg, Virginia. Solar energy is used for preheating Domestic Hot Water (DHW). The solar energy system has an array of flat-plate collectors with a gross area of 1,225 square feet. The array faces 15 degrees west of south at an angle of 37 degrees from the horizontal.

The collector panels have two low-iron glass covers and a nonselective absorber surface (Nextel black velvet by $3 M$ ). The absorber surface has a solar absorptivity of 0.98 and an infrared emissivity of 0.89 . Total solar transmissivity of the glazing is 0.72 . The absorber surface is composed of two sheets of stainless steel (stainless 439) resistance roll welded. The circulation pump (Pl) is rated 1-hp (240-volt, 3-phase).

A silicone oil solution is the transfer medium that delivers solar energy from the collector array to a heat exchanger. Solar energy is stored within the building in a 2,056-gallon water tank.

Preheated water is supplied from the solar storage tank to a 1,000gallon DHW tank. Hot water from the DHW tank is circulated through the service hot water lines and back to the DHW tank to instantly provide hot water at the service taps. This circulation is controlled by a time clock so that circulation occurs only during hours of normal use. An electrical heating element immersed in the DHW tank provides auxiliary energy, as required, to maintain the desired $140^{\circ} \mathrm{F}$ service water temperature.

The system, shown schematically in Figure A-28, has four modes of operation, all of which operate independently of one another.

Mode 1 - Collector-to-Storage - This mode activates when there is a temperature difference of $20 \% \mathrm{~F}$ between a control sensor located at the collector and a control sensor located inside the storage tank (near the bottom). At this time, tlie concroller turns on pump Pl which circulates the transport fluid through the collectors and the heat exchanger located inside the storage tank. Pl continues to operate until the temperature difference between the control sensors is less than 50F. At this point, $P l$ is turned off and the mode terminates. Mode l will also terminate when the storage tank temperature exceeds $200^{\circ} \mathrm{F}$, as measured by another control sensor near the top of the storage tank.

Mode 2 - Solar Energy Preheat - This mode activates when there is a temperature difference of $200 \mathrm{~F}$ between a control sensor located near the top of the storage tank and a control sensor located near the bottom of the DHW tank. At this time, the controller energizes pump $P 2$, which delivers preheated water from the storage tank to 
the DHW tank and recirculates water from the DHW tank to the storage tank. When the temperature difference between the control sensors becomes less than $5^{\circ} \mathrm{F}$, pump $P 2$ turns off and the mode terminates. An electrical element in the DHW tank is energized to provide auxiliary water heating when the DHW tank temperature falls below a set point.

Mode 3 - Recirculate - This mode activates (under time-clock control) during hours of normal use, i.e., primarily during daylight and early evening hours every day of the week except sunday. When activated, pump $P 3$ is energized and hot water circulates from the hot water tank through the service hot water lines and returns to the hot water tank.

Mode 4 - DHW Load - This mode activates when hot water is drawn from any of the hot water taps in the building. The hot water demand is replenished by cold water supplied to the storage tank. The make-up water to the DHW tank from the storage tank goes through P2 (if Mode 2 is active at this time) or bypasses $P 2$ if Mode 2 is inactive. Mode 3 need not be activated to supply the demand at the hot water taps. 


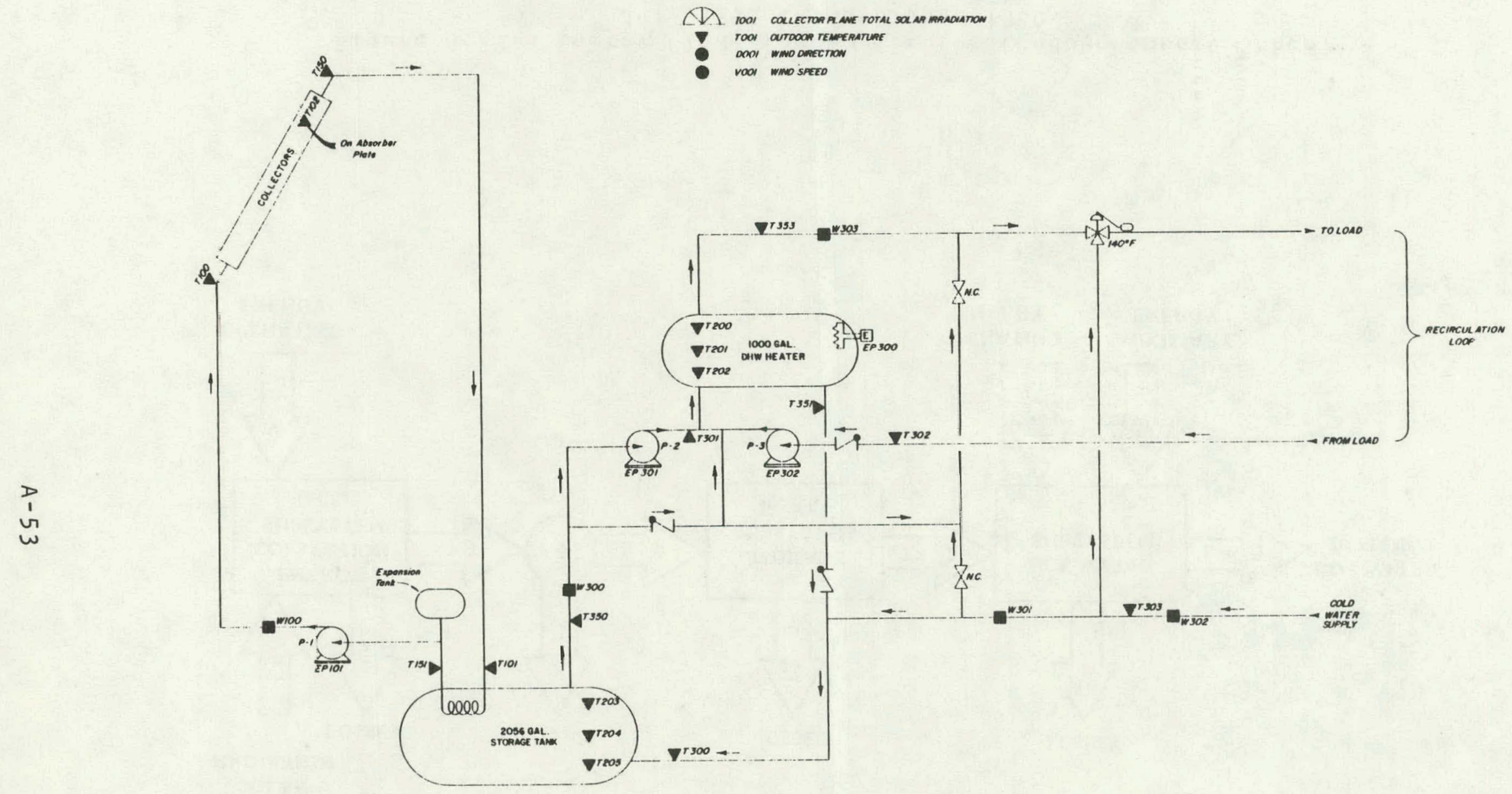

SEPTEMEER 12,1900

Figure A-28. Loudoun County School Solar Energy System Schematic 


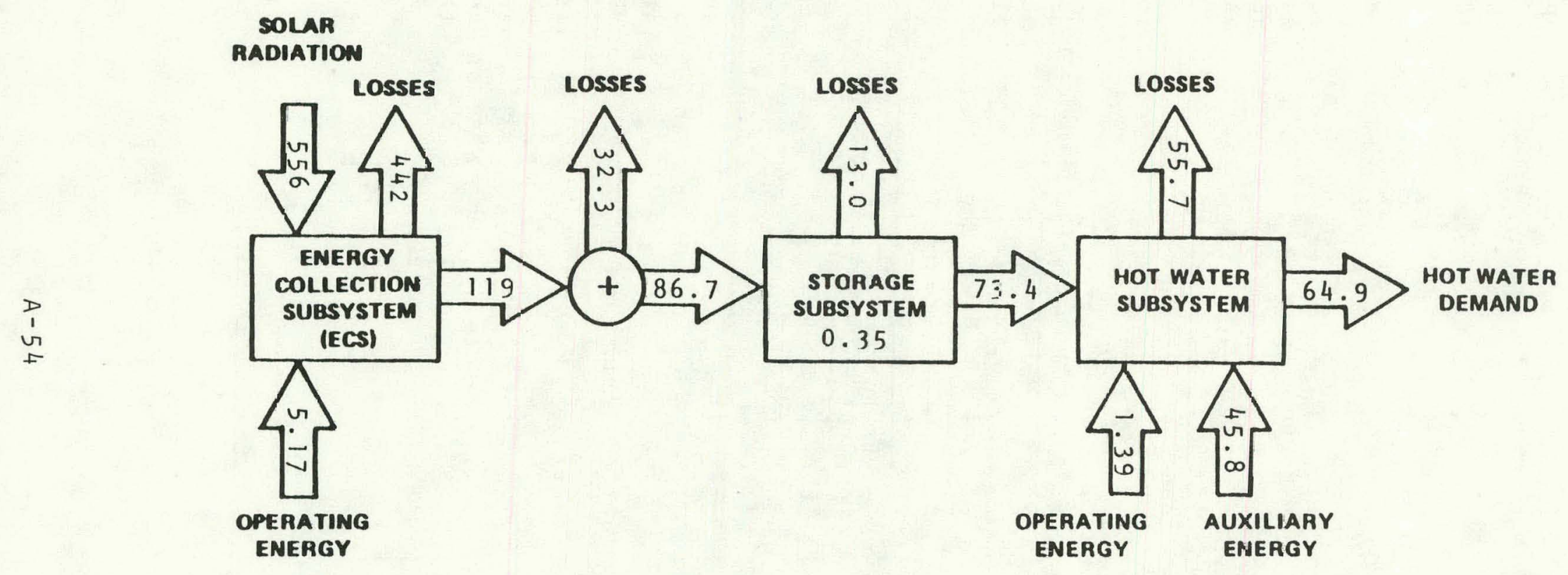

Figure A-29. Energy Flow Diagram for the Loudoun County School July 1979 through June 1980

(Figures in million BTU) 
The Loyola University solar energy system, located in New Orleans, Louisiana, supplies energy necessary to preheat approximately 9,000 gallons of Domestic Hot Water (DHW) each day to Biever Hall Dormitory. Biever Hall is a six-story dormitory that houses 420 students. The system is designed to supply $140^{\circ} \mathrm{F}$ water to bathrooms, showers, and eight washing machines.

The solar energy system was added to the existing water heating system and has 15 arrays of General Energy Devices Model $2400 \mathrm{C}$ flat-plate collectors with a gross area of 4,590 square feet, and a net area of 4,320 square feet. The collectors face 16 degrees west of south at an angle of 38 degrees from the horizontal. The system is an open-loop system which uses potable water as both the collector fluid and storage medium.

A Hawthorne Industries BT-100 controls the solar collector operation.

City water is preheated by the flat-plate collectors on the roof and stored in a 5,000-galion tank located on the west side of the building at ground level. Upon demand, the preheated water is transported to two existing 1,500-gallon hot water tanks. When solar energy is insufficient to satisfy the hot water load, auxiliary energy is supplied by a central heating plant via a high temperature/high pressure line.

The system, shown schematically in Figure A-30, has five modes of operation.

Mode 1 - Collector-to-storage - This mode activates when the temperature difference between the collector outlet and the water in the bottom of the storage tank exceeds $16^{\circ} \mathrm{F}$. Pump EPIO0, or backup pump EPIOl, turns on to circulate the solar heated water from storage to collector and back to storage. This mode terminates when the temperature difference between the collector outlet and the water in the bottom of the storage tank is less than $3^{\circ} \mathrm{F}$.

Mode 2 - Storage-to-Load - This mode activates when there is a hot water demand. In this mode, makeup water from the cold water supply flows through a water softener system and then to the 5,000-gallon storage tank. Solar heated water is then forced out of the top of the tank and transferred to the two 1,500-gallon DHW tanks, where, if not hot enough, auxiliary heat is used to maintain $140^{\circ} \mathrm{F}$ water temperature.

Mode 3 - Recirculation of DHW - Pump EP300 and, alternately, pump trjul are used to continuously recirculate the DHW throughout the six-story dormitory. Thus, hot water is always available at the taps. 
Mode 4 - Freeze Protection - When the outdoor ambient temperature is less than or equal to $380 \mathrm{~F}$, Mode 4 is then activated. Warm water is pumped through the collector arrays, thus preventing freezing.

Mode 5 - Heat Rejection - When the temperature exiting the collectors equals or exceeds $180^{\circ} \mathrm{F}$, a valve is activated, the water is drained and not allowed to enter the storage tank. 


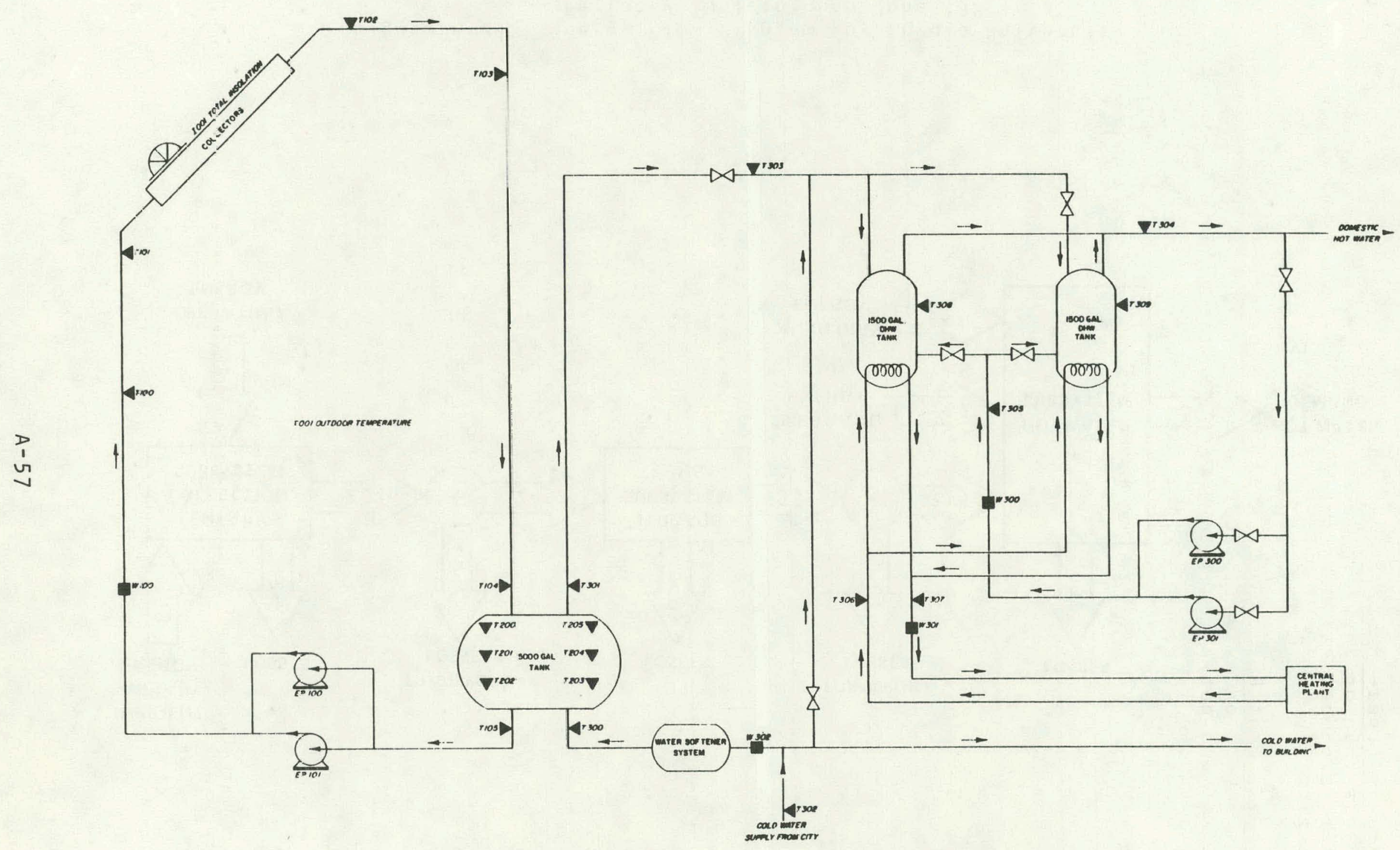

Figure A-30. Loyola University Solar Energy System Schematic 


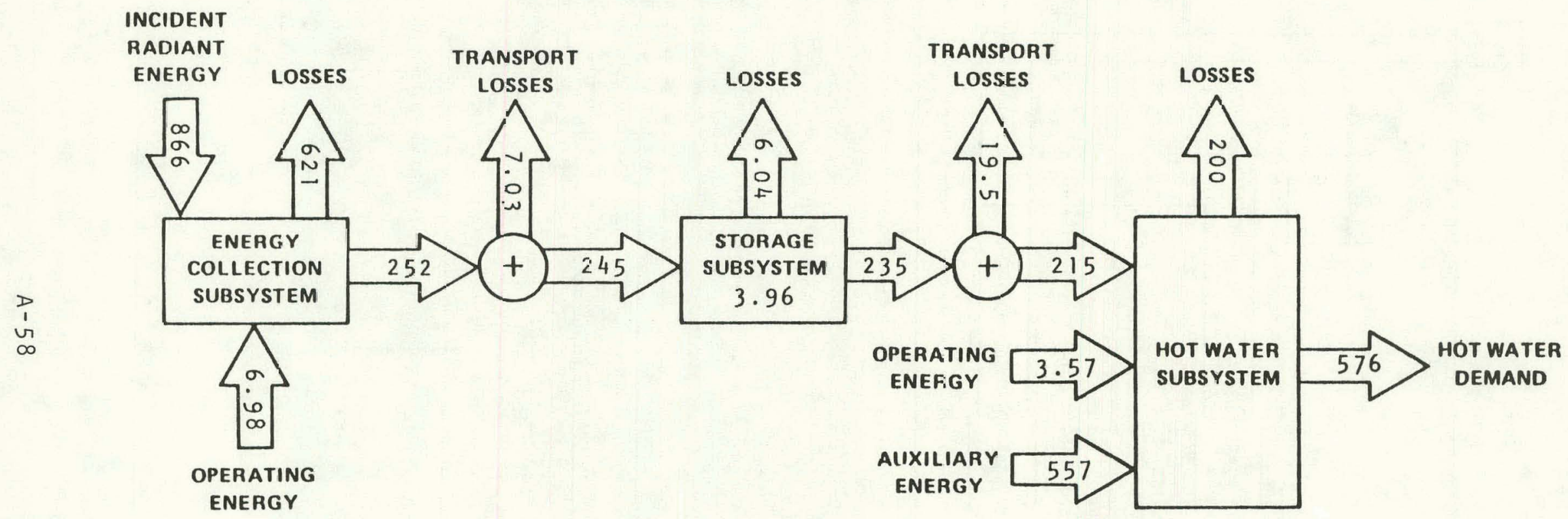

Ficure A-31. Energy Flow Diagram for Loyola University

February 1981 through June 1981

(Figures in million BTU) 


\section{OAKMEAD INDUSTRIES}

The Renault and Handley Building, referred to as Oakmead Industries, is one of two nearly identical solar heated buildings located at the oakmead Industrial Park in Santa Clara, California. This commercial building contains approximately 60,000 square feet of floor area. The solar energy system installation is a retrofit and was originally designed to provide $85 \%$ of the annual heating requirements and $90 \%$ of the annual hot water demand.

The building has two central heating zones, one for the north zone of the building and the other for the south zone. The north zone is heated by a combination of solar energy from a liquid-based flat-plate collector array and an auxlllary gas-fired furnace. The south zone heating system provides space heating for the warehouse area. The south zone is heated by a hybrid passive/active solar energy system installed on the south wall, solar energy.from the liquid flat-place collectors, and by an auxiliary gas-fired furnace.

Staefa, Inc. (Switzerland) provided the control system for oakmead Industries.

The Revere Sun-Aid liquid-based solar collectors utilize a $10 \%$ solution of propylene glycol in water as the heat transfer medium for collecting solar energy. The flat-plate collector array faces due south at a tilt of 45 degrees from the horizontal and employs a 2,622-square-foot collector array. The collector. surface is enhanced with a black chrome selective surface and a single layer of water-white crystal glass.

The system, shown schematically in Figure A-32, has eight modes of solar operation.

Mode 1 - Liquid Collector Subsystem-tn-Thermal Control Loop - In this mode, collector loop pump Pl starts if the collector plate stagnation temperature is greater than $120^{\circ} \mathrm{F}$. An adjustable time delay provides an off delay for pump $P l$ (normally five minutes). At the end of the delay period, pump PI will continue to operate if the collector plate temperature is $5^{\circ} \mathrm{F}$ greater than the Thermal Control Loop (TCL) temperature. Pump P3 is interlocked with pump Pl to provide constant operation of collector to the TCL. Pumps $P I$ and $P 3$ are deactivated when the differential temperature between the collector plate and the TCL falls below $5^{\circ} \mathrm{F}$.

Mode 2 - Liquid Collector Subsystem Protection - If the collector plate temperature exceeds $240^{\circ} \mathrm{F}$ or the top of the storage tank is greater than $200^{\circ} \mathrm{F}$, valve AV 3 connects the solar loop to the heat rejector, energizes the heat rejector fan, deenergizes pump $P 3$, and energizes pump Pl. This provides collector protection from extremely high temperatures. This mode is deactivated when the plate temperature falls below $240^{\circ} \mathrm{F}$ or the storage tank falls below $200^{\circ} \mathrm{F}$. 
Mode 3 - Thermal Control Loop to Storage (Liquid Subsystem) - In this mode, solar energy is transferred to storage when the TCL temperature exceeds $1200 \mathrm{~F}$. Valve AV2 modulates flow to and from storage while valve AVI provides makeup water from the top or bottom of the storage tank. This mode is completely controlled by the operation of valves AVI and AV2.

Mode 4 - Thermal Control Loop-to-Space Heating (Liquid Subsystem) This mode is energized when there is a demand for space heating. Pump P2 is interlocked to operate with pump P3 if the TCL temperature is greater than $800 \mathrm{~F}$ or the storage tank top temperature is gleater thon $800 \mathrm{~F}$. Solar energy is provided to the north and south space heating zones until there is no demand for space heating or the temperature in the TCL and storage tank falls below $80^{\circ} \mathrm{F}$.

Mode 5 - Storage-to-DHW Subsystem (Liquid Subsystem) - In this mode, solar energy is transferred from the storage tank to the DHW preheat tank if the DHW preheat tank is less than $160^{\circ} \mathrm{F}$, storage tank is greater than $100^{\circ} \mathrm{F}$, and the storage tank temperature is $10^{\circ} \mathrm{F}$ greater than the DHW preheat tank. Pump $P 4$ is activated to deliver energy to the DHW subsystem and deactivates when the difference between the storage tank temperature and the DHW preheat tank falls below $5^{\circ} \mathrm{F}$.

Mode 6 - Auxiliary Space Heating (Liquid and Air Subsystems) - This mode activates when there is a need for space heating and solar energy is insufficient to meet the demand. The auxiliary gas-fired furnace will provide the remaining building spact heating domand. (There are two gas-fired furnaces for the north and south heating zones.)

Mode 7 - Auxiliary Hot Water Heating (Liquid Subsystem) - In this mode, auxiliary hot water is provided by an electric heater. If solar energy is insufficient, then the electric hot water provides auxiliary energy upon demand. The DHW tank is maintained at a control set point of approximately $140^{\circ} \mathrm{F}$.

Mode 8 - Air Collector Subsystem-to-Space Heating - This mode activates when there is a need for space heating in the south zone only. If the temperature in the air collectors is greater than $85^{\circ} \mathrm{F}$, then the fan in the auxiliary furnace will activate to deliver heated alr to the south zone. This mode is deactivated when the temperature in the air collectors falls below $85^{\circ} \mathrm{F}$ or there is no space heating demand in the south zone. (The return plenum damper is closed during the summer months.) 
- 1001 COllector plane total insolation

- TOO1 OUTDOOR TEMPE BatUAE

VOO1 WIND SPEEO

- RH9O1 OUTDOOR RELATIVE HUMUOITY

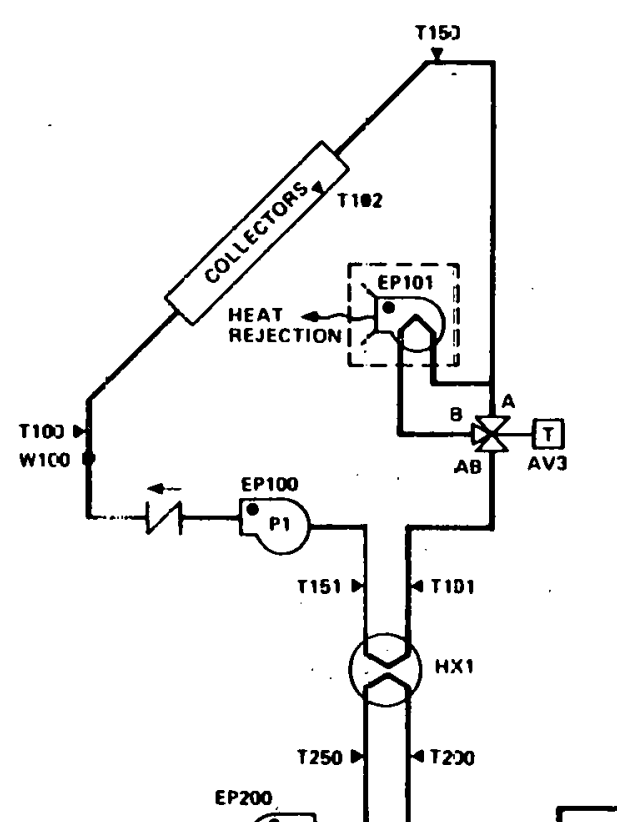

- 1002 COLleCtOR PLANE TOTAL INSOLATION.

- TO02 OUTDOOR TEMPERATURE
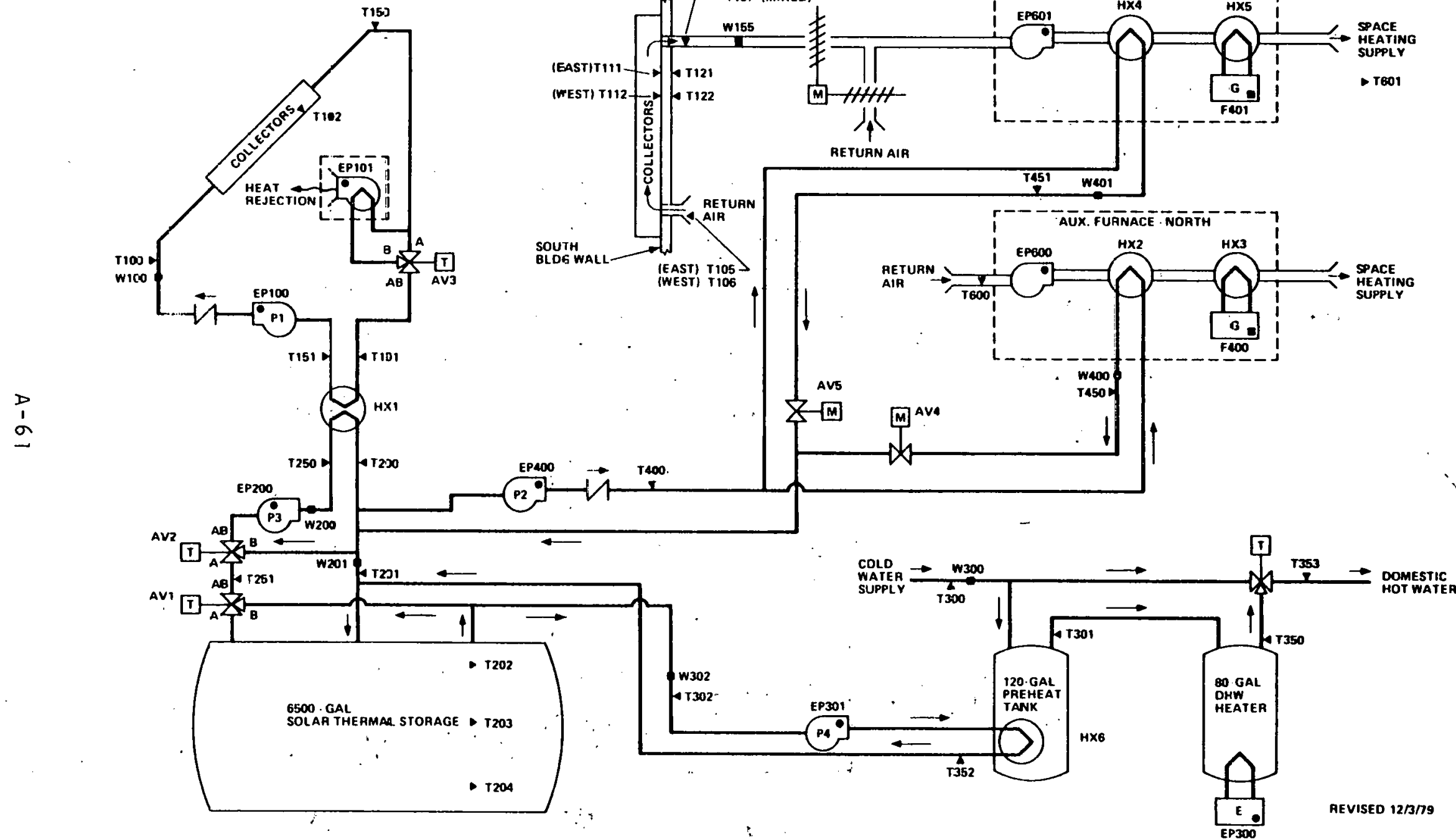

Figure A-32. Oakmead Industries Solar Energy System Schematlc 
SOLAR

AADIATION

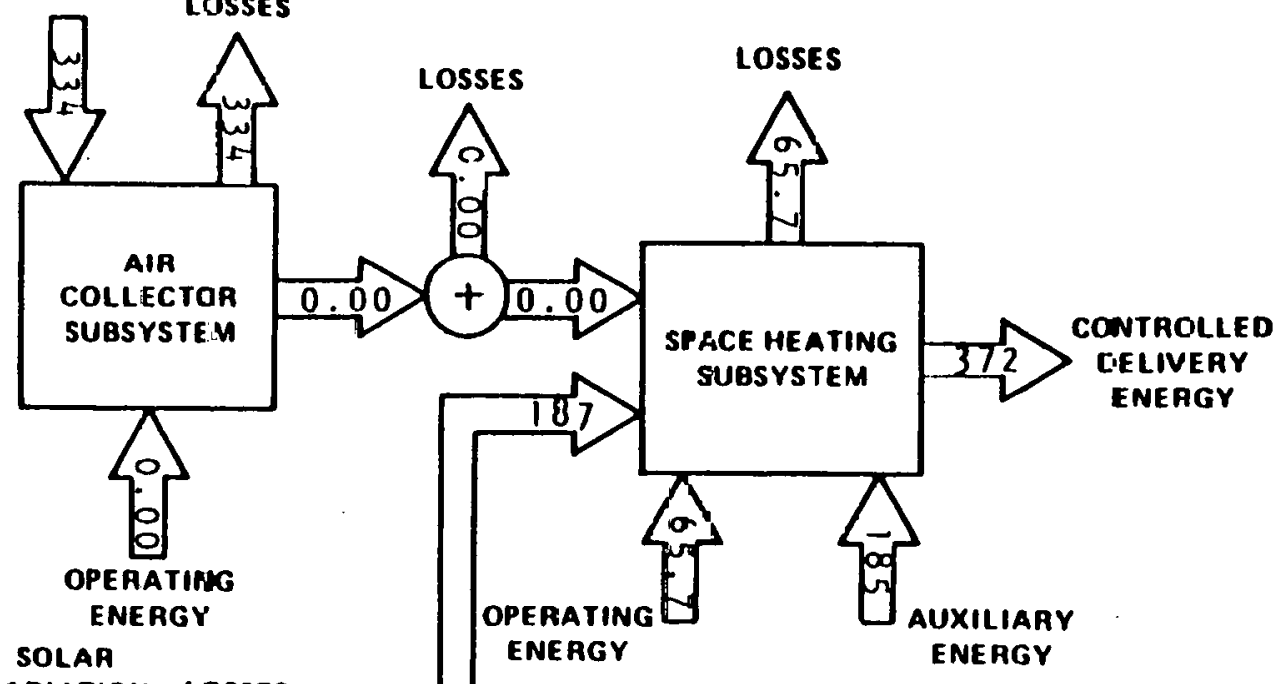

AADIATION LDSSES

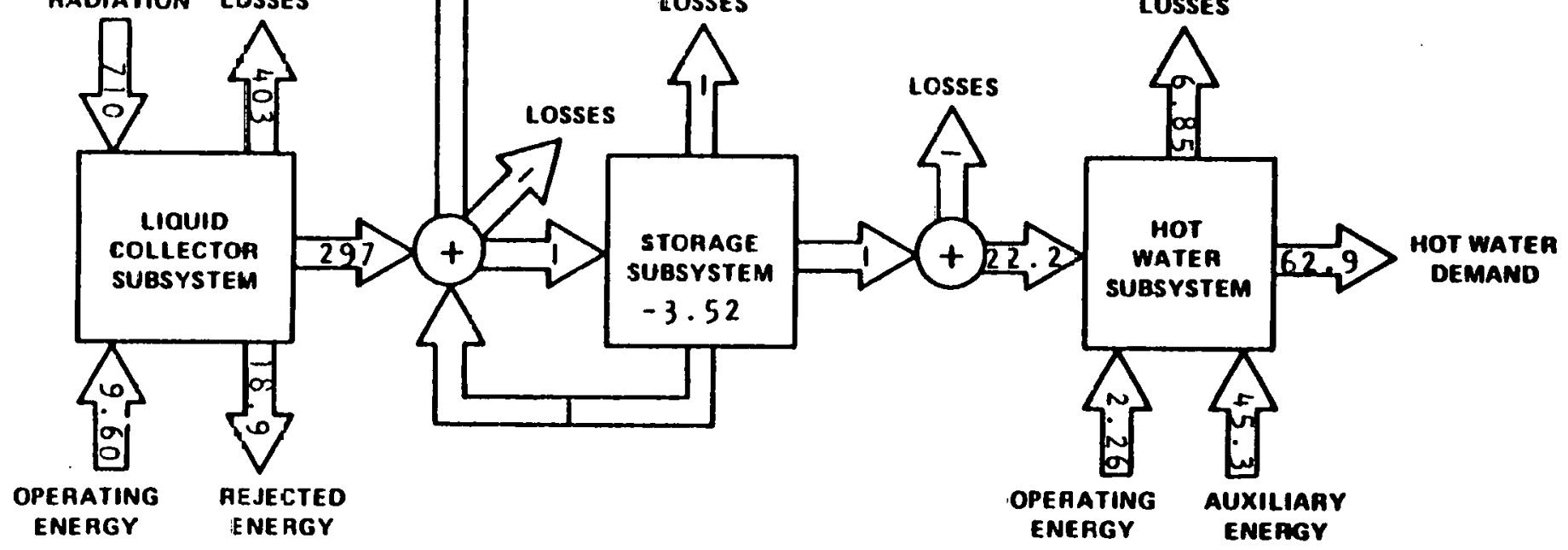

I Denotes invalid data.

Figure A-33. Energy Flow Diagram for 0akmead Industries october 1931 through April 1982

(Figures in million BTU) 
The Saddle Hill Trust Lot 36 site is a single family residence in Medway. Massachusetts. Solar energy is used for space heating the home and preheating Domestic Hot Water (DHW). The system has an array of 14 liquid flat-plate Daystar Model 2001 collectors with a gross area of 315 square feet. The array faces south at an angle of 58 degrees from the horizontal.

A Rho Sigma controller operates the solar collector pump.

A $60 \%$ glycerol solution is the transfer medium that delivers solar energy from the collector array to storage; water is the transfer medium that delivers solar energy from storage to the space heating and hot water loads. Solar energy is stored in the basement in a 750-gallon storage tank. The tank is made of steel and lined with polyurethane. Preheated city water is supplied, on demand, to a conventional 80-gallon DHW tank. When solar energy is insufficient to satisfy the space heating load, a Friedrich Model QUA112-AMA oil furnace provides auxiliary energy for space heating. Similarly, the conventional electric Vaughn Model C8N2 80-gallon DHW heater provides auxiliary energy for water heating.

The system shown schematically in Figure A-34, has three modes of operation.

Mode 1 - Collector-to-storage. - This mode activates the collector solar pump when the collector temperature is either more than $40^{\circ} \mathrm{F}$ higher than storage temperature or higher than $150^{\circ} \mathrm{F}$. Solar energy transfer takes place through a heat exchanger located inside the storage tank.

Mode 2 - Storage-to-Space Heating - This mode activates the space heating solar pump when there is a demand for space heating, storage temperature is $70^{\circ} \mathrm{F}$ or higher, and house temperature is lower than storage temperature. Solar energy transfer takes place through a heat exchanger located inside the air duct.

Mode 3 - Storage-to-DHW Tank - This mode activates the DHW solar pump when storage water is $50 \mathrm{~F}$ higher than water in the DHW tank. Solar energy transfer takes place through a heat exchanger located inside the DHW heater. 


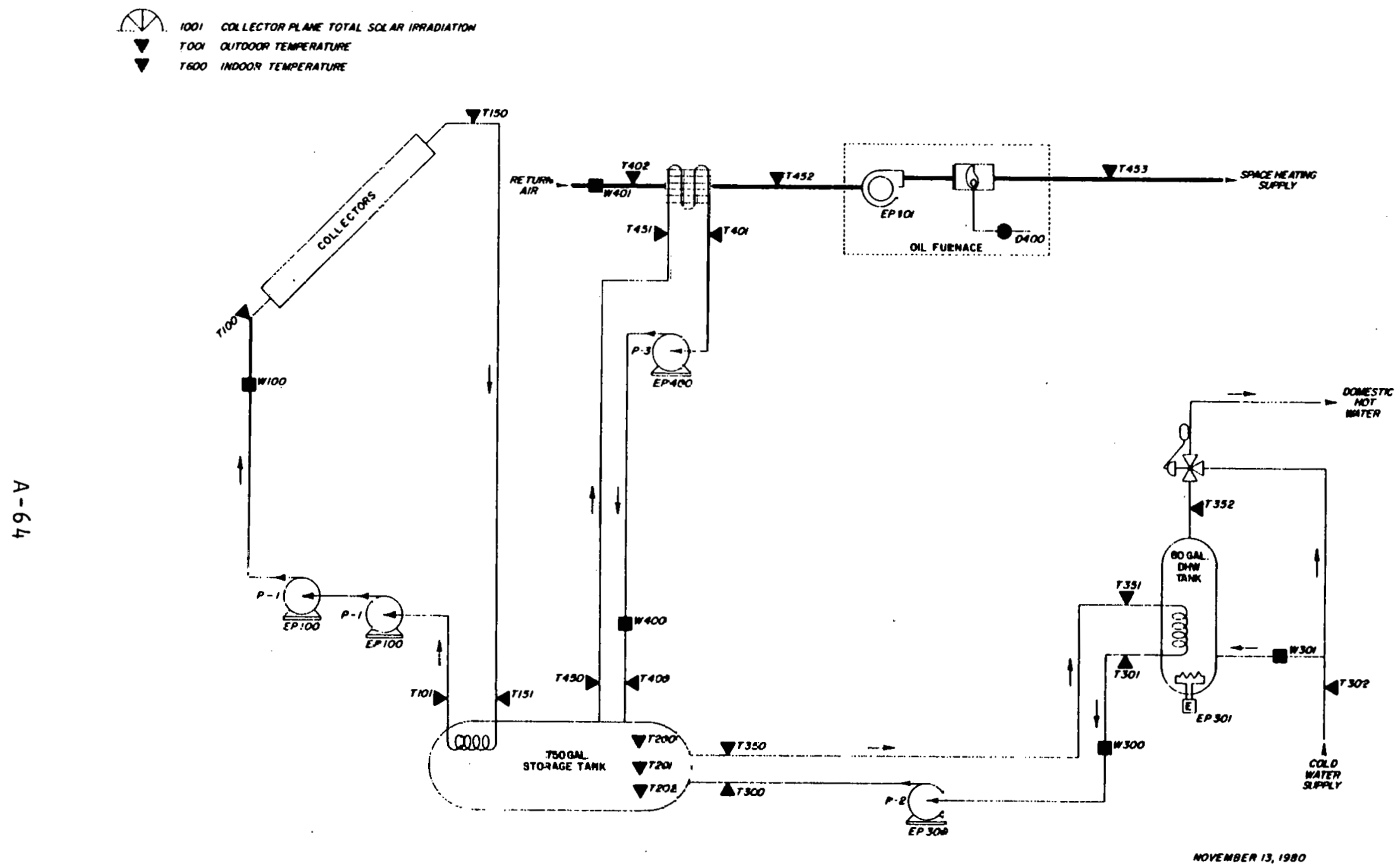

Figure A-34. Saddle Hill Trust Lot 36 Solar Energy System Schematic 


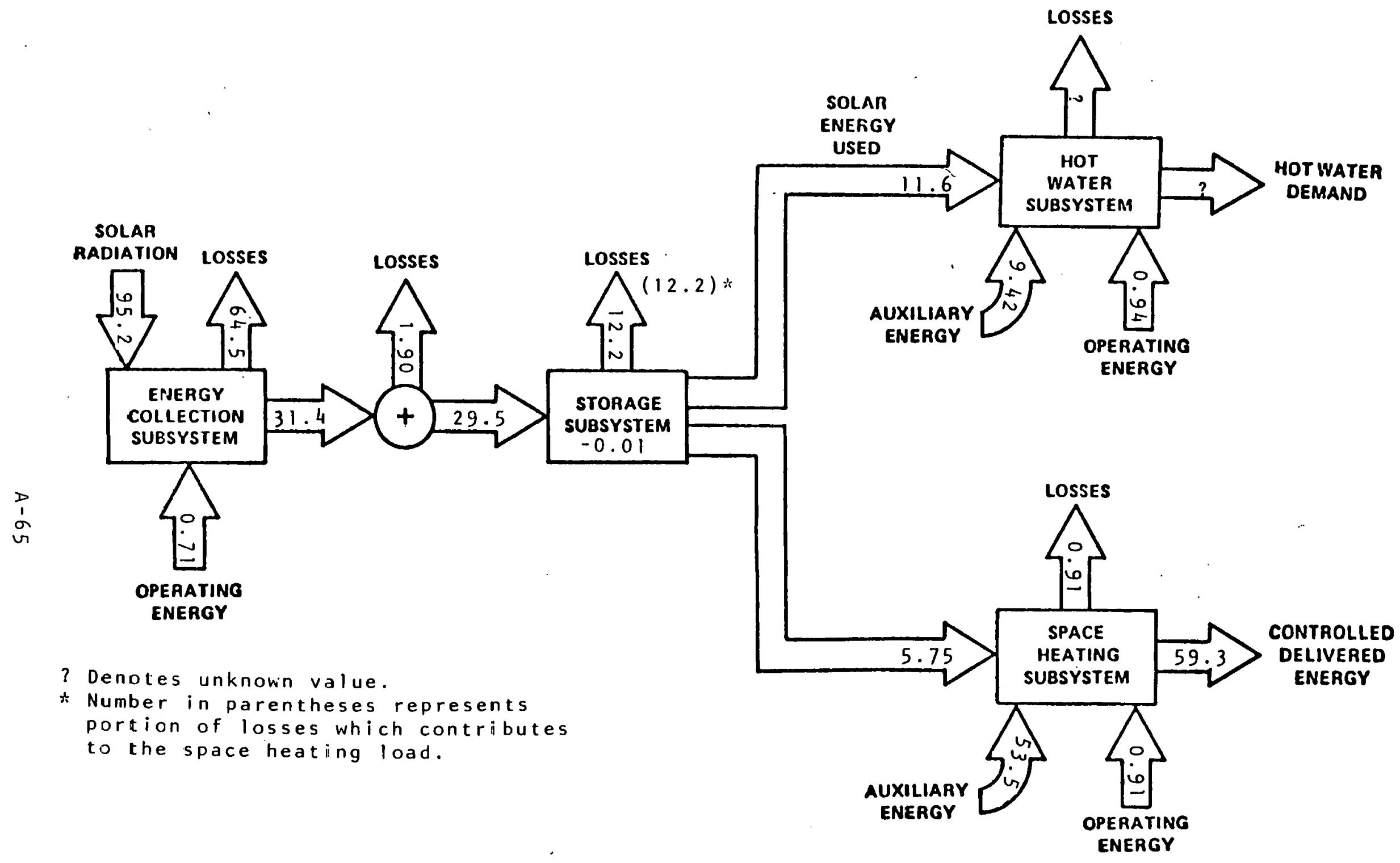

Figure A-35. Energy Flow Diagram for Saddle Hill Trust Lot 36 October 1980 through May 1980

(Figures in million BTU) 
The Saddle Hill Trust Lot 73 site is a single family residence in Medway, Massachusetts. Solar energy is used for preheating incoming city water. The system has an array of two liquid flat-plate Daystar Model 2001 collectors, with a gross area of 45 square feet, which faces south at an angle of 45 degrees to the horizontal. A $60 \%$ glycerol solution is used as the medium for delivering solar energy from the collector array to storage. Water is the transport medium that delivers solar energy to storage and to the Domestic Hot Water (DHW) heater.

The collector panels have one glass cover and a nonselective absorber surface. The absorber surface has a solar absorptivity of 0.97 and an infrared emissivity of 0.97 . Between the glass cover and the absorber plate, there is a special "heat trap" which is a thin layer of a high-temperature polymer which is tolded in an accordian shape. Total solar transmissivity of the glazing is 0.83 . The absorber surface is composed of a black painted copper plate. The fluid circulated through the collectors is a glycerol solution.

A Rho Sigma differential thermostat activates the solar collector pump.

Solar energy is stored in the basement in an 80-gallon preheated tank. Model SWH/TC 80 manufactured by Ford Products. This preheated city water is supplied, on demand, to a conventional 40-gallon natural-gas DHW tank, Model SV-40-NRT7 manufactured by State. When solar energy is insufficient to satisfy the hot water requirements, the gas-driven DHW heater provides auxiliary energy for water heating.

The system, shown schematically in Figure A-36, has two modes of solar operation.

Mode 1 - Collector-to-storage - This mode activates the solar pump when a $400 \mathrm{~F}$ temperature difference exists between the collector and the preheated tank. This mode continues operating until the temperature difference drops to $20^{\circ} \mathrm{F}$.

Mode 2 - Storage-to-DHW Tank - This mode aclivates when there is a demand for hot water. Hot water from the top of the preheated tank is transferred to the DHW tank to replace the amount removed. simultaneously, city water is automatically supplied to the preheated tank. 


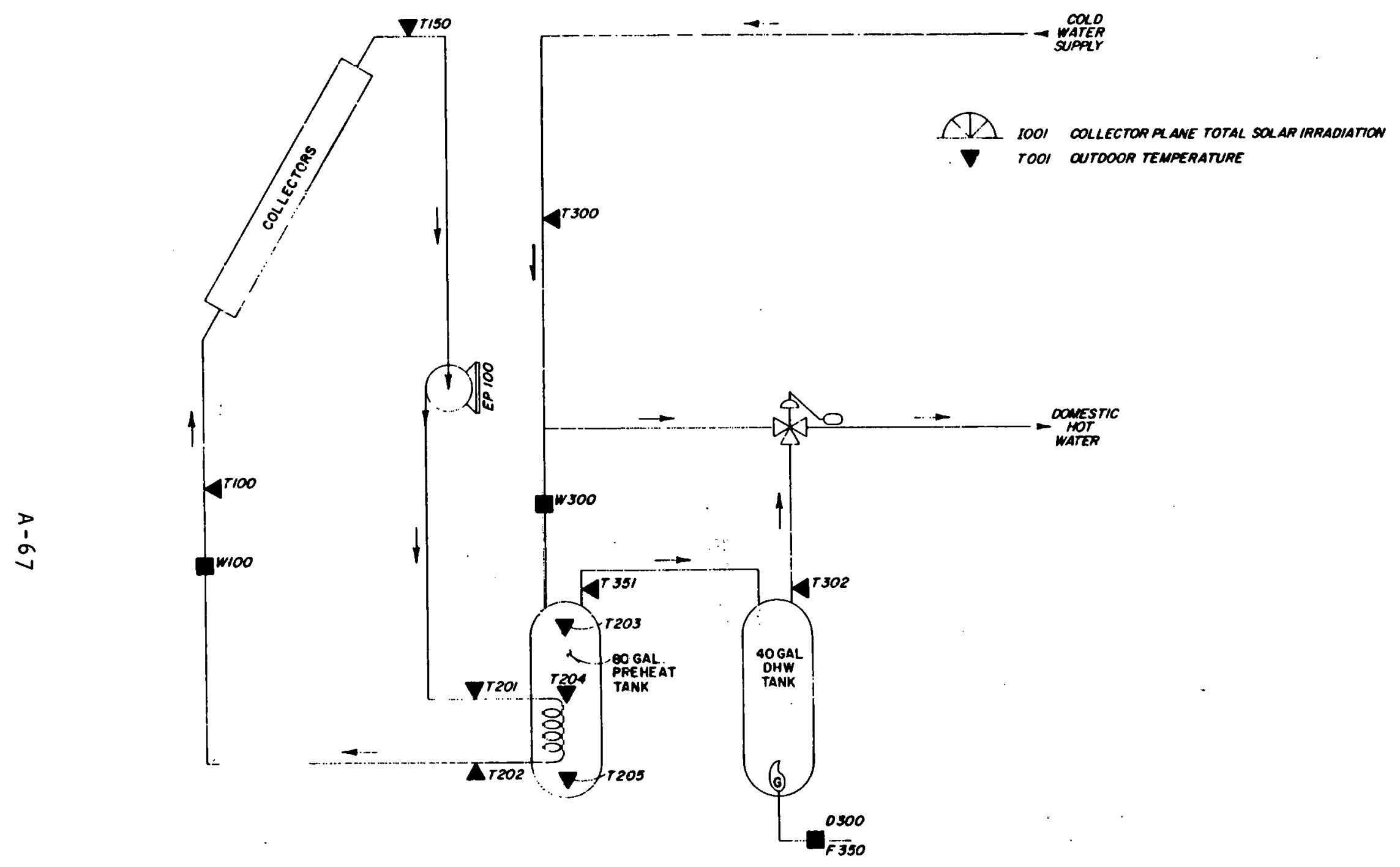

AUGUST 19,1980

Figure A-36. Saddle Hill Trust Lot 73 Solar Energy System Schematic 


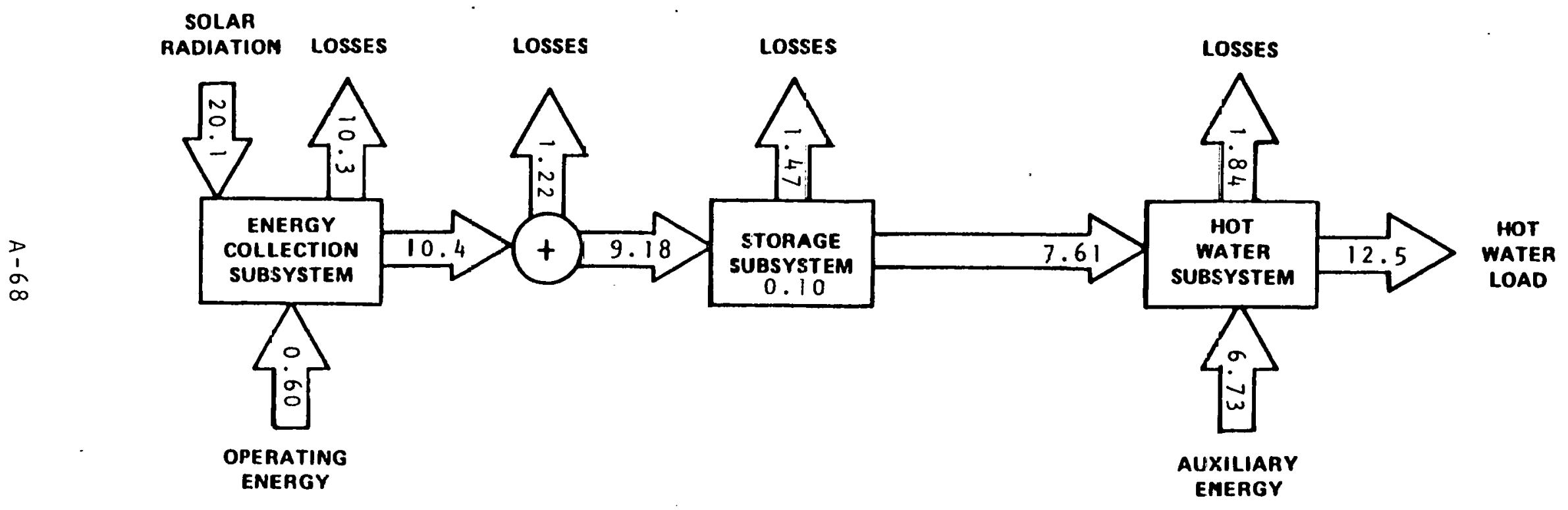

Figure A-37. Energy Flow Diagram for Saddle Hill Trust Lot 73 January 1980 thraugh December 1980

(Figures in million BTU) 
The Saddle Hill Trust Lot 77 site is a single family residence in Medway, Massachusetts. Solar energy is used for preheating incoming city water. The solar energy system has an array of solaron flat-plate collectors with a gross area of 78 square feet. The array faces south at an angle of 38 degrees from the horizontal. Air is used as the medium for delivering solar energy from the collector array to an air-to-liquid heat exchanger located in the collector air duct. Water is the medium used to transport solar. energy from the heat exchanger to storage.

The solaron collector panels have two glass covers and a nonselective absorber surface. The absorber surface has a solar absorptivity of 0.94 and an infrared emissivity of 0.10 . Total solar transmissivity of the glazing is 0.89 . The absorber surface is composed of black steel. The medium circulated through the collectors is air.

A Robertshaw Solar Commander differential thermostat, Model SD-10, provides control of the solar collectors.

Solar energy is stored in the basement in a 120-gallon preheat storage tank. This preheated city water is supplied, on demand, to a conventional State "Super Lift" Model SV-40-RRT7 40-gallon Domestic Hot Water (DHW) tank. When solar energy is insufficient to satisfy the hot water requirements, the gas-driven DHW heater provides auxiliary energy for water heating.

The system, shown schematically in Figure A-38, has two modes of solar operation.

Mode 1 - Collector-to-Preheat - This mode activates the fan and pump when the difference between the temperature of the collector air and the temperature of the water in the preheat tank exceeds $400 \mathrm{~F}$ and the temperature of the water in the tank is below $1400 \mathrm{~F}$. This mode continues until the temperature difference drops to $20^{\circ} \mathrm{F}$.

Mode 2 - Preheat-to-Domestic Hot Water - This mode activates when there is a demand for hot water. Hot water from the top of the preheat tank is transferred to the DHW tank to replace water removed. Simultaneously, city water is automatically supplied to the preheat tank. 


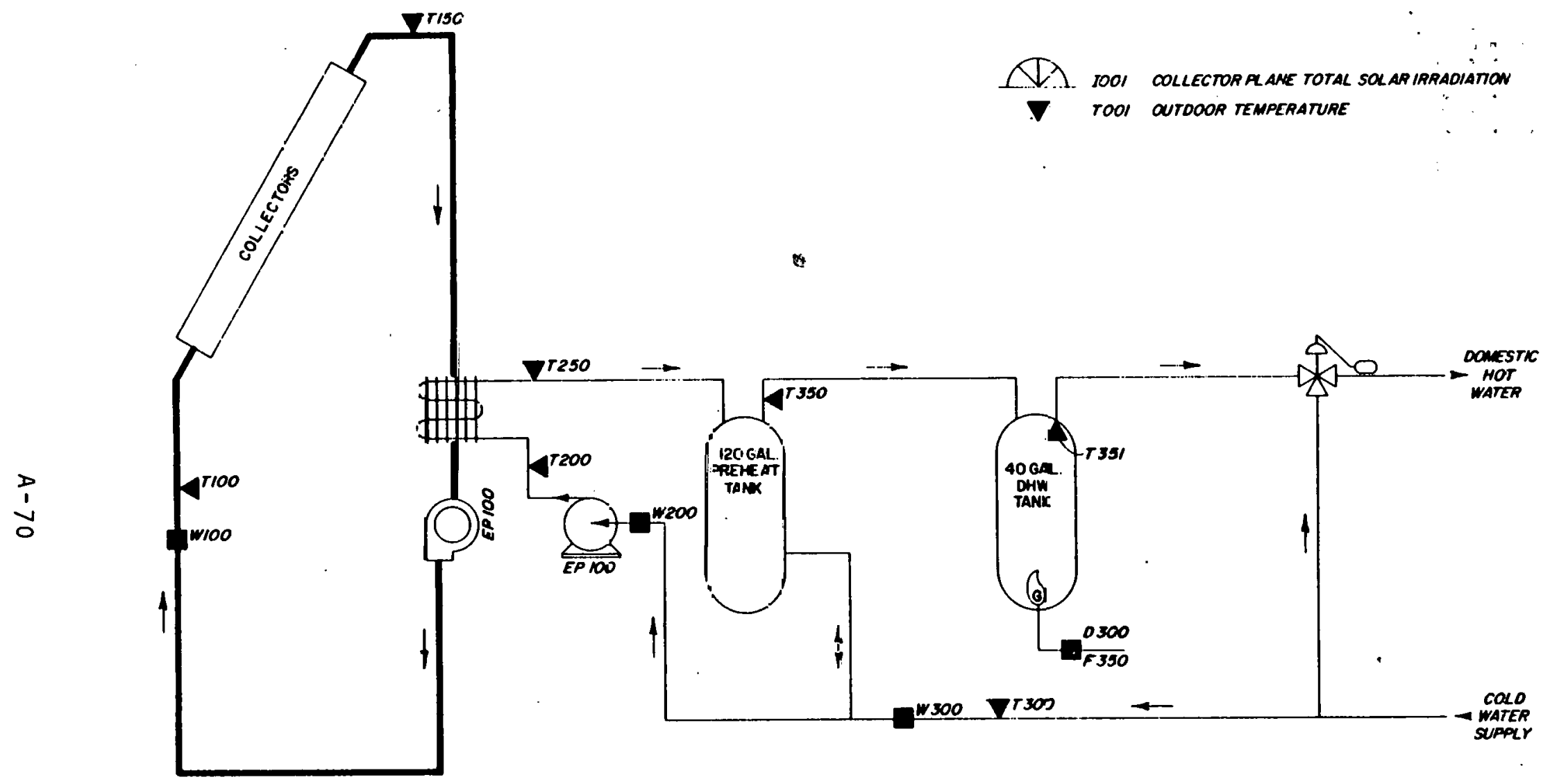

AMGUST 19,1980

Figure A-3.8. Saddle Hill Trust Lot 77 Solar Energy System Schematic 
SOLAR

RADIATION

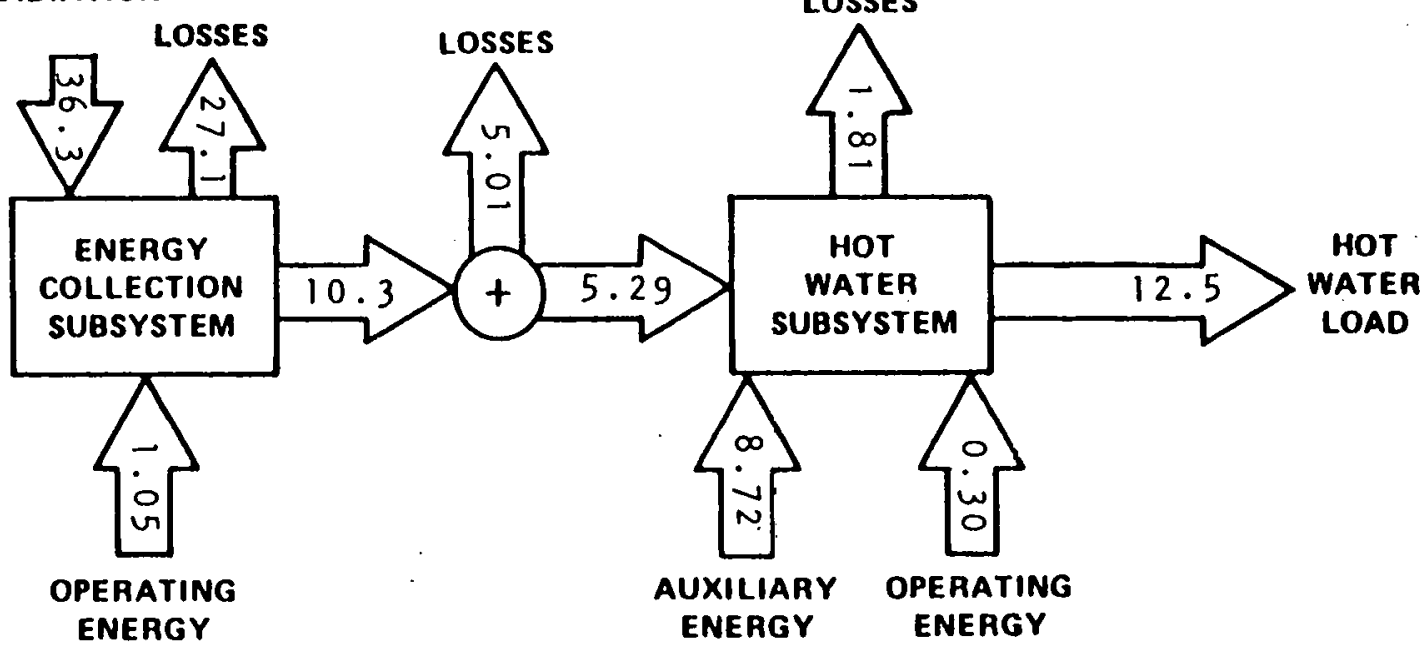

Figure A-39. Energy Flow Diagram for Saddle Hill Trust Lot 77 September 1979 through August 1980

(Figures in million BTU) 
The South Bridge Towers is a high-rise cooperative housing project located in New York City. The solar energy system is used to preheat the Domestic Hot Water (DHW) for the 350 apartments in Tower 6 The system of 150 Daystar 21-B flat-plate collectors faces 14 degrees west of south, at a tilt of 40 degrees from the horizontal. The collector array has a gross area of 3,742 square feet and uses a $50 \%$ propylene glycol and water solution for the energy transport fluid. Additional freeze protection is provided by electric heat tapes mounted on the collector headers and exposed piping.

The Daystar 21-B Series 1200 solar collectors utilize a "Black Velvet" flat-black absorber plate coating ( $3 M$ Nextel), an internal plastic heat trap folded into accordian pleats, and double covers of low-iron tempered glass.

The controller is an Independent Energy C-100 Energy Manager.

The collected solar energy is stored in a 3,750-gallon stone-lined storage tank. Preheated water leaving the storage tank is further heated by passing through the condenser cooler which uses the depleted low pressure steam return. Low pressure steam, purchased from the local utility, heats the water to delivery temperature. The water is then circulated to the apartments.

The system, shown schematically in Figure A-40, has two modes of solar operation.

Mode 1 -Collector-to-storage - This mode activates when the temperature difference between the collectors and storage is $200 \mathrm{~F}$. There is a time delay to keep the collectors from cycling on and off. This mode deactivates when the temperature difference is $3^{\circ} \mathrm{F}$ or less.

Mode 2 - Storage-to-Load - This mode activates when there is a hot water demand. Incoming city water is preheated in the solar storage tank and then passes through the DHW heater before being delivered to the apartments. 
W1) I0OI TOTAL Insolation

- Toos OUTOOOR AMBIENT TEMPERATURE

- EPOI SREEZE MateCtION

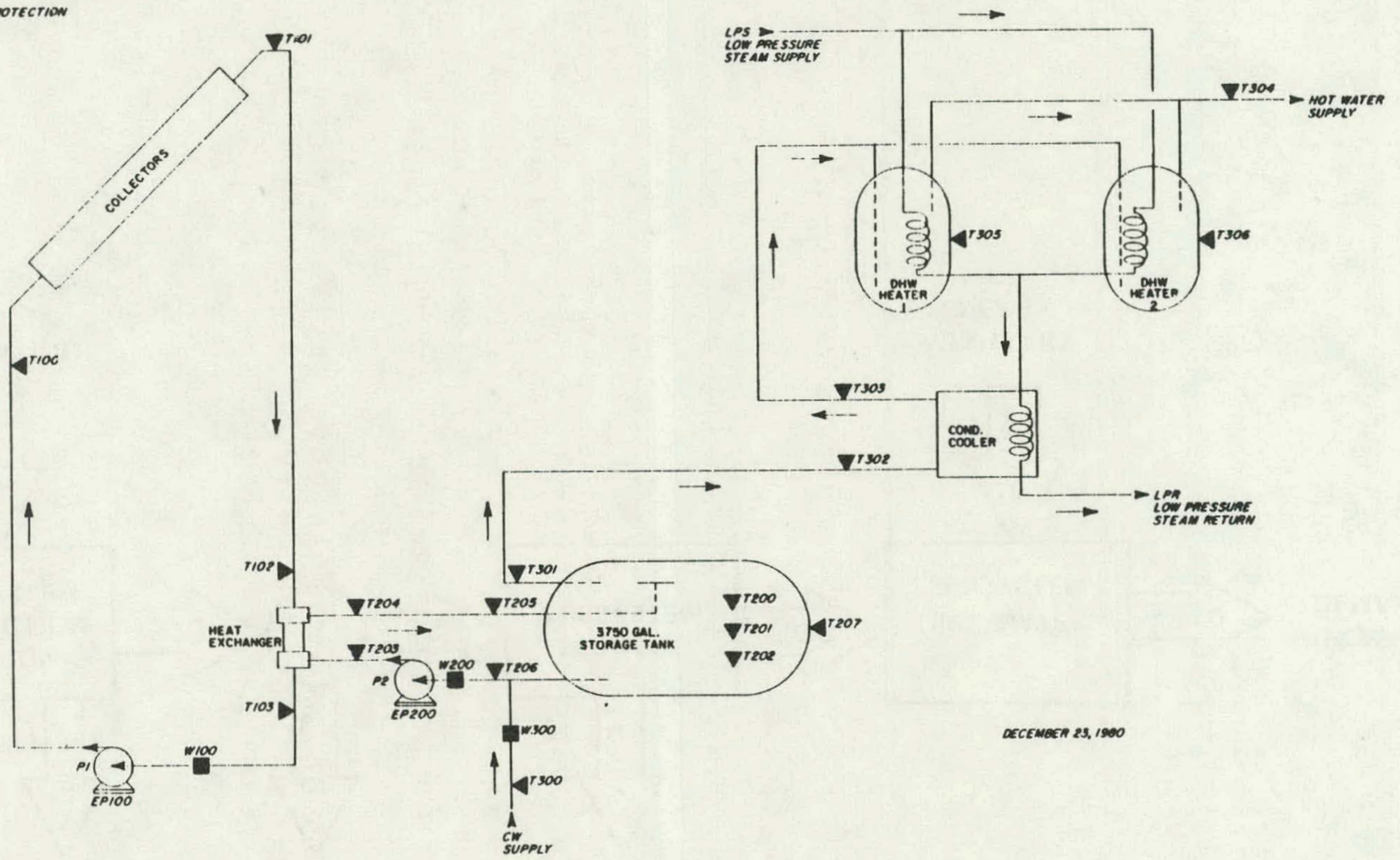

Figure A-40. South Bridge Tower Solar Energy System Schematic 
SOLAR

RADIATION

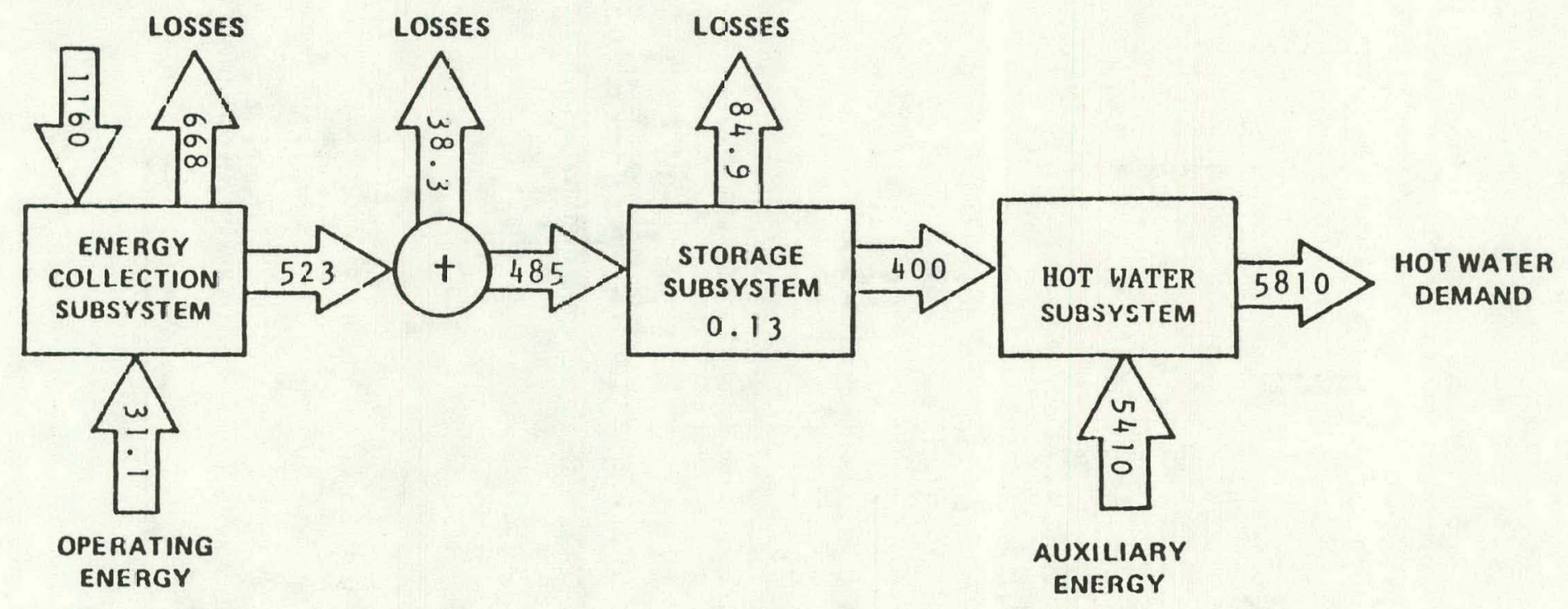

Figure A-41. Energy Flow Diagram for South Bridge Tower January 1981 through February 1982

(Figures in million BTU) 
SPEARFISH HIGH SCHOOL

The Spearfish High School solar energy system consists of a highvolume flat-plate (Solaron, Inc.) collector array of 8,034 square feet mounted at 62 degrees tilt facing 26 degrees west of south, operated by a circulating fan on the outlet duct return to the storage air handler. Upstream of the storage rock bin, capacity 4,150 cubic feet, is a damper system which selects solar heated air flow to a Domestic Hot Water (DHW) preheat heat exchanger ( 36 inches $\times 68$ inches) directly to the space heating load, to the rock bin for storage, or for simultaneous heating of the conditioned space and the storage rock bin with solar energy.

The Solaron Series 2000 flat-plate collector uses a 28-gauge steel absorber with a flat black ceramic enamel coating. Two l/8-inch low-iron tempered-glass covers seal the steel collector pan.

Barber-Coleman controls operate the solar and HVAC system.

Auxiliary energy for space and hot water heating is provided by natural-gas-fired packaged boilers.

The system, shown schematically in Figure A-42, has three modes of operation for space heating.

Mode 1 - Collector-to-Storage - The solar energy is transferred to storage after the heating load. is satisfied, by repositioning dampers so air flows from the top plenum of the rock box to the bottom plenum and back to the collector array.

Mode 2 - Collector-to-Space Heating - The solar collector air handler circulating fan is activated when the absorber plate temperature reaches $80^{\circ} \mathrm{F}$. Solar heated air is moved to the air handler at the rock storage box where control logic, actuated by system demands for heat or DHW or both, determines damper positions. Mode 2 selects direct solar space heating in which solar heated air is provided to roof-mounted air handlers which make up the required thermal energy from conventional hot water boilers to satisfy the load.

Mode 3 - Collector-to-Space Heating and Storage - The collector circulating fan and the storage delivery fan can operate simultaneously in this new mode to provide both stored and direct heated solar energy to the load. This is accomplished by positioning the storage air handler dampers and opening the damper downstream of PCF 2 .

The DHW subsystem is enabled by operation of the main collector circulating fan. Appropriate damper positions are selected by control logic which senses hot water demand and routes water to be preheated into the air-to-water heat exchanger while damper positions are selected to route solar heated air to the heat exchanger. 


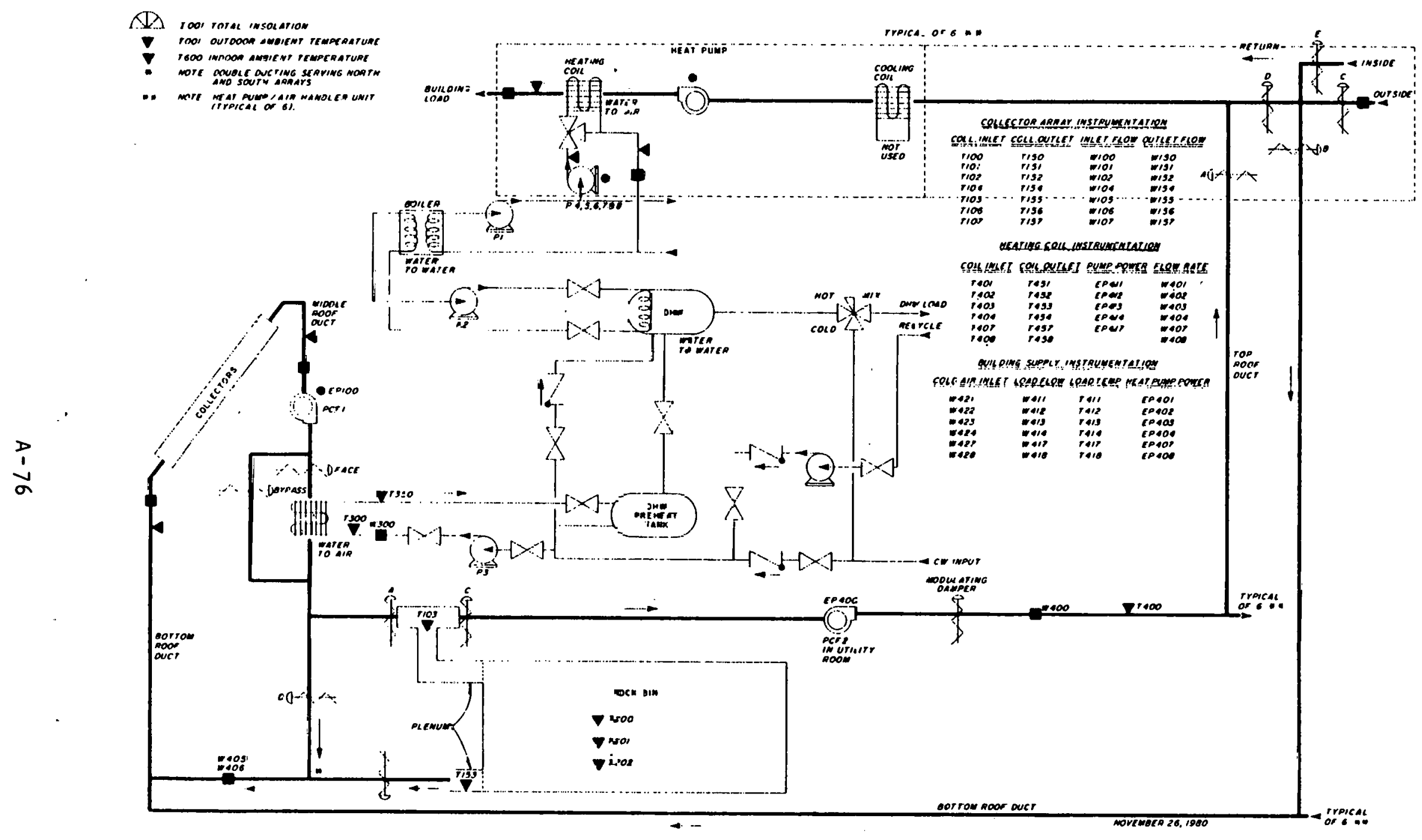

Figure A-42. Spearfish High School Solar Energy System Schematic 


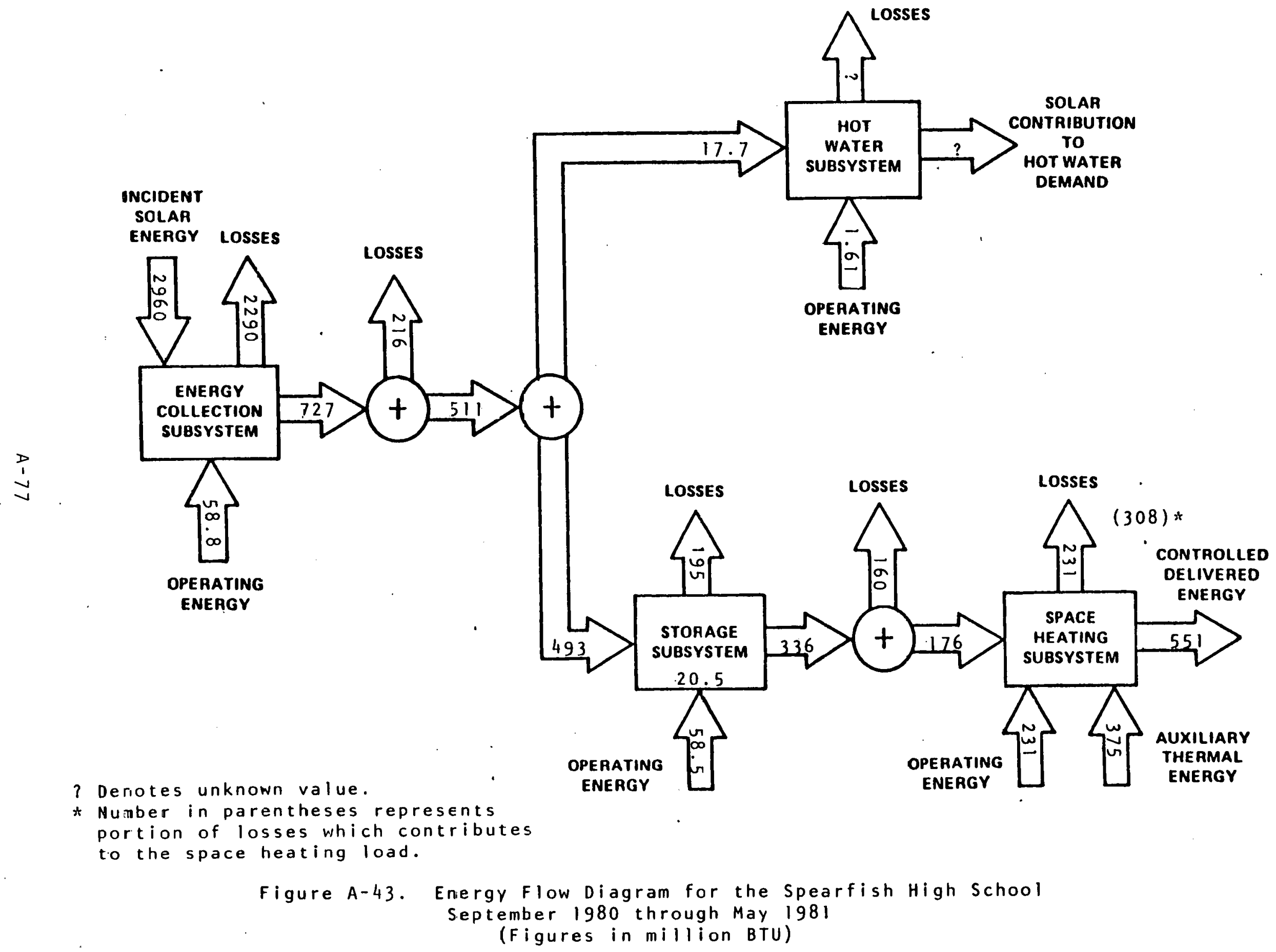


SUMMERWOOD M

The Summerwood Associates site is a cluster of condominiums overlooking Long Island Sound. Two adjacent units are instrumented: a Madison model designated Summerwood $M$, and a Guilford model designated Summerwood $G$. The Summerwood $M$ site is described in this report.

The Summerwood $M$ site is a rowhouse residence in 0ld Saybrook, Connecticut. The home has approximately 1,375 square feet of conditioned space. Solar energy is used for space heating and preheating Domestic Hot Water (DHW). The solar energy system has an array of flat-plate collectors with a gross area of 378 square feet. The array faces 12 degrees west of south at an angle of 50 degrees from the horizontal. Water is the transfer medium that delivers solar energy from the collector array to storage and to the space heating and DHW loads. Draindown provides collector freeze protection.

The collectors have a single 3/16-inch low-iron glass cover with 0.92 solar transmittance. The absorber is copper sheet with a selective black surface manufactured by Enthone. The surface has an absorptivity of 0.90 and an emissivity of 0.12 . Fluid passages are 1/4-inch copper tubes spaced 16 inches apart with a one-inch copper manifold. The tubes are soft-soldered to the absorber sheet. Insulation behind the absorber is two and one-half inch fiberglass. The transfer fluid used is water. All collectors are plumbed in parallel. When the collector pump turns off, all fluid drains back into the storage tank.

A Johnson Controls system controls the solar system.

Solar energy is scored in a 600-gallon poured-conclete insulated tank located in a crawl space. Solar heated water is supplied to a liquid-to-air heat exchanger within the space heating duct and to a heat pump for water-to-air operation. A closed heat transfer loop between the solar storage tank and a $120-g a l l o n$ DHW tank provide solar energy to the DHW supply. When solar energy is insufficient to satisfy the entire space heating load, the heat pump operates in its water-to-air mode, extracting heat from the solar heated water. When the storage tank temperature falls below $40^{\circ} \mathrm{F}$, the heat pump automatically disconnects from the solar heated water supply and operates in an air-to-air mode using an outjuor evaporator. An electric heater in the space heating duct provides auxiliary energy for space heating in conjunction with both solar and conventional heating modes. An electrical heating element in the DHW tank provides auxiliary energy for water heating.

The system, shown schematically in Figure A-44, has four modes of solar operation.

Mode 1 - Collector-to-storage - This mode activates when collector temperature exceeds the storage temperature by $15^{\circ} \mathrm{F}$ and terminates when a temperature difference of $2^{\circ} \mathrm{F}$ is reached. Collector loop pump Pl is operated in this mode. 
Mode 2 - Storage-to Space Heating - Direct Solar Mode - This mode activates when there is a demand for space heating and solar storage temperature is above $85^{\circ} \mathrm{F}$. Circulating pump $P 2$ and the air-handling subsystem blower are operated in this mode.

Mode 3 - Storage-to-Space Heating - Solar-Assisted Heat Pump Mode This mode activates when there is a demand for space heating and the solar storage temperature is less than $85^{\circ} \mathrm{F}$ and greater than $40^{\circ} \mathrm{F}$. Circulating pump P2, the air-handling subsystem blower, and the heat pump are operated in this mode.

Mode 4 - Storage-to-DHW - This mode activates when the temperature difference between solar storage and the DHW tank exceeds $15^{\circ} \mathrm{F}$ and terminates when the temperature difference drops below $6^{\circ} \mathrm{F}$. Pump P3 is operated in this mode. 


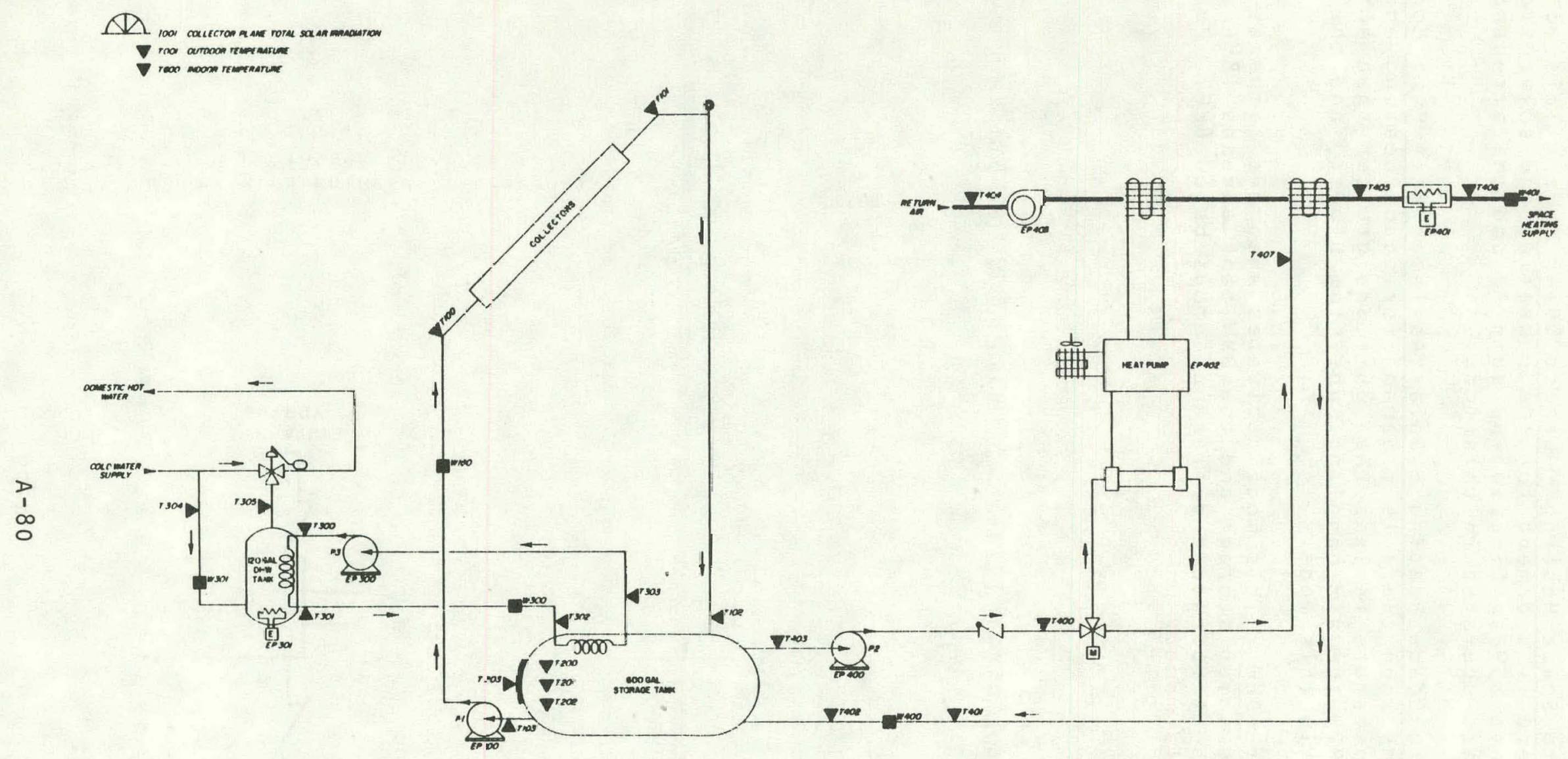

Figure A-44. Summerwood M Solar Energy System Schematic 


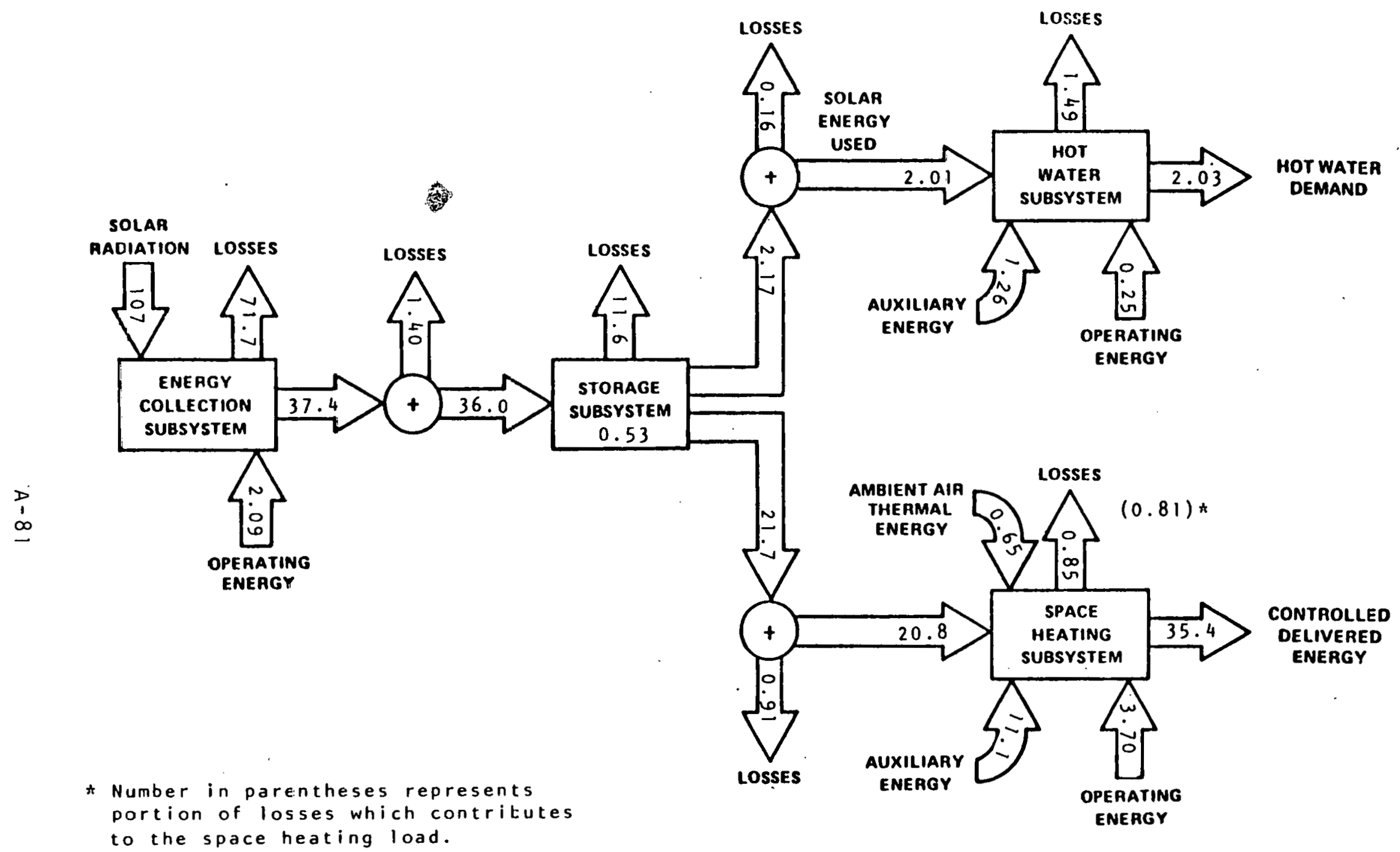

Figure $A-45$. Energy Flow Diagram for Summerwood $M$ october 1980 through May 1981

(Figures in million BTU) 


\section{TELEX COMMUNICATIONS}

The Telex Communications, Inc. site is a single-story manufacturing plant in Blue Earth, Minnesota. The solar energy systen is a retrofit designed to provide $70 \%$ of the annual space heating requirements for the building, which has 97,000 square feet of conditioned area. The system has an array of 360 flat-plate collectors manufactured by - InterTechnology/Solar Corporation. The array has a gross area of 11,520 square feet and faces south at an angle of 59 degrees from the horzontal. Water is used as the medium for delivering solar energy from the collectors to storage. The collected energy is stored in a 20,000-gallon storage tank. Gravity draindown is used for collector freeze protection.

In order to increase the performance of the collectors, a black chrome selective absorber coating and water-white glass are used. The black chrome selective coating is electroplated on a nickelcoated aluminum extension. The solar absorptivity and thermal emissivity of the black chrome coating are nominally 0.95 and 0.12 respectively. The low thermal emissivity results in reduced radiative heat losses from the absorber plate and thus increases efficiency. Honeywell controls are used.

The stored energy is transferred to the space heating subsystem by circulating the solar heated water from the storage tank to 12 parallel water-to-air heat exchangers and back to storage. Nine of the heat exchangers were installed in nine existing air-handler units; three are an integral part of space heaters with motorized fans which were added to the existing system. Fluid flow to each air-handler unit and solar space heater is individually and thermostatically controlled. Auxiliary heat is provided by electplcal hed strips in each air-handler unit and by three electrical space heaters located near the solar space heaters. The air-handler units provide ventilation year-round.

The system, shown schematically in Figure $A, 16$, has lwo modes of solar operation.

Mode 1 - Collector-to-storage - This mode is entered ature of the collector surface exceeds the water temperature in the water thermal storage by $250 \mathrm{~F}$. Water is circulated from storage through the collectorg until the storage temperature reaches $190^{\circ} \mathrm{F}$, or until the difference between the collector plate temperature and storage temperature is less than $2^{\circ} \mathrm{F}$.

Mode 2 - Storage-to-Space Heating - This mode is controlled by manually preset thermostats. The minimum designed operational temperature in water thermal storage is $100^{\circ} \mathrm{F}$, although the control system does not inhibit operation below this temperature. Water is circulated through the heat exchangers and returned to storage until the demand is satisfied. 


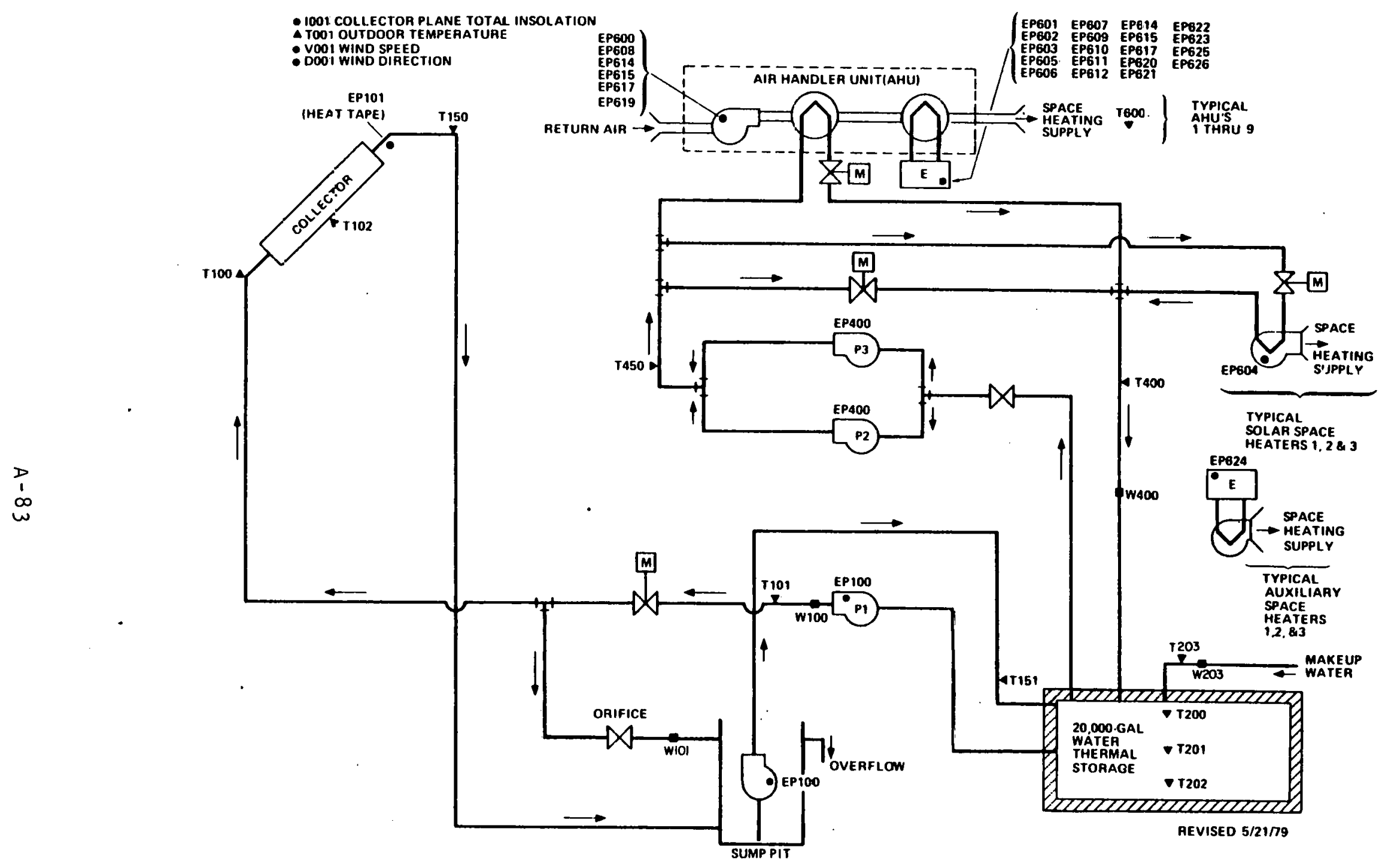

Figure A-46. Telex Communications Solar Energy System Schematic 
SDLAR

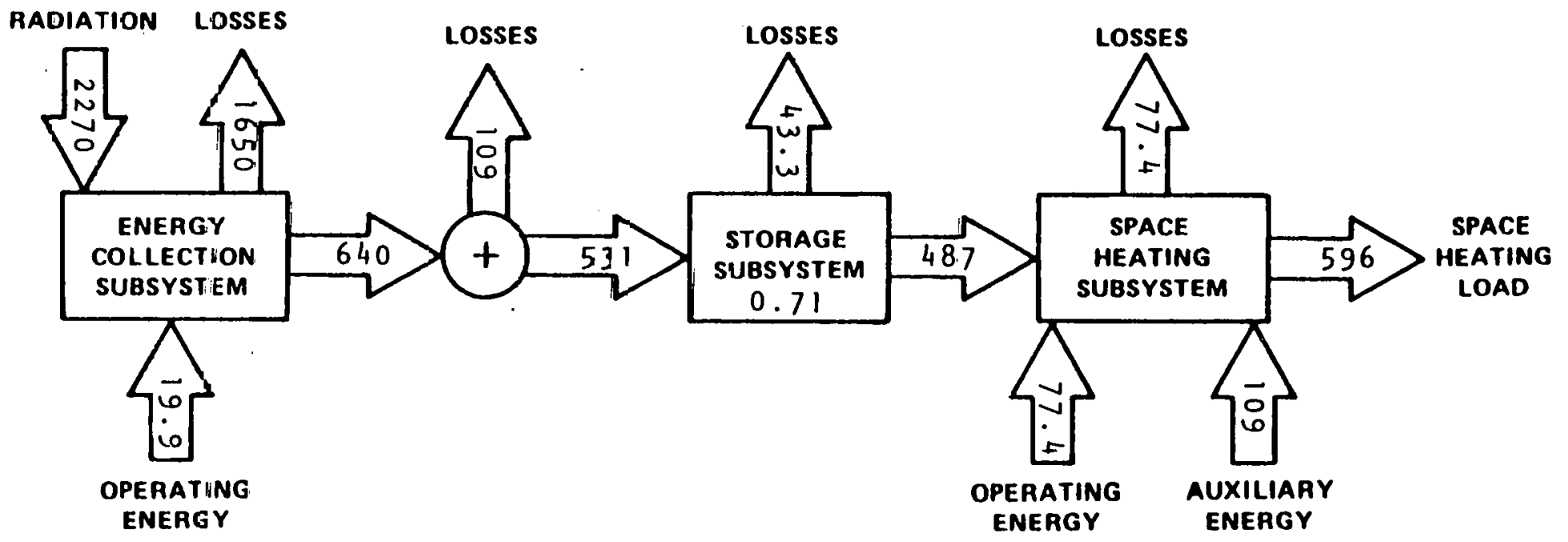

Figure A-47. Energy F ow Diagram for Felex Communications November 1979 through April 1980

( $F$ igures in million BTU) 
The Terrell E. Moseley, Inc. site is a 1,780-square foot, singlestory, commercial office building with attached warehouse in Lynchburg, Virginia. The solar energy system is designed to provide approximately $70 \%$ of the space heating and hot water energy requirements of the office building. Because the hot water consumption is very low, only the space heating system is monitored for performance evaluation. The site has a collector array of 16 flat-plate collectors built by T.E. Moseley, Inc. The collector array has a gross area of 400 square feet, and faces south at a tilt angle of 50 degrees from the horizontal. Water is the heat transfer medium throughout the solar energy system. Collected solar. energy is delivered to the $2,000-g a l i o n$ storage tank, which is in an unheated attached warehouse building. The insulation on the tank is four inches of fiberglass.

The collector panels have one 3/16-inch tempered glass cover manufactured by Pittsburgh Plate Glass Co. and a nonselective absorber surface. The absorber surface has an estimated solar absorptivity of 0.95 and an infrared emissivity of 0.90 . Total solar transmissivity of the glazing is 0.85 at normal incidence angles. The absorber surface is composed of a 16-gauge aluminum plate with a series of 5/16-inch 00 copper tubes fastened to the plate with thermal mastic and pipe straps. The fluid circulated through the collectors is untreated water.

A Dayton differential thermostat which operates the solar collectors is part of the integrated control system for the building.

When solar energy is insufficient to maintain $55^{\circ} \mathrm{F}$ storage temperatures, a gas-fired boiler (auxiliary heater) provides additional energy to storage. Space heating is provided by circulating storage water through a heat exchanger located in the air distribution system of the building. In addition, a solar-assisted heat pump is employed to provide auxiliary energy to the space heating demand. since the collector fluid automatically drains into storage after each solar energy collection operation, additional collector freeze protection measures are not required.

The system, shown schematically in Figure A-48, has three modes of solar operation.

Mode 1 - Collector-to-Storage - This mode is entered when the collector absorber plate temperature exceeds the middle storage temperature by $200 \mathrm{~F}$. The transfer fluid is circulated from storage through the collectors and back to storage until this temperature differential drops to less than $3^{\circ} \mathrm{F}$.

Mode 2 - Storage-to-space Heating - This mode is entered when there is a demand for space heating and the sensed temperature of the storage water is greater than $85^{\circ} \mathrm{F}$. Water is circulated between storage and liquid-to-air heat exchanger $H X l$ in the air-handling 
unit distribution duct until the space heating demand is satisfied, or the sensed storage temperature drops below $85^{\circ} \mathrm{F}$.

Mode 3 - Storage-to-Heat Pump - This mode of operation provides space heating when Mode 2 operation is not available. This mode is entered when there is a demand for space heating and the temperature of the storage water is below $85^{\circ} \mathrm{F}$. Energy input to the heat pump is supplied by opening the normally closed valve V2, closing the normally open valve $V l$, and circulating storage water through heat pump evaporator HX2. This mode is terminated when either the sensed storage temperature rises above $90^{\circ} \mathrm{F}$, or when no space heating demand exists. 


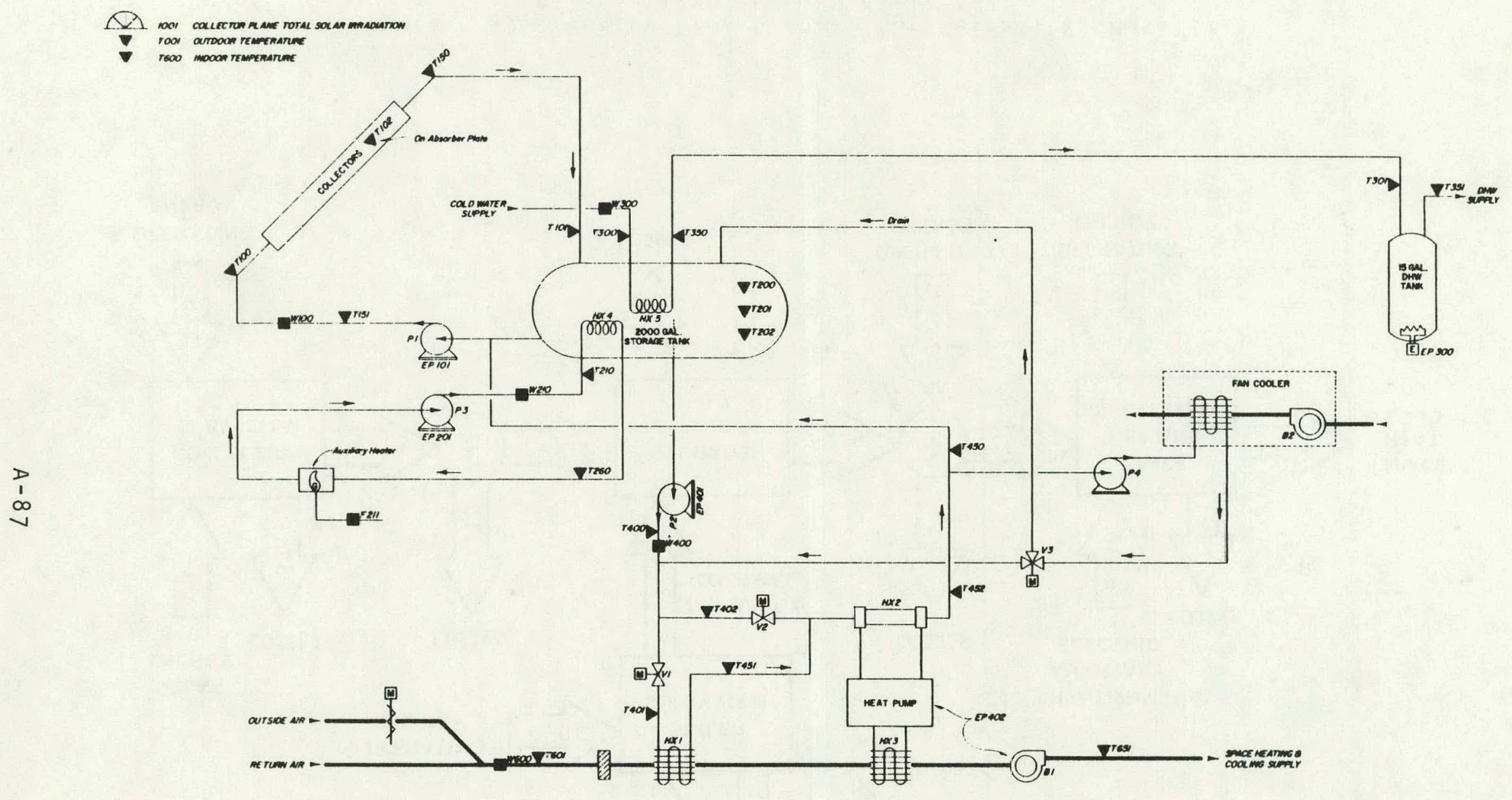

Figure A-48. Terrell E. Moseley Solar Energy System Schematic 


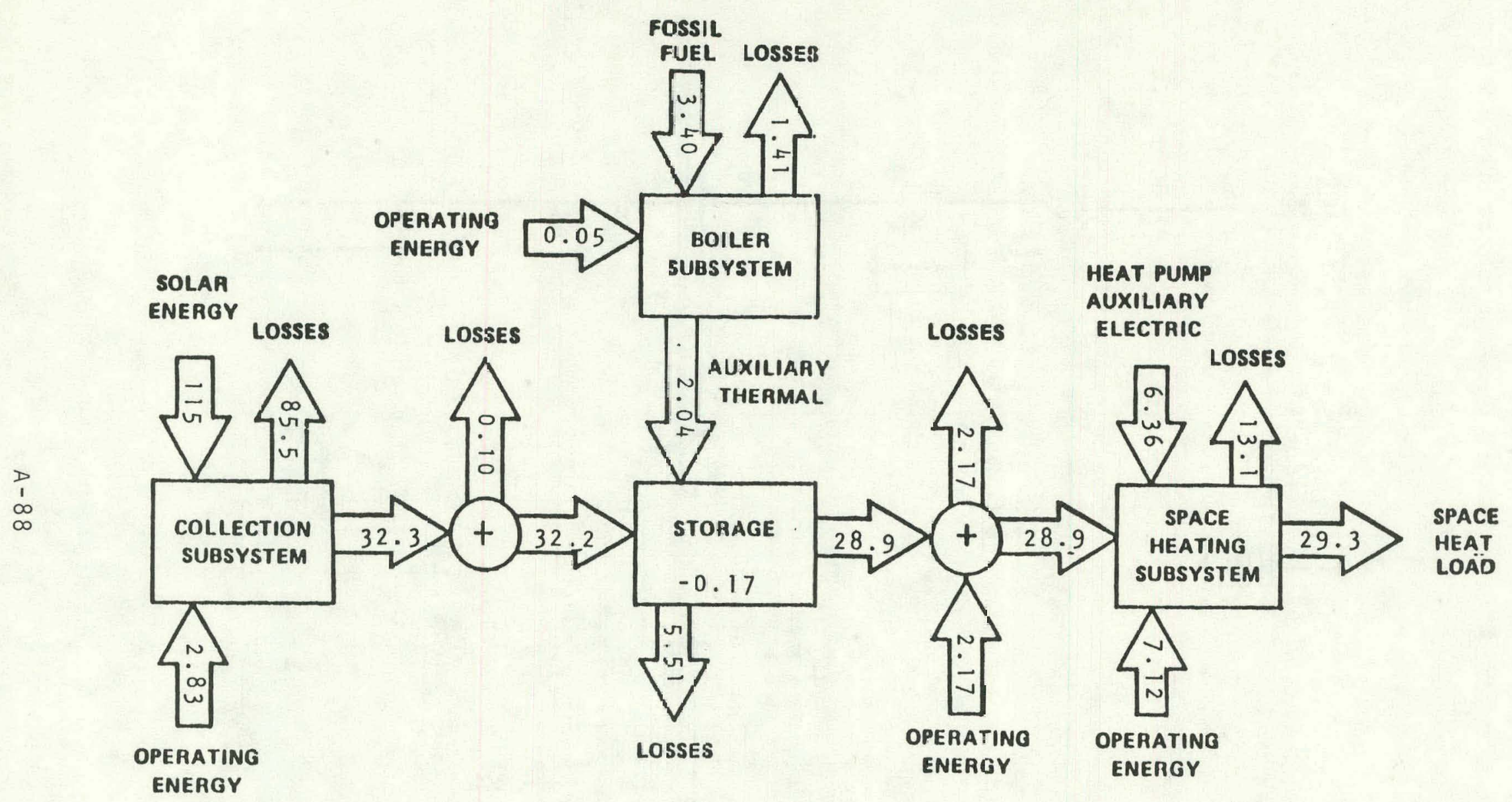

Figure A-49. Energy Flow Diagram for Terrell E. Moseley October 1980 through April 1981

(Figures in million BTU) 
The Vitro Tes't Site is a service hot water preheat system providing hot water to a commercial office building located at the vitro Corporation in Silver Spring, Maryland.

The 105-square-foot collector array faces south at an angle of 45 degrees from the horizontal, and is composed of four flat-plate, single-glazed Sunjammer $D-277$ solar collectors manufactured by Ametek, Inc., incorporating a selective-coated copper absorber plate. A 120-gallon stone-lined preheat tank with a double-walled heat exchanger provides solar heated water to a conventional electric hot water tank. The preheat tank and auxiliary tank are located in a penthouse equipment room on the roof of the threestory office building. The solar collectors are mounted on the south wall of the penthouse and are connected to the preheat tank by 80 feet of 3/4-inch copper pipe, insulated with $1 / 2$-inch of rubber foam insulation. A propylene glycol/water mixture is circulated from the array to the preheat tank by either a $120 \mathrm{~V}$ AC pump or a $12 \mathrm{~V}$ DC pump powered by a small photovoltaic panel. A recirculation loop maintains hot water availability throughout the building.

An Independent Energy C-30 controller operates the AC collector pump.

The system, shown schematically in Figure A-50, has two modes of operation.

Mode 1 - AC Pump Operation - When the temperature at the collectors reaches $20^{\circ} \mathrm{F}$ above the storage temperature, the AC solar collector pump activates and circulates the heat transfer fluid between storage and the collectors. Pump P2 activates when return water from the recirculation loop drops below $100^{\circ} \mathrm{F}$. The solar pump shuts off when the collectors are within $5^{\circ} \mathrm{F}$ of the storage tank temperature.

Mode 2 - DC Pump Operation - In this mude, the AC pump is switiched off manually using the $c-30$ controller. The photovoltaic panel is directly wired to the DC pump, and when insolation reaches a level sufficient to activate the pump (around 70 BTU/ft2-hr), the heat transfer fluid circulates between storage and the collectors. When insolation drops below 70 BTU/ft2-hr, the DC pump ceases operation. 
F cool total insolation

IOO2 HORIZONTAL INSOLATION

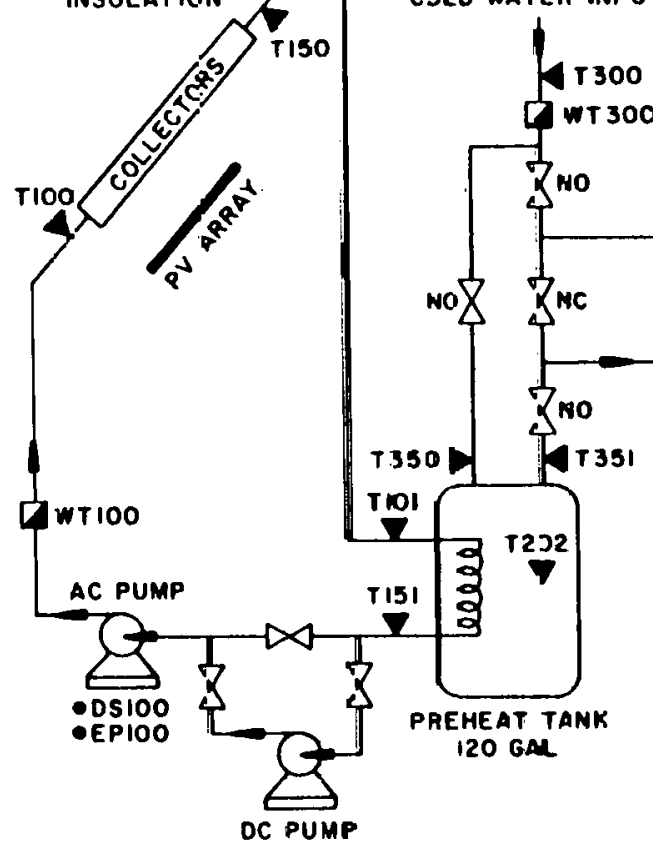

7 TOOI OUTDOOR AMBIENT

$\checkmark$ TGO0 INDOOR AMBIENT

- DOOII WINO DIRECTION

- vool wind velocity

- RHOC.I OUTDOOR RELATIVE humIOITY

- pVocil photovoltaic array voltage

- pVOce photovoltalc array AMperage
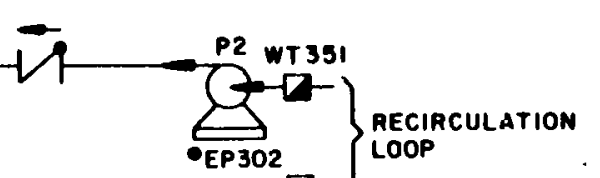


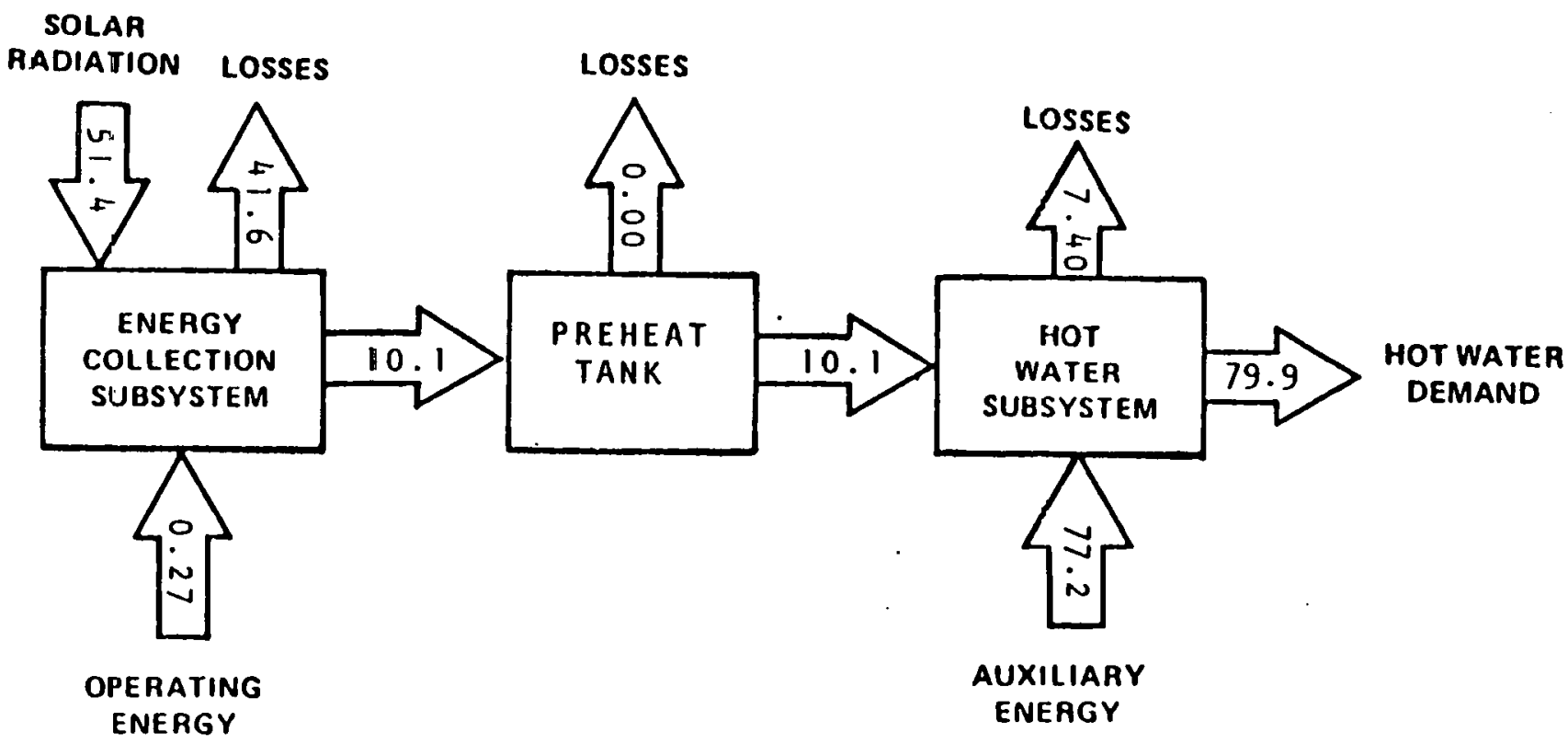

Figure A-51. Energy Flow Diagram for the Vitro Test Site January 1982 through December 1982

(Figures in million BTU) 



\section{APPENDIX B}

THE F-CHART VERSION 5.1

\section{B. 1 THEORY}

The f-Chart simulation program was developed at the solar Energy Laboratory at the University of Wisconsin, Madison, Wisconsin, to aid designers and researchers in the selection of the correct size and type of solar collectors to supply a system load at minimum cost (Reference $B-1$ ).

The f-Chart was developed to provide a relatively straightforward method of predicting long-term solar system thermal performance, without using a detailed computer simulation directly as a design tool. The approach taken by the authors was to identify the key variables of solar system performance, and to perform detailed computer simulations in order to provide a correlation between the key variables and long-term simulated performance of solar systems. The correlation variables are essentially as follows:

$$
\begin{aligned}
& y \cong \frac{\text { Absorbed Solar Energy }}{\text { Heating Load }} \\
& x \cong \frac{\text { Reference Collector Loss }}{\text { Heating Load }}
\end{aligned}
$$

$y$ is the ratio of the total energy absorbed by the solar collectors to the total solar system load over a month; $x$ is essentially a ratio of a standard (reference) collector energy loss to the total system load over the month.

A correlating equation was developed from a large number of computer simulations representing a number of locations over a range of design criteria. The equation provides a fraction, $f$, of the load which will be met by the solar system. Both $x$ and y are calculated, and substituted into the equation below.

$$
\begin{aligned}
f= & a y-b x-c y^{2}+d x^{2}+e y^{3} \\
& \text { for } 0<y<3 \text { and } 0<x<18
\end{aligned}
$$

where $a, b, c, d$, and e are coefficients dependent on the system type (air, liquid, etc.)

Various mathematical manipulations are required to calculate $x$ and $y$, including modeling of theorctical collestor performance results, provision of insolation values (which require manipulation from horizontal values to values in the plane of the array), ambient temperature, and estimation of heating loads, hot water loads, process loads; etc.

Monthly values of $f$ are calculated, and tiered to provide an estimate of the total annual solar fraction, F. 


\section{B. 2 THE F-CHART 5.1 , MICROCOMPUTER VERSION}

The version of $f$-chart used in this study is the f-Chart 5.1 Version for Microcomputers, $l$ provided by f-Chart Software, 4406 Fox Bluff Rd., Middleton, Wisconsin 53662. The program is written for various microcomputers, including the Apple $1 / 2$ (as in this application), the IBM PC, 3 Tandy TRS-80,4 and a CP/M version5 (Digital Research Corp.).

The program performs the necessary calculations relating to the f-Chart algorithms described in section B.l of this appendix.

System performance was modeled using actual parameters from each site, such as measured collector area, measured system lodu, measured heat exchanger effectiveness, ASHRAE 93-77 single-panel collector test results, and flow rates. The measured values were. taken from site information files and actual performance data.

Weather data, from thc f-chart user files supplled with the program, was used to predict yearly system performance.

The f-chart 5.1 has the capability of modeling seven generic system types, as listed below.

1. Pebble Bed Storage Space and Domestic Water Heating Systems

2. Water Storage Space and/or Domestic Water Heating Systems

3. Active Collection with Building Storage Space Heating systems

1. Direct..Gain Passlve Systerns

5. Collector-storage Wall Passive Systems

6. Pool Heating Systems

7. General Solar Heating Systems (e.g., process heating systems)

This study ulilized system types 1, 2 , and 7 to model the 25 sites' performances.

\footnotetext{
The f-Chart 5.1 is a copyrighted program by f-chart software. 2 APPLE is a registered trademark of Apple Computer, Inc.

3 I BM is a registered trademark of International Business Machines. ${ }_{5}^{4}$ TRS -80 is a registered trademark of the Tandy Computer Corporation. ${ }^{5} \mathrm{CP} / \mathrm{M}$ is a registered trademark. of Digital Research, Inc.
} 


\section{B. 3 COMMENTS ON USE}

The program, f-Chart Version 5.1, was implemented on an Apple Il Plus microcomputer at Vitro Corporation.

Most sites were easily modeled using the measured/actual system parameters and long-term weather data.

There were some problems with the operation and execution of the program, which were divided into two categories:

1. Problems with definition of parameters to be modeled (conceptual problems)

2. Problems with execution and operation of the program

\section{Category l Problems}

a. There appears to be a lack of consistency between the definition of "load" as described in f-Chart and the "load" as defined by the NSDN. For the case of Domestic Hot Water (DHW), for example, system models 1 and 2 (see Section B.2) for combined space heating and DHW systems utilize a load which is based on total energy use by the hot water system, or:

$$
\text { DHW Load = Auxiliary Energy + Solar Energy }
$$

System type 7, however, treats "load" for a hot water only system as:

$$
\begin{aligned}
\text { DHW Load }= & \text { Consumption in Gallons } x \text { Density } \\
& x \text { Specific Heat } x \text { Temperature } \\
& \text { Rise Across System }
\end{aligned}
$$

System type 7, when used to model a large DHW system, does not include DHW system losses as part of the load. Solar contribution to losses, therefore, is not calculated, making prediction results suspect.

b. When running a combined DHW/SH system, as in system types 1 and 2 , if the system load is determined using daily hot water consumption (for DHW) and monthly UA $x$ heating degree-days (for space heating), some problems result if the heatllig load is zcroed during the summer months. Apparently, the f-Chart 5.1 program switches the entire collector output from the main (large) storage system to the DHW tank, and the program stops execution. The solution is to instruct $f$-Chart to create a small heat load (using a building UA of one, along with a zero value for heating degree-days), which retains the large storage tank in the simulation. When a zero appears 
in the monthly values of building UA (as might occur during summer months), the system is assumed to be a DHWonly system, and the simulation goes out of range.

This may not be a severe problem, but this problem causes wasted time reentering data and reloading the program.

\section{Category 2 Problems - Operational}

a. The program has the capability of using five sets of variable monthly input parameters for various factors such as loads, collector angle, etc. There are occasions when the program "locks up" the cuuller which indicates to the program the number of system parameters which have multiple values, and sticks un rlve when less than five are in use. This results in a case where, for example, only three multiple values (such as hot water consumption, building UA, and monthly liot water set temperature) are allowed. One must then start the entire model over again from the beginning, since the counter cannot be reset by the user.

b. Negative values for collector azimuth (i.e., collector azimuth values east of south) are rejected by f-chart 5.1 as "out of range."

c. Variable monthly values for all input parameters having different values by month are always zeroed on the parameters list after a run. If one wants to examine the values on the monitor or printout, the data file for the site (assuming it was saved before the run) must be re * called from dise to read monthly values. Again, this is a time-consuming prublem, since, unce the values are lost, they must be reentered by hand.

d. When using the printer, the prompts which f-chart responds with appear after the answers (such as Yes, No, etc.) are typed. One must be familiar with the question/answer sequence to operate the printer feature. (At Vitro Corporation, an Epson FX-100 printer is used.) 


\section{APPENDIX B}

\section{REFERENCE}

B-1. Beckman, W.A., S.A. Klein, and J.A. Duffie, Solar Heating Design by the f-Chart Method," John Wiley $\varepsilon$ Sons, New York, 1977 . 